\title{
Structural Behaviour of Composite Slab with High Performance Concretes
}

\author{
By \\ Haile Mengistu \\ B.Sc. Civil Engineering, Bahir Dar University \\ Bahir Dar, Ethiopia 2009
}

\author{
A Project Presented to Ryerson University \\ In partial fulfilment of the requirement of the degree of \\ Master of Engineering \\ In the program of Civil Engineering \\ Toronto, Ontario, Canada 2014 \\ (C) Haile Mengistu, 2014
}

\section{Dedication}


TO MY FAMILY

\&

TO MY INSTRUCTOR WHO MENTOR ME ON MY PATH. 


\begin{abstract}
Composite slabs with profiled steel deck and concrete toping have gained wide acceptance as they lead to faster, lighter and economical construction. Extensive research works have been conducted on the behaviour of composite slabs to study their structural behavior and steel-concrete interface shear bond resistance which primarily governs the failure. However, the use of emerging highly durable engineered cementitous composite (ECC) in composite slab is new and no research has been conducted yet. High strain hardening and intrinsic crack width characteristics of ECC can significantly improve structural performance of composite slabs through enhancing ductility, energy absorbing capacity and steelconcrete shear bond. In this study, experimental investigations are conducted to evaluate the shear bond characteristics of composite slabs made with ECC and conventional self-consolidating concrete (SCC) using Code based $\mathrm{m}-\mathrm{k}$ method. Twelve slab specimens having variable shear span and two types of profiled steel deck were tested under four point loading. The performance of ECC and SCC composite slabs are compered based on load-deflection response, stress-strain development in concrete and steel, failure modes, energy absorbing capacity and steel-concrete shear bond parameters ( $\mathrm{m}$ and $\mathrm{k}$ ) and bond stress.
\end{abstract}




\section{Acknowledgement}

I would like to take this opportunity to express my honest and deepest gratitude to my supervisor Dr. Khandaker M. Anwar Hossain for his dedication, guidance, support and patience during the development of this project. This project is the result of the belief and encouragement of my supervisor and mentor that made this project possible. I would like to thank Dr. Hossain for his kind words and always willingness to help and fatherhood love that pulled me through this project. This is my privilege to been mentor and supervised by him.

I would like to thank all Ryerson's Civil Engineering Technicians for always being there for help with laboratory equipment's and procedures. The laboratory work itself would not have been possible without your guidance.

The financial support from Dr. Hossain through NSERC Engage grant is greatly appreciated. I would like to acknowledge the financial and technical support of Canam Canada for this project. The supports of Dr. Shah Alam (post-doctoral fellow), research assistants, IFMA French visiting scholar Florian Vallée and technical staffs are also acknowledged.

Finally, special gratitude goes to my beloved family, without their constant love, support and sacrifices my success would not be possible. 


\section{Table of Contents}

Dedication.

Abstract.

Acknowledgement.

Table of content

List of Figure.

List of table

Notation

1 Introduction

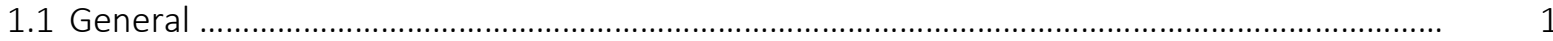

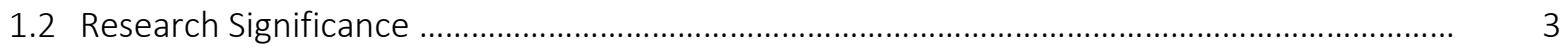

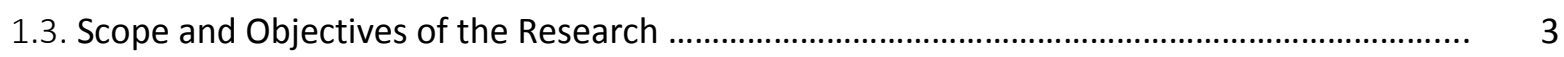

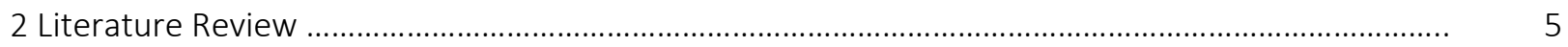

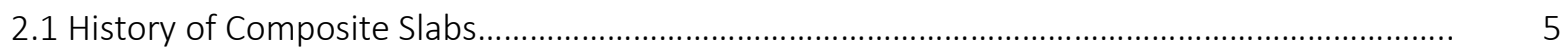

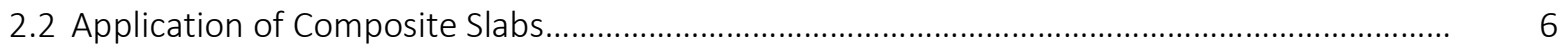

2.3 Benefits of Composite Slab ..............................................................................................

2.4 Material of composite slabs and its property. ........................................................................

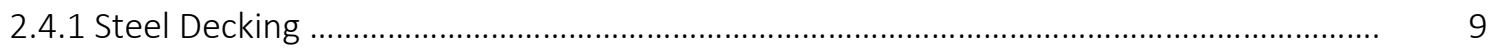

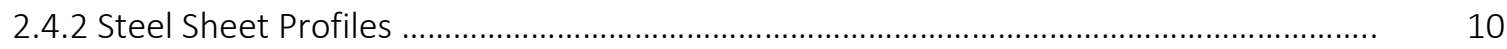

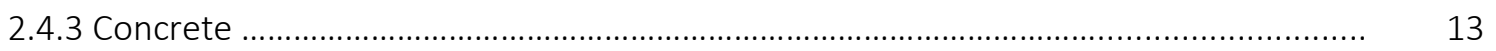

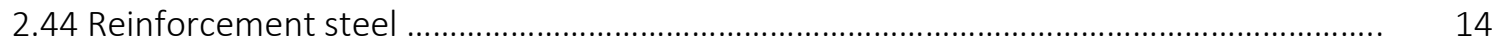

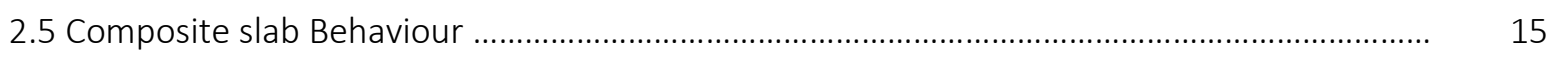

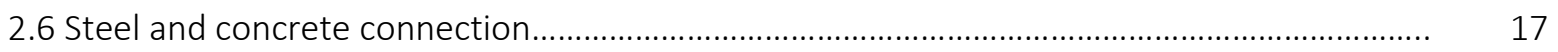

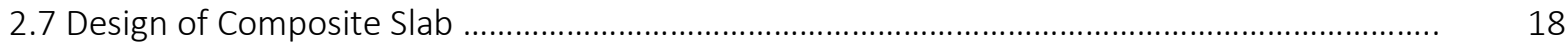

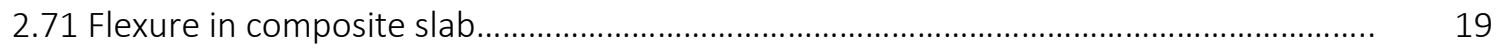

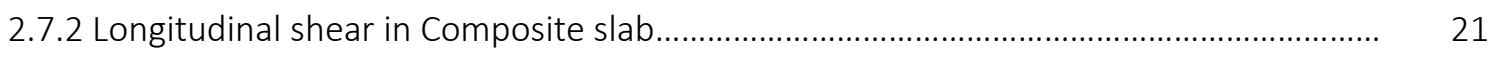

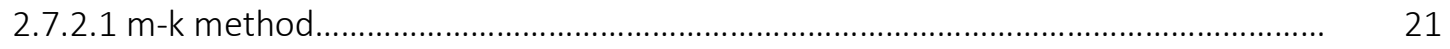

2.7.2.2 Partial-interaction design ( $\tau_{\vee}$ method) ................................................................... 24

2.8 Criteria for the testing of composite slabs according to CSSBI.................................................. 26

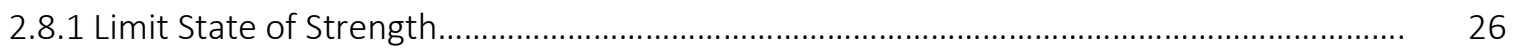

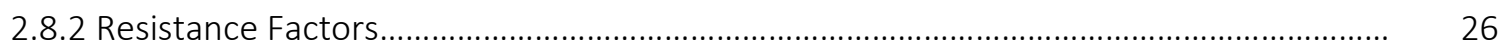

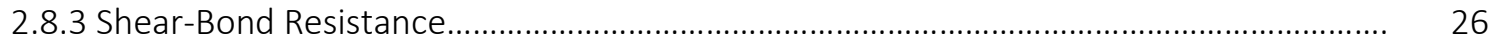

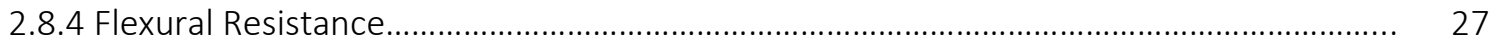




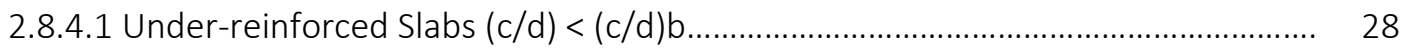

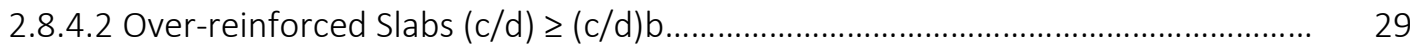

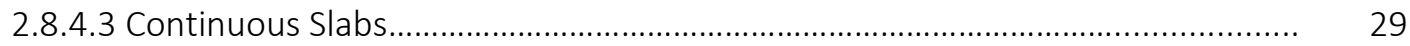

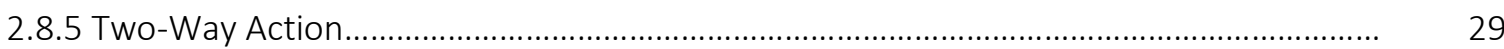

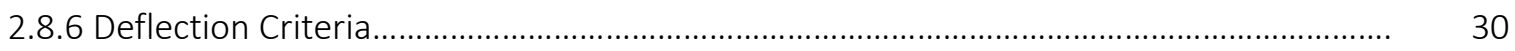

2.8.6.1 Flexural Properties for Deflection Calculations................................................. $\quad 30$

2.8.6.2 Deflection Limitations..................................................................................... 30

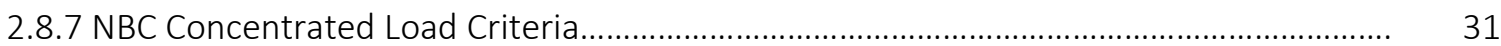

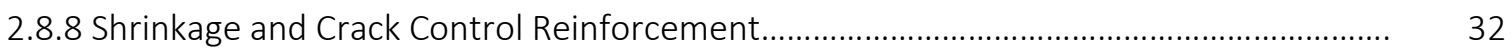

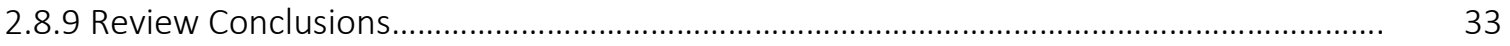

3 Experimental and Theoretical Investigation ……..........................................................................

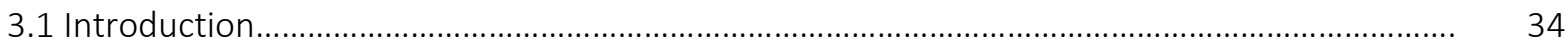

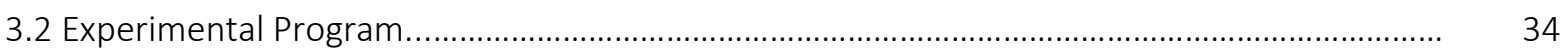

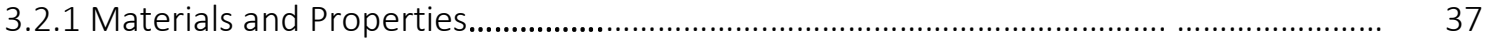

3.2.2 Casting and Curing of Composite Slabs ..............................................................................

3.3 Test Set-up, Instrumentation and Testing Procedure …............................................................

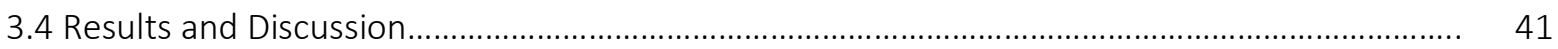

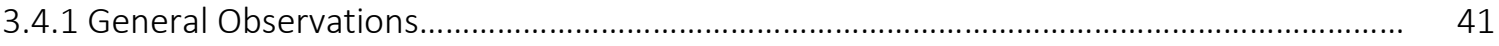

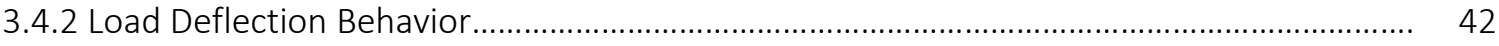

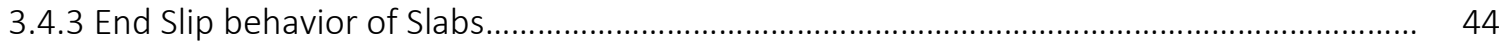

3.4.4 Strain Development in the Concrete Surface....................................................................... 49

3.4.5 Strain Reading in the Profile Steel Sheet........................................................................ 52

3.4.6 Evaluation of $\mathrm{M}$ - K Value and Shear bond capacity ..................................................... 55

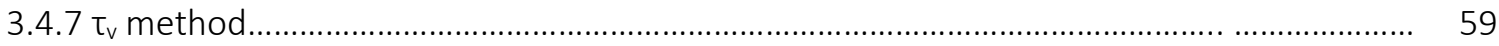

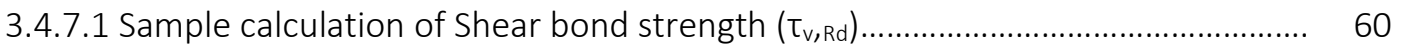

3.4.8 Energy Absorbing Capacity of Composite Slab ...................................................... 65

4 Conclusions and Recommendations for Further Research ............................................................... 67

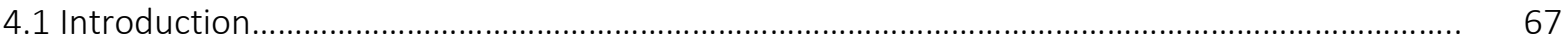

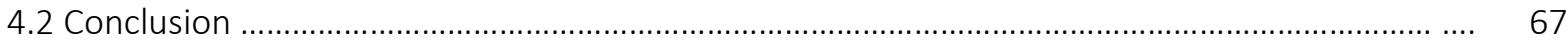

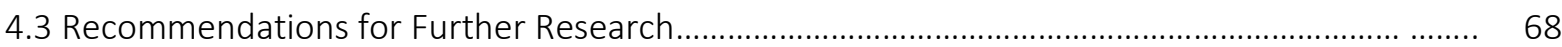

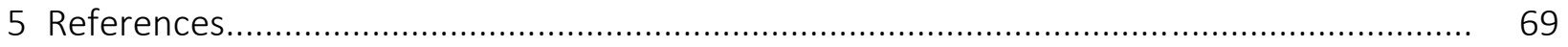




\section{List of Figure}

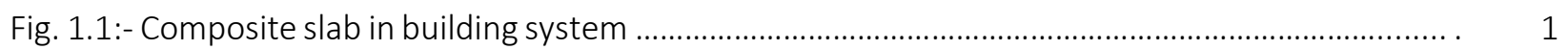

Fig. 2.1:- Composite system with showing wire welded ..................................................................

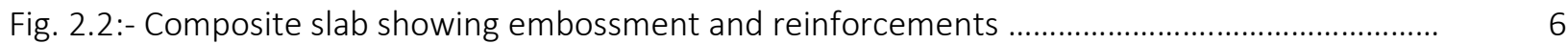

Fig. 2.3:- Typical example of composite slab construction, showing the steel sheet placed on steel

frame)

Fig. 2.4:- Example of re-entrant deck profile used for composite slab ................................................ 11

Fig.2.5:- Example of trapezoidal deck profile up to 60mm deep......................................................... 12

Fig. 2.6:- Example of trapezoidal deck profile greater than 60mm deep................................. 12

Fig 2.7:- Typical engineered cementitious composites (ECC) stress-strain-crack width curve........... 14

Fig. 2.8:- Stress-Strain curve of concrete and steel structure ........................................................... 15

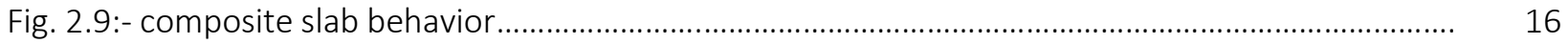

Fig. 2.10:- Composite slab failure mode types................................................................................... 17

Fig. 2.11:- Typical forms of interlock in composite slabs..................................................................... 18

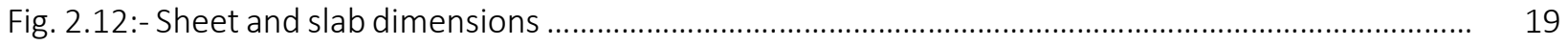

Fig.2.13:- Stress distribution when neutral axis above the steel sheet................................................ 19

Fig .2.14:- Stress distribution when neutral axis below the steel sheet.................................................. 20

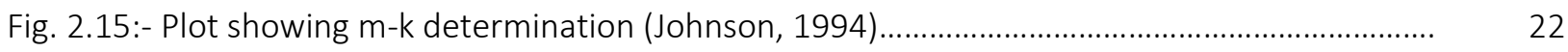

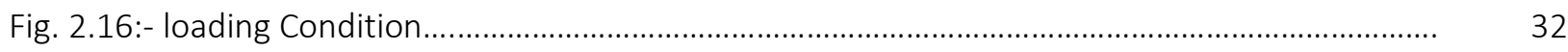

Fig. 3.1:- Geometric and dimensional parameters of composite slab............................................

Fig. 3.2(a):- P3623 composite slab showing reinforcements and instrumentation.......................... 35

Fig. 3.2(b):- P-2423 composite slab showing reinforcements and instrumentation ............................ 36

Fig. 3.3:- Profile sheets (a) P-3623 and (b) P-2432 $(0.76$ mm thick steel sheet................................ . 38

Fig. 3.4:- ECC production in the mixer machine .................................................................................

Fig. 3.5:- Composite slab forms and sheets in the formwork with reinforcement (a) P-3623, and (b)

P-2432..

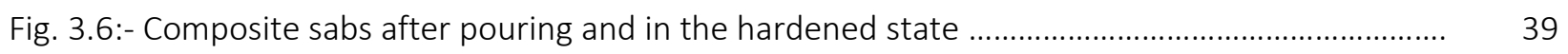

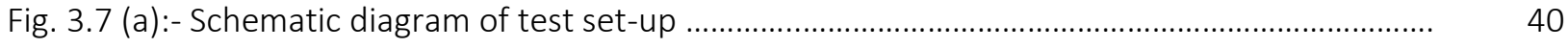

Fig. 3.7 (b):- Actual set-up with specimen and instrumentation ..................................................... .

Fig. 3.8:- Cracking and steel-concrete separation of composite slab................................................ 
Fig. 3.9(a):- Load-deflection behaviour with different shear span (ECC - sheet A P-2432)................... 43

Fig. 3.9(b):- Load-deflection behaviour with different shear span (SCC - sheet A P-2432).................

Fig. 3.9(c):- Load-deflection behaviour with different shear span (ECC - sheet B P-3623).................

Fig. 3.9(d):- Load-deflection behaviour with different shear span (SCC - sheet B P-3623)................

Fig. 3.10:- End slip between steel sheet and concrete in composite slabs...................................... .

Fig. 3.11 (a):- Load-slip relation of composite slabs with different shear span (ECC - sheet A P-2432).... 46

Fig. 3.11 (b):- Load-slip relation of composite slabs with different shear span (SCC - sheet A P-2432).... 46

Fig. 3.11 (c):- Load-slip relation of composite slabs with different shear span (ECC - sheet B P-3623)... 47

Fig. 3.11 (d):- Load-slip relation of composite slabs with different shear span (SCC - sheet B P-3623).... 47

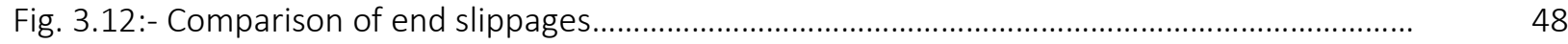

Fig. 3.13 (a):- Concrete strain development (ECC-sheet A P-2432) …………..................................

Fig. 3.13 (b):- Concrete strain development (SCC-sheet A P-243) .................................................... 50

Fig. 3.13 (c):- Concrete strain development (ECC-sheet B P-3623) ................................................... 50

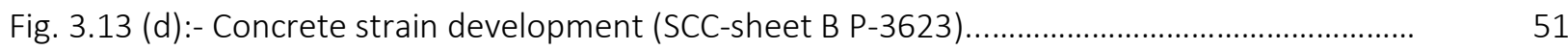

Fig. 3.14:- Comparison of compressive strains in concrete.............................................................

Fig. 3.15 (a):- Tensile steel strain development (ECC-sheet A P-2432) ............................................ 52

Fig. 3.15 (b):- Tensile steel strain development (SCC-sheet A P-2432) ............................................

Fig. 3.15 (c):- Tensile steel strain development (ECC-sheet B P-3623)................................................. 53

Fig. 3.15 (d):- Tensile steel strain development (SCC-sheet B P-3623)............................................ 54

Fig. 3.16:- Comparison of strain development in profile steel sheet ..............................................

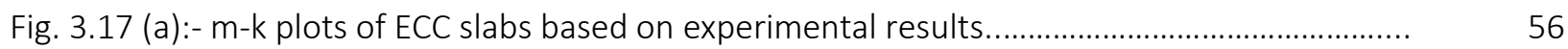

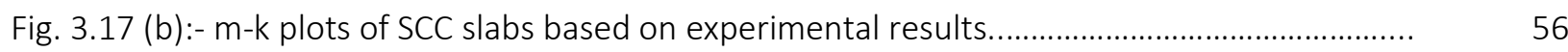

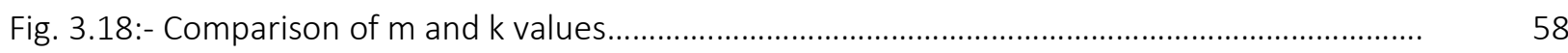

Fig. 3.19:- Comparison of Shear bond capacity (in Mpa) by M - K value method ............................ 59

Fig. 3.20:- Stress distribution for sagging bending moment if the neutral axis is above the steel

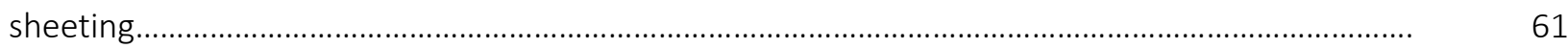

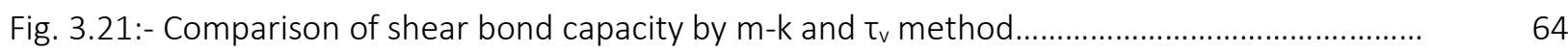

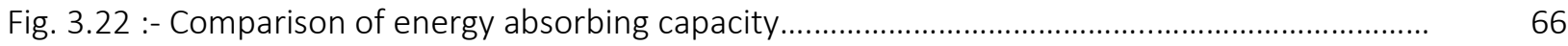




\section{List of table}

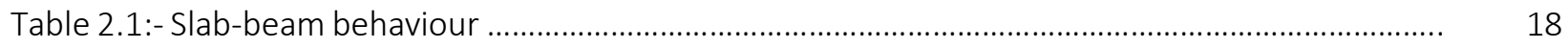

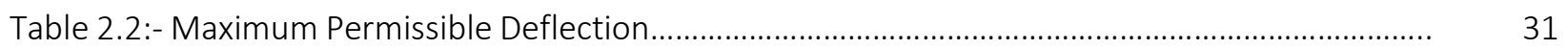

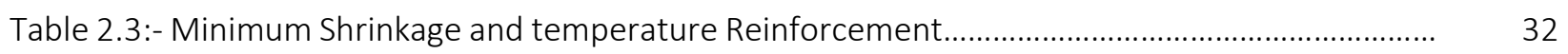

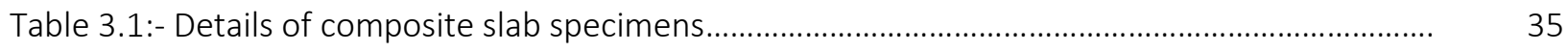

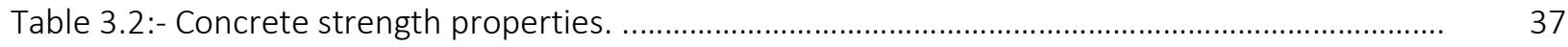

Table 3.3:- Experimental Failure modes behavior, shear force different sabs respect to Euro-code $4 . . .49$

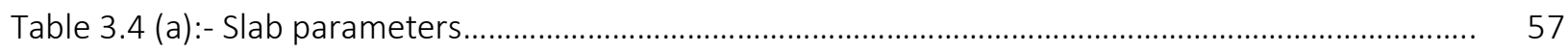

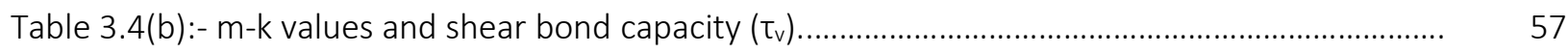

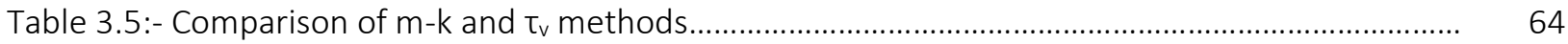

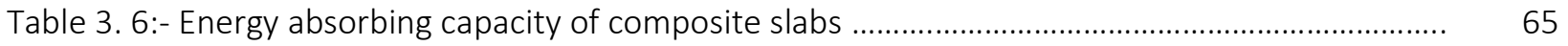


Notation

$A_{p} \quad$ Cross sectional area of profile steel sheet

b Width of the composite slab centroid of profile sheet

$d_{s} \quad$ depth of profile steel sheet

$d_{p} \quad$ Effective depth of slab

e

Distance from the centroidal axis of profiled steel sheeting to the extreme fibre of the composite slab in tension.

$e_{p}$

Distance from the plastic neutral axis of profiled steel sheeting to the extreme fibre of the composite slab in tension

$E_{c}$ Modulus of elasticity of concrete, $\mathrm{M}_{\mathrm{pa}}$

$\mathrm{E}_{\mathrm{s}}$ Modules of elasticity of steel deck, $\mathrm{M}_{\mathrm{pa}}$

$f_{c}$ Mean value of the measured cylinder compressive strength of concrete Design value of the yield strength of structural steel

$h_{t}$ Overall thickness of test specimen Empirical value of friction between concrete and sheet center line span of a simple supported slab

$L_{v}$ Effective shear span length Length of overhang

Empirical value of Mechanical interlocking between concrete and sheet Design bending moment Design value of the plastic resistance moment of the effective cross-section of the profiled steel sheeting

$\mathrm{M}_{\mathrm{pl}, \mathrm{Rd}} \quad$ Design value of the plastic resistance moment of the composite section with full shear connection

$\mathrm{M}_{\mathrm{pr}} \quad$ Reduced plastic resistance moment of the profiled steel sheeting

$\mathrm{M}_{\mathrm{Rd}} \quad$ Design value of the resistance moment of a composite section or joint N Compressive normal force;

$\mathrm{N}_{c} \quad$ Design value of the compressive normal force in the concrete flange 


$\begin{array}{ll}N_{c f} & \text { Design value of the compressive normal force in the concrete flange with full } \\ & \text { shear connection } \\ V_{E} & \text { Maximum experience shear force } \\ \tau_{v, R D} & \text { Shear bond capacity } \\ X_{p l} & \text { Distance between the plastic neutral axis and the extreme fibre of the concrete } \\ \alpha & \text { Slab in compression } \\ \gamma_{c} & \text { Factor; parameter } \\ \gamma_{s} & \text { Partial factor for concrete } \\ \gamma_{v} & \text { Partial factor for reinforcing steel } \\ \delta & \text { Partial factor for design shear resistance of a headed stud } \\ \mu & \text { Dentral deflection }\end{array}$


Intentional left for blank space 


\section{CHAPTER 1: INTRODUCTION}

\subsection{General}

The EN 1994-1-1:2004 defines "composite slab like a slab in which profiled steel sheets are used initially as permanent shuttering and subsequently combine structurally with the hardened concrete to act as tensile reinforcement in the finished floor (Fig. 1.1)". Since the last decade, a composite slab with profile steel sheet decking has seen accepted by the construction industry due to many advantages of the combination effect of the two construction material (Rackham et al., 2009). This system has provided the simpler, faster, lighter, and economical construction in steel-framed building system. Because of these benefits, composite floor slab system is common and one of the viable option practices in construction industry. In this flooring/slab system, cold-formed profiled steel decking with different type of embossments are commonly used. This steel deck performs as a formwork during concrete casting in the construction stage and as tensile reinforcement after concrete has hardened in the service stage. The only additional reinforcement steel is provided for control of shrinkage and temperature. For continuous composite slab, reinforcement steel is required at the support to resist the negative bending moment (Marimuthua et al., 2006).

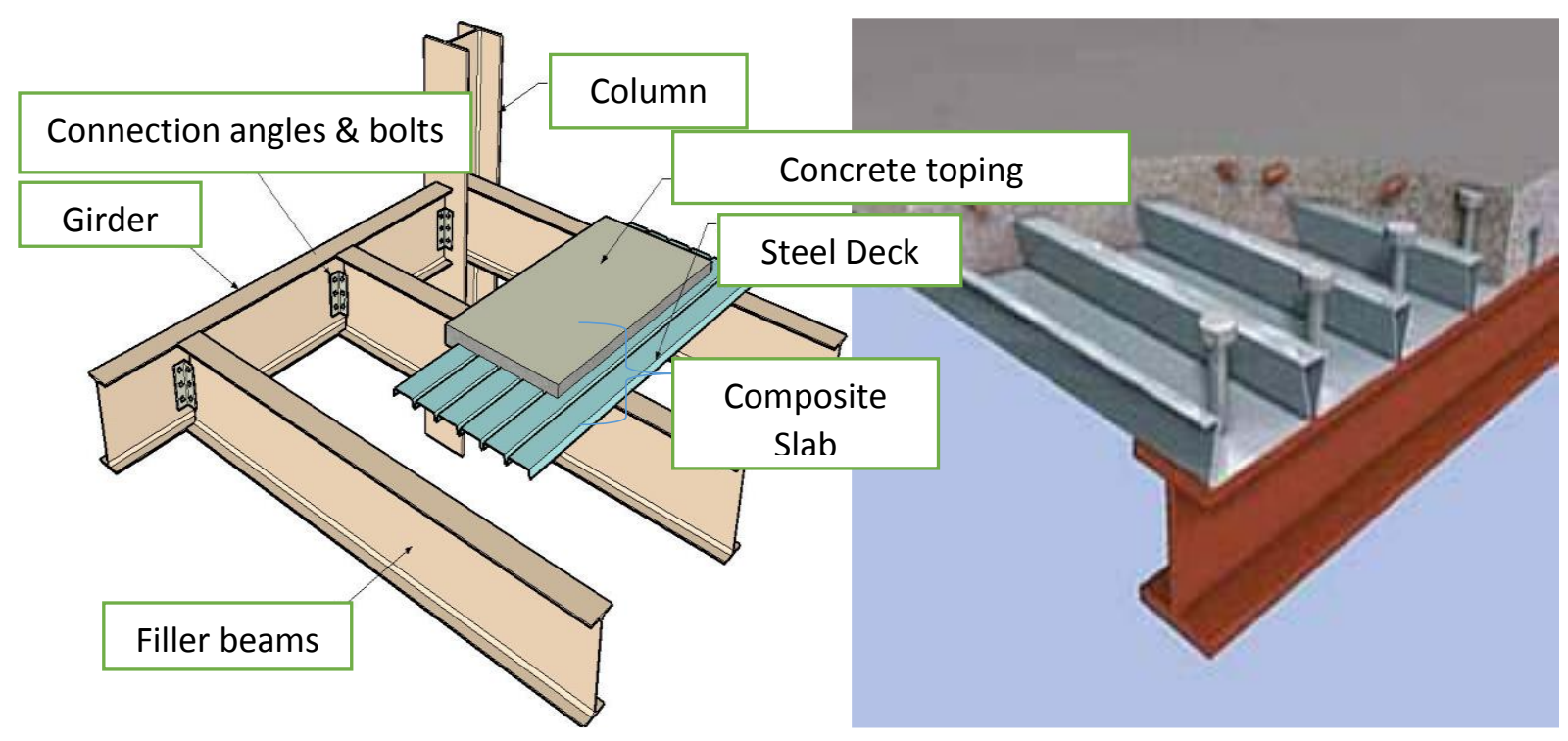

Fig. 1.1:- Composite slab in building system (McGraw-Hill Concise Engineering, 2002) 
In composite slab, two load carrying structural components (profiled steel deck and concrete toping) that are connected together deflect as a single unit because of sufficient shear bond between the components. This type of flooring results in reduced weight and size of the primary structure and foundation that helps decrease the total cost. On the other hand helps construct shallower construction. Other advantages include easy handling, a good celling surface and convenient utility installation services. Some of disadvantage are inadequate fire resistance, sensitive for corrosion and proper bonding between the concrete and steel sheet.

Although structural performance of composite slabs with traditional concrete was the subject matter of numerous research studies, limited research has been conducted to envisage the behaviour of composite slabs with different profile steel sheeting and newly emerging high performance concrete (HPCs) (Mohammed et al. 2011; Mohammed, 2010; Hossain and Vinay, 2012). Structural behavior of composite slab using different concretes including rubber concrete have been investigated (Bashar 2010, Marimutu et al. 2007, Chen 2003, Makelainen and Sun 1999).

The better shear bond interaction between steel sheet and HPC can significantly improve the structural performance of composite slabs in addition to improve durability. Therefore the study of structural performance of composite slabs with different HPCs with varying profile geometry and mechanical connectors is warranted. Design of composite slabs can be achieved by using $\mathrm{m}-\mathrm{k}$ method, if $\mathrm{m}$ (parameter that defines shear bond due to mechanical interlock between steel and concrete) and $\mathrm{k}$ (parameter that defines shear bond due to friction between steel and concrete) values are known from experiments. $\mathrm{m}$ and $\mathrm{k}$ values normally change with different concrete and different steel sheets (Mohammed 2010; Eurocode 4, 2004). Composite slabs with better structural performance can be obtained by using newly developed high performance concretes (HPCs) especially emerging highly ductile Engineered Cementitious Composite (ECC).

Cost-effective highly flowable green ECCs (developed recently at Ryerson University) made of locally available materials (Hossain 2014; Hossain and Anwar 2014; Sherir et al. 2014) could yield better composite action between the profiled steel sheeting and the concrete. The high strain capacity (300 to 500 times greater than normal concrete) while maintaining low crack widths (less than $60 \mu \mathrm{m}$ ) could resolve the problems through shear bond optimization and improving constructability (faster construction and better concrete quality control through self-consolidation) as well as enhancing ductility and durability. No research has been conducted on the development of high performance composite slabs 
using ECC. There is an urgent need to conduct research on the structural performance of ECC based composite slabs compared to their traditional concrete counterparts and develop design specifications.

\subsection{Research Significance}

The proposed ECC based composite floors can resolve the problems through shear bond optimization (by increasing ECC-steel deck interaction) and improving constructability (faster construction and better concrete quality control through self-consolidation) as well as enhancing ductility and durability. It is essential to evaluate the structural performance of proposed ECC based composite flooring system (to develop design specifications which are not currently available) through experimental and theoretical investigations. The recommendations of this research will contribute to the development of a new composite flooring system with enhanced ductility, durability, energy absorbing capacity and service life compared with traditional flooring systems.

\subsection{Scope and Objectives of the Research}

This research is a timely initiative to study the structural performance of the proposed ECC based new composite flooring system with profiled steel decks. The main objectives of this research are to:

- Evaluate the performance of profiled steel decks as formwork, observe ease of casting with fresh concrete (self-flowing and self-compacting characteristics of ECC and SCC) and determine other associated fresh state properties including concrete finished surface characteristics during construction.

- Carry laboratory testing of composite floor/slab specimens under static monotonic loading to study the structural performance in the service stage taking into account concrete types (ECC and SCC) and profiled steel deck types as well as variable shear span.

- Evaluate the structural performance of ECC composite slabs compared to their SCC counterparts based on experimental and theoretical analyses using load-displacement response, shear/moment resistance, failure modes, strain development in concrete/steel, load-slip behaviour, ductility, energy absorbing capacity and steel-concrete shear bond resistance. Longitudinal shear bond stress of composite slabs is calculated using two approaches as per Eurocode 4 (EN 1994-1-1:2004) such as shear bond method (m-k method) and the partial shear connection (PSC).

- Make recommendations for the values of shear bond parameters that can be used in existing Code based equations/specifications to predict the strength of both ECC and SCC composite slabs. 
Introduction and the objectives of this research are presented in chapter 1 . Literature review of composite slabs is covered in depth in chapter 2. Chapter 3 presents detail experimental investigation, analysis and discussion. Conclusion and recommendation of this research are presented in chapter 4 . 


\section{CHAPTER 2: LITERATURE REVIEW}

\subsection{History of Composite Slabs}

Suspended floor construction for steel-framed buildings widely used composite slabs several decades ago in North America. The first form of composite element using steel and concrete was used for flexure member. In 1926, Loucks and Gillet patented the construction of structural steel decking. At that time, the function of concrete was to protect the steel deck from suspected fire. The resistance of composite slab came from the steel deck only (Penza, 2010). Granco Steel Product Company produced the first metal deck profile for composite floor slab in 1950. At that time composite slab system was developed by using the welded transverse wires on the top of corrugated sheet to get composite resistance (Fig. 2.1). Such composite resistance was very similar to that of reinforced concrete resistance.

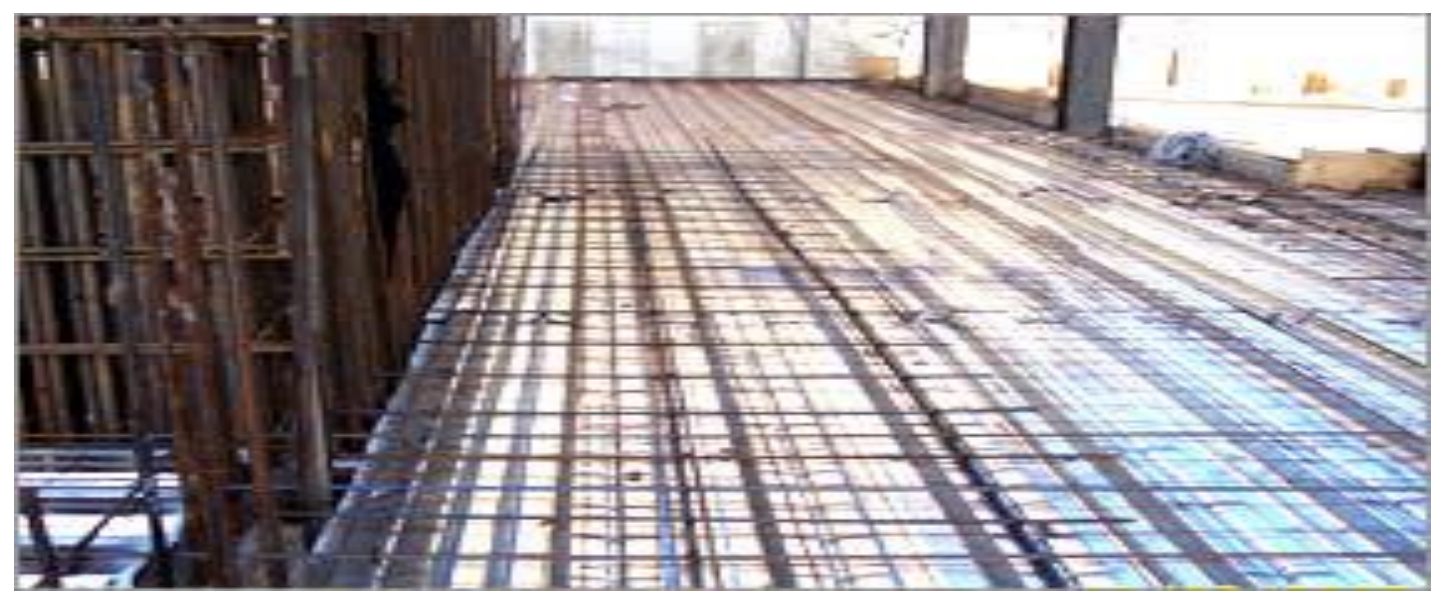

Fig. 2.1:- Composite system with showing wire welded (McGraw-Hill Concise Engineering, 2002)

In 1961, Hibond steel deck was produced. This steel deck avoided the welded wires and used the new trapezoidal profile with embossment and re-entrant parts in the deck profile. This trapezoidal shape and embossment helped to develop the connection of concrete and steel deck like welded wire mesh (Fig. 2.2). After this, several investigations were carried out on different deck cross sectional profiles. Under sponsorship of AISI (American Iron and Steel Institute) ultimate strength design approach was developed in 1967. This approach is considered as the ancestor of current m-k method (Johnson, 1994). 


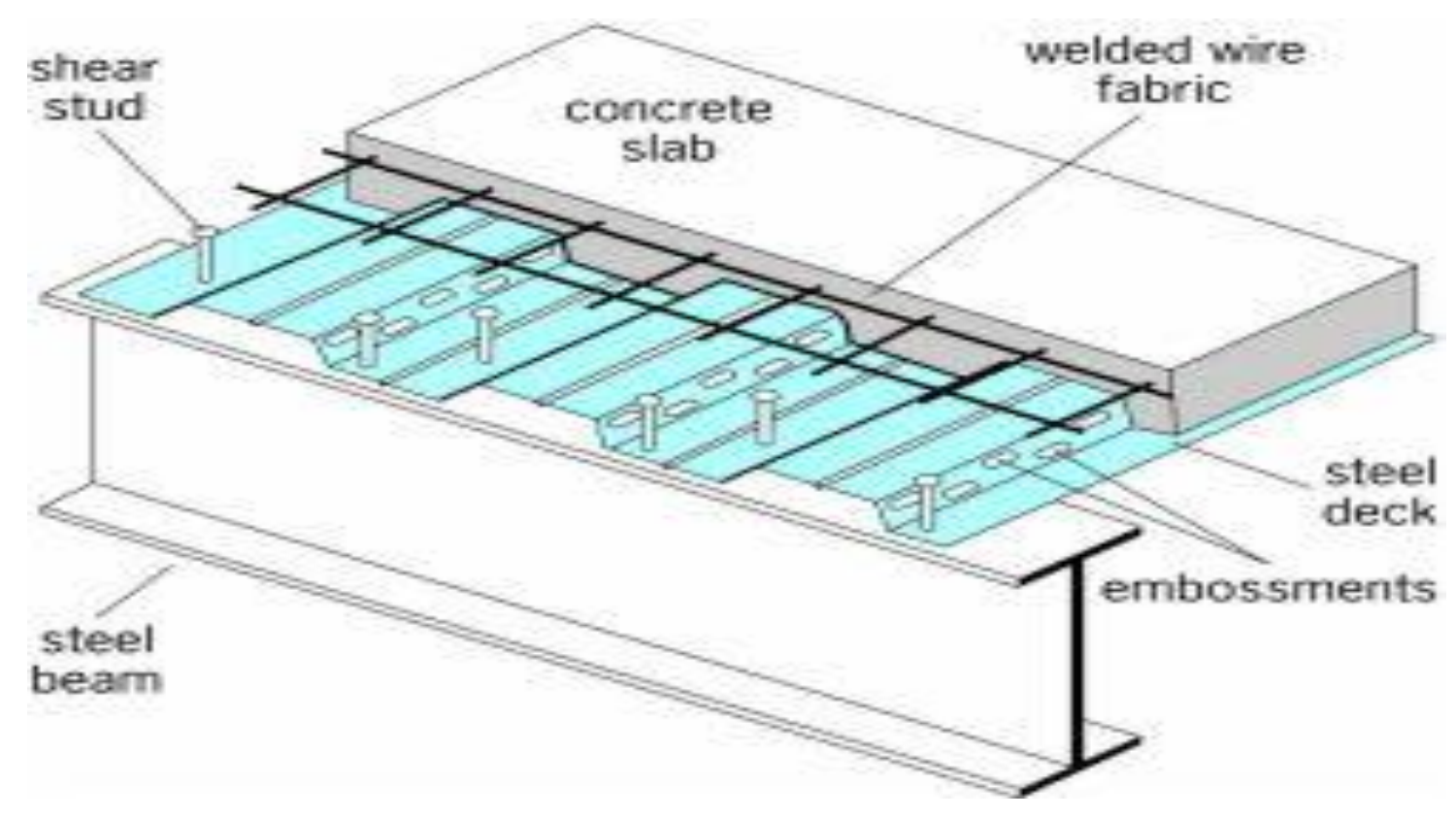

Fig. 2.2:- Composite slab showing embossment and reinforcements (McGraw-Hill Concise Engineering, 2002)

In composite slab (Fig. 2.2), the steel sheet acts as both permanent formwork and as tensile reinforcement producing tensile force when anchored with concrete. This anchorage depends on the pattern/geometry of profile sheet and its embossments. When well anchored, composite slab generates sufficient shear bond between the concrete and steel deck. This shear bond (composite interaction) increase depends on the attachment of shear connecters to the steel sheets. The shear connectors provide sufficient longitudinal shear connection between the concrete and the steel sheet to generate composite action ( Ehlers, 2001). During the last decades, many advanced research studies have been conducted on the design procedure in Europe. In 1982, the first British standard for the design of composite slab was appeared (Johnson, 1994).

\subsection{Application of Composite Slabs}

Composite slabs have several different application field because it combine joint benefit of steel sheet and concrete properties. These application of composite slabs have been listed by Penza (2010), Rackham et al. (2009) and Johnson (1994). These slabs have traditionally found their greatest application in steelframed office building. They are also appropriate for commercial/industrial/residential buildings, warehouse, hospitals, schools, cinemas, individual houses and refurbishment projects. 


\subsection{Benefits of Composite Slab}

Composite floor system are considered highest quality type of construction that is why many architects, engineers and developers are selected as a standard type of construction. In the composite slab system the concrete with steel deck to create a stiffer, lighter, and less expansive (economical) structure (Abdullah \& Easterling, 2006). Because of this, it has a reduced structural steel frame cost, weight of the structural steel frame decreases which may reduce foundation cost, reduced live load deflections, shallower structure may be used that may help reduced the height of the building, increased span lengths and stiffer floors. Composite slabs are commonly used in the commercial, industry, health and residential buildings due to the benefit of above and speed of construction that can be achieved.

A typical example of the commercial building constructed by composite steel deck flooring shown in the Fig. 2.3.

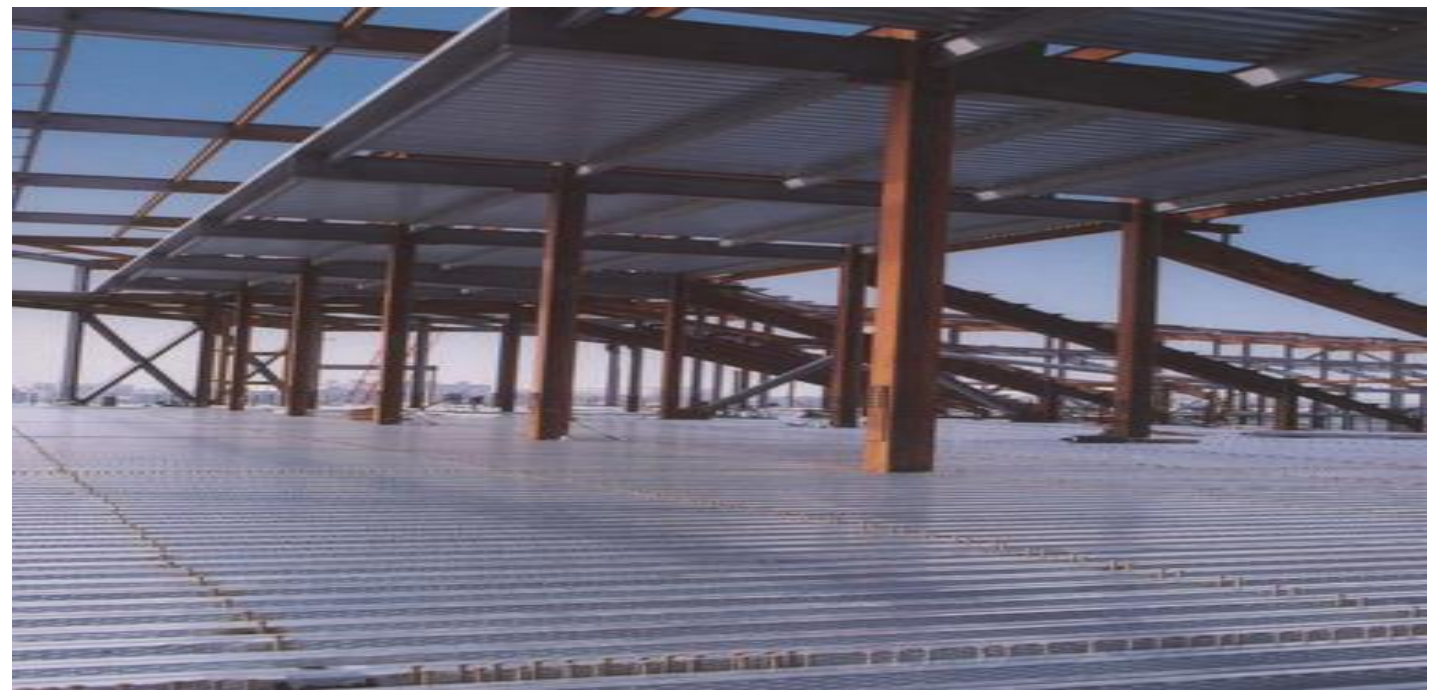

Fig. 2.3:- Typical example of composite slab construction, showing the steel sheet placed on steel frame (Canam, 2014)

Composite slabs act as a diaphragm to resist horizontal loads in buildings (BS EN 1994-1-1:2004). The deck and the reinforcement used to control shrinkage and temperature also help to control cracking of concrete.

The main benefit of composite slabs (Penza 2010, Rackham et al. 2009 and Johnson 1994):

- Speed of construction: Bundles of decking can be positioned on the structure by crane and the individual sheets then installed by hand. Using this process, crane time is minimal, and in excess of $400 \mathrm{~m}^{2}$ of decking can be installed by one team in a day, depending on the shape and size of the building footprint. The use of the decking, as a working platform, speeds up the construction 
process for following trades. Minimal reinforcement is required, and large areas of floor can be poured quickly.

- Economical construction form: Composite beams incorporating composite slabs with profiled sheeting are an economical form of construction. This type of construction allows long span without propping.

- Safe method of construction: The decking can provide a safe working platform and acts as a safety "floor" to protect workers below from falling objects.

- Saving in weight: Composite construction is considerably stiffer and stronger than many other floor systems, so the weight and size of the primary structure can be reduced and the foundation size can also reduce.

- Saving in transport: Decking is light and is delivered in pre-cut lengths that are tightly packed into bundles. Typically, one truck can transport in excess of $1000 \mathrm{~m}^{2}$ of decking. Therefore, a smaller number of deliveries are required when compared to other forms of construction.

- Structural stability: The decking can act as an effective lateral restraint for the beams, provided that the decking fixings have been designed to carry the necessary loads and specified accordingly. The decking may also be designed to act as a large floor diaphragm to redistribute winds load in the construction stage, and the composite slab can act as a diaphragm in the completed structure. The floor construction is robust due to the continuity achieved between the decking, reinforcement, concrete and primary structure.

- Sustainability: Steel has the ability to be recycled repeatedly without reducing its inherent properties. This makes steel framed composite construction a sustainable solution. At least $94 \%$ of all steel construction products can be either re-used or recycled upon demolition of a building.

- Easy installation of services: Cable trays and pipes can be hung from hangers that are attached using special dovetail recesses rolled into the decking profile, thereby facilitating the installation of services such as electricity, telephone and information technology network cabling. These hangers also allow for installation of false ceiling and ventilation equipment.

- Strict tolerances: This benefit is achieved by using steel members manufactured under controlled factory conditions to established quality procedures

- Shallower construction: The stiffness and bending resistance of composite beams means that shallower floors can be achieved than in non-composite construction. This may lead to smaller storey heights, more room to accommodate services in a limited ceiling to floor zone, or more 
storeys for the same overall height. This is especially true for slim floor construction, whereby the beam depth is contained within the slab depth.

Comparative structural cost of modern commercial buildings shows composite construction is economical than steel or concrete alternatives for both a conventional four story office block and an eight stories prestigious office block with an atrium ( Rackham et al. 2009).

\subsection{Materials for Composite Slabs}

Composite slabs are made of two materials - steel sheet and concrete. If the two materials are not working together, the slab will not be able to develop composite resistance that results in weak structure. So that, the material type and the connection between the materials are important and vital to build composite slab structure.

\subsubsection{Steel Decking}

The arrangement and selection of decking is the responsibility of the structural designer. Design data is provided by a manufacturer will normally be used to select the decking but if the structure is complex it will be better to determine from the test. The design must consider the fire resistance and the main function of the decking structure.

The steel decking has two main structural functions:

- During concreting (construction): the decking supports the weight of the wet concrete and reinforcement used for control shrinkage and temperature and the temporary loads associated with the construction process. It is normally intended to be used without temporary bracing.

- In service: the decking acts "compositely" with the concrete to support the loads on the floor. Composite action is obtained by shear bond and mechanical interlock between the concrete and the decking. This is achieved by the embossments rolled into the decking and by any re-entrant parts in the deck profile, which prevent separation of the deck and the concrete.

The deck also helps to resist lateral load due to wind and torsional buckling during construction, and stabilize the structure by acting as a diaphragm that transfer the wind load to the wall and columns. The deck can achieve the above function if it is designed using Eurocode 4 (BS EN 1994-1-1:2004). All manufactured steel sheet should be tested using the standard procedure. 


\subsubsection{Steel Sheet Profiles}

Numerous types of steel profile sheeting are used in composite slab. This different types of sheeting are presented by type of shape, depth, thickness, distance of embossment and covering. Steel sheeting is thin (between $0.8 \mathrm{~mm}$ to $1.2 \mathrm{~mm}$ ) because of economic reasons. The recommended value of the thickness $(\mathrm{t})$ of the sheet is $t \geq 0.70 \mathrm{~mm}$ by (Eurocode 3,2005 ). The standard protection against corrosion used a thin layer of galvanizing on both faces for durability purpose. The thickness of the sheet quoted by manufacturer in overall thickness that included the galvanized coating. This adds about $0.04 \mathrm{~mm}$ to the overall thickness. The steel is galvanized before forming and this designation in the steel grade by letter GD followed by a number corresponding to the number of grammes of zinc per $\mathrm{m}^{2}$. The normal specification is GD 275 , i.e. 275 grammes of zinc per $\mathrm{m}^{2}$.

As specified Eurocode 3; part 1.3 that where design is based on the nominal thickness of the steel and the sheet must have at least $95 \%$ of that thickness, but it is difficult to check this. The sheets are pressed or cold rolled, and are typically about $1 \mathrm{~m}$ wide and up to $6 \mathrm{~m}$ long. They are designed to span in the longitudinal direction only. For many years, sheets typically $50 \mathrm{~mm}$ deep, and the limiting span was about $3 \mathrm{~m}$. The cost of propping the sheets during concreting, to reduced deflection, led to the development of deeper profiles; but design of composite slabs is still often governed by a limit on deflection.

The local buckling stress of a flat panel within sheeting should ideally exceed its yield strength: but this requires breadth/thickness ratios of less than about 35. Modern profiles have local stiffening ribs for flexure when the buckling stress is below the yield stress. Calculation of the resistance to bending then become complex and trial and error is involved. Because of the work hardening, the yield strength which specified the nominal yield strength of the flat sheet is higher at every bend and corner. However, the nominal yield strength of the sheeting made is lower than the finished product. Dimples are pressed into the surface of the sheeting to act as shear connectors but this dimples areas may not be fully effective in resisting longitudinal stress.

There are two generic type of decking with respect to shaping; trapezoidal profiles and re-entrant profiles. The example of re-entrant profile is shown the Fig.2.4 while for trapezoidal profiles are shown in Fig.2.5 and Fig.2.6 (Rackham et al. 2009). 

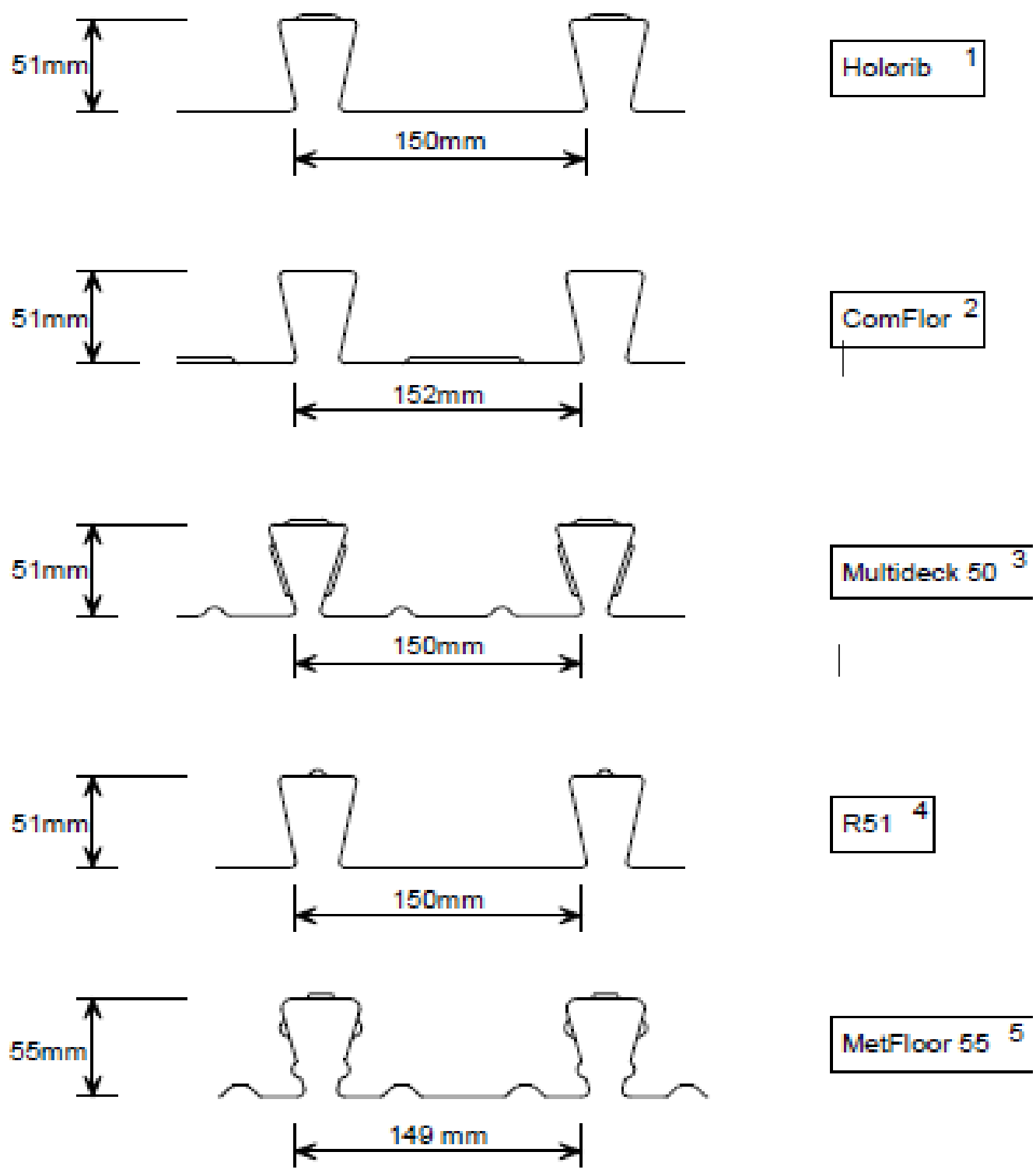

MetFloor 555

1. Richard Lees Steel Decking Ltd., 2. Corus Panels and Profiles, 3. King span Structural Products Ltd., 4. Structural Metal Decks Ltd., 5. CMF Ltd

Fig. 2.4:- Example of re-entrant deck profile used for composite slab (Rackham et al., 2009) 


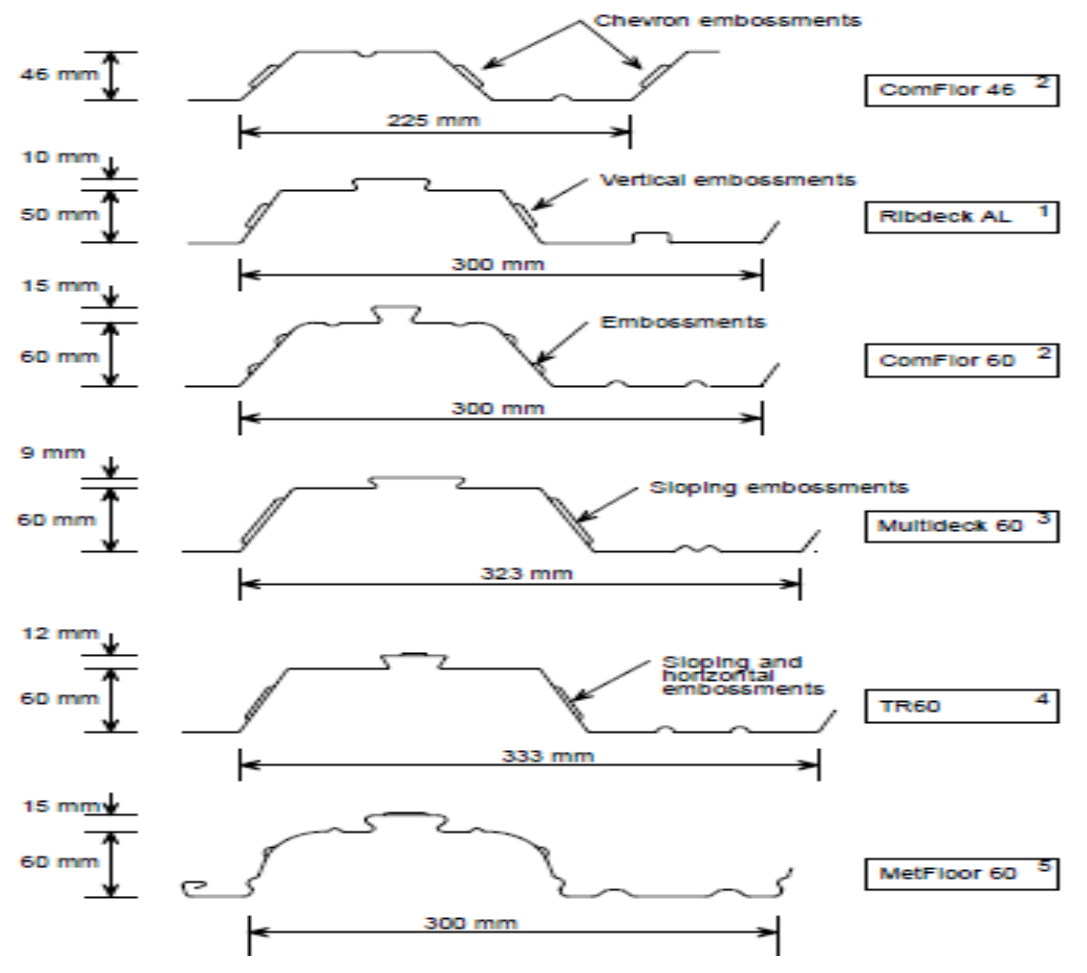

Fig.2.5:- Example of trapezoidal deck profile up to 60mm deep (Rackham et al., 2009)

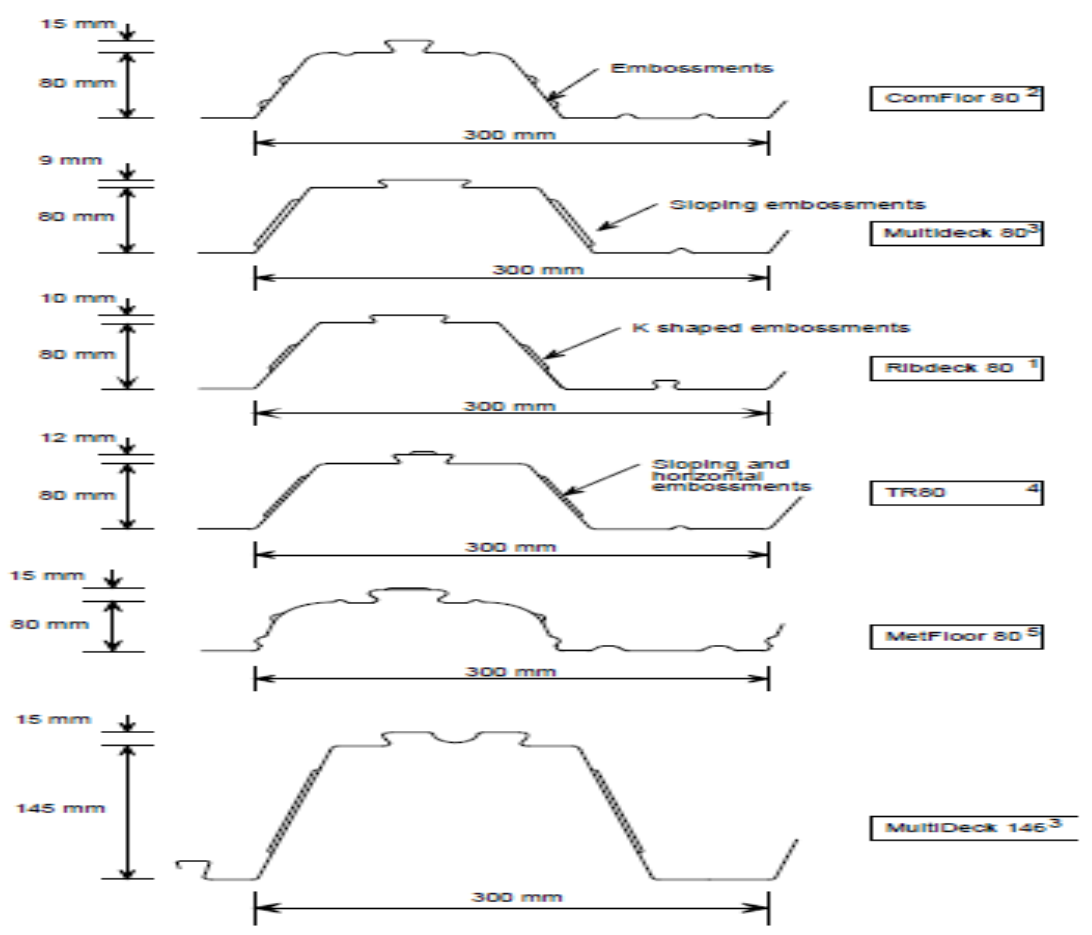

Fig. 2.6:- Example of trapezoidal deck profile greater than $60 \mathrm{~mm}$ deep (Rackham et al., 2009) 
Generally, the spanning capability of a given decking profile clearly increases as the steel thickness increases, but not in direct proportion to the strength. The thickness of the galvanizing should not be considered as a practical way of increasing durability because, the non-standard thicknesses of galvanizing are difficult to obtain. Especially for outside structure so that it needs additional anticorrosion painting. This material is available with yield strengths $\left(f_{y p}\right)$ ranging from $235 \mathrm{~N} / \mathrm{mm}^{2}$ to at least $460 \mathrm{~N} / \mathrm{mm}^{2}$.

\subsubsection{Concrete}

Concretes are classified according to their compressive strength in all national and international codes. The strength of concrete does not depend only on its composition but also on its size, shape, age and its moisture content at the time of testing. Concrete may be classified by the unit weight:

- Light weight concrete with an over-dry density not exceeding $2000 \mathrm{~kg} / \mathrm{m}^{3}$

- Normal weight concrete with an over-dry density greeter than $2000 \mathrm{~kg} / \mathrm{m}^{3}$ but not exceeding $2800 \mathrm{~kg} / \mathrm{m}^{3}$

- Heavyweight concrete with an over-dry density exceeding $2800 \mathrm{~kg} / \mathrm{m}^{3}$

Concrete may also classified by property such as high performance concrete (HPC) and conventional concrete.

High performance concrete (HPC): High performance concrete exceeds the properties and constructability of normal concrete. Normal or special materials are used to make these concrete such as super-plasticized, special mixing, curing and placing. Plasticizers are usually used to make these concretes fluid and workable because it has low water-cementing materials ratio between 0.20 and 0.40 . HPC is defined as a concrete meeting special combination of performance and uniformity requirements that cannot always be achieved routinely using conventional concrete (Ready Mixed Concrete Association of Ontario, 2009). Some of the properties includes: high strength, high early strength, low modulus of elasticity, high abrasion resistance, high durability and long life in severe environments, low permeability, and resistance of chemical attack, toughness and impact resistance, volume stability, and ease of placement compaction without segregation. Self-consolidating concrete (SCC) is flowable HPC that can be placed and cast without external compaction.

Engineered cementitious composite (ECC): ECC is a flowable fiber reinforced cementitious composite (an emerging HPC) that has been optimized through the use of micromechanics to achieve high tensile ductility and tight crack widths. As seen in Figure 2.7, ECC has the ability to reach tensile strain capacities 
of 3\%-5\% under loading (compared with $0.01 \%-0.02 \%$ for normal concrete) while maintaining tight cracks widths of less than $60 \mu \mathrm{m}$. These tight crack widths are a basic material property of ECC and promote robust self-healing behavior that is not easily attainable in brittle concrete with uncontrolled crack widths.

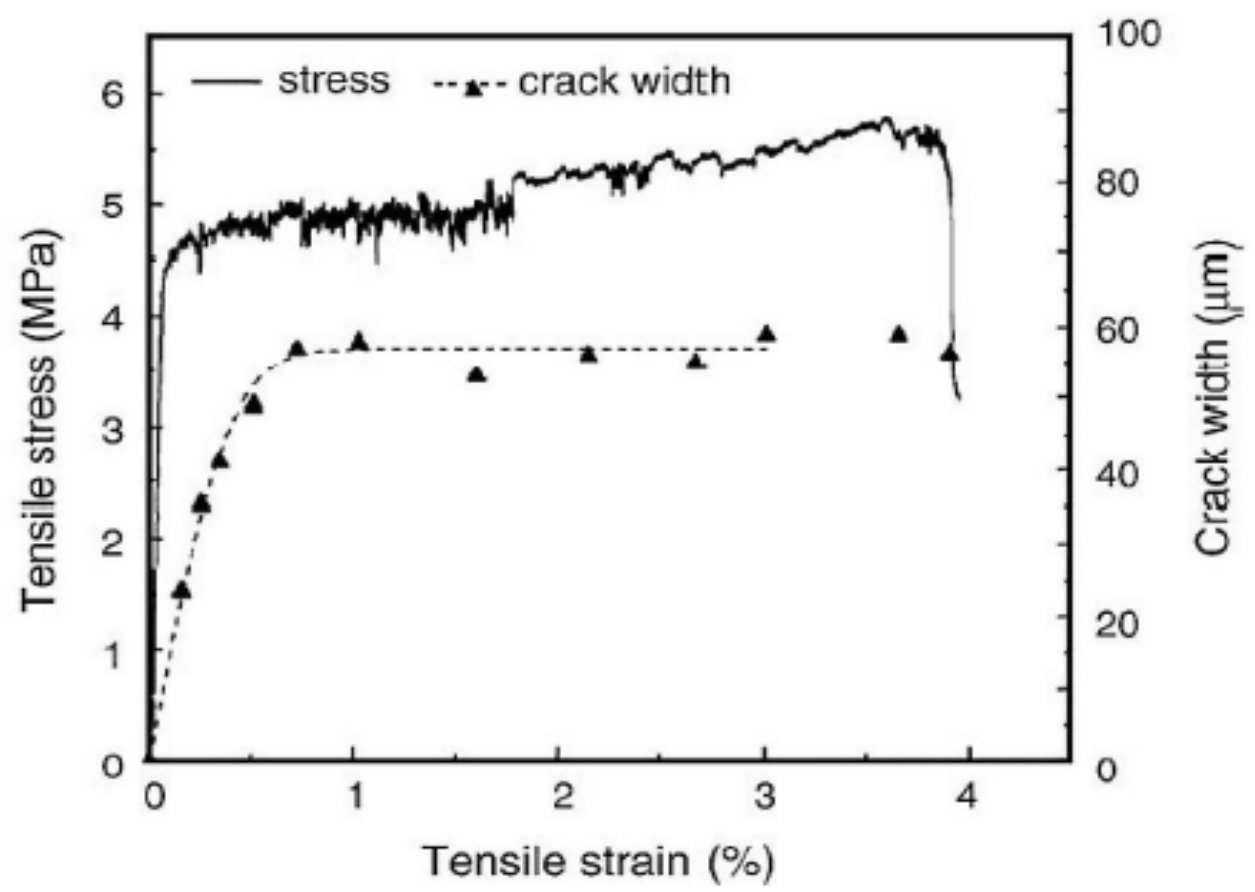

Fig 2.7:- Typical engineered cementitious composites (ECC) stress-strain-crack width curve

(Herber \& Li, 2013)

\subsubsection{Reinforcement Steel}

Reinforcement steel is not the main component of the composite slab because of the steel sheet acts as the tensile reinforcement when the concrete is hardened. However, additional small reinforcing steel that needs to be provided for preventing shrinkage and temperature cracking. This reinforcements should be provided both transverse and longitudinal directions within the depth of the concrete. The amount of reinforcement in both directions should be not less than $80 \mathrm{~mm}^{2} / \mathrm{m}$ (EN 1994-1-1:2004). It is generally useful to provide reinforcement in the slab for the following reasons:

- Load distribution of line or point loads

- Local reinforcement of slab openings

- Fire resistance

- Upper reinforcement in hogging moment area. 
For the determination of the bending moments and shear forces in a composite structure all the three material assumed to behave in a linear- elastic manner, though an effective modulus has to be used for the concrete, to allow for its creep under sustained compressive stress. The effects of shrinkage crack are rarely significant in buildings.

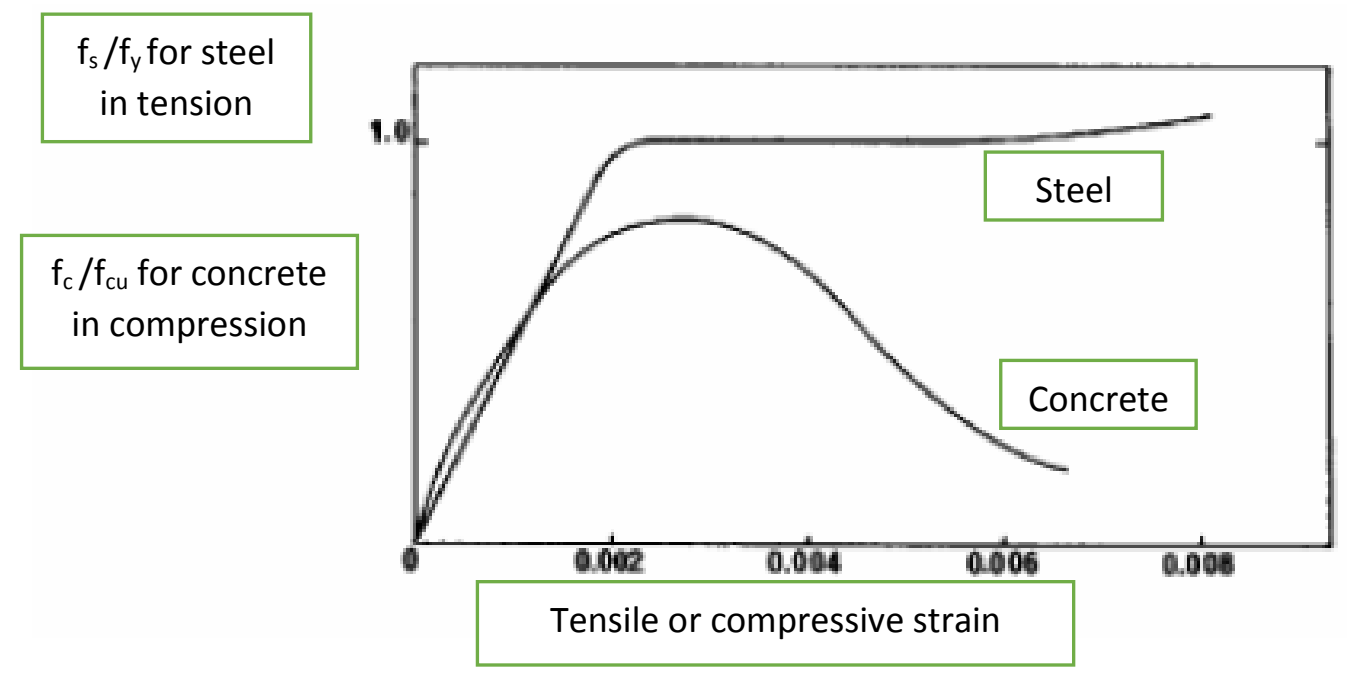

Fig. 2.8:- Stress-Strain curve of concrete and steel structure (Johnson, 1994)

Typical stress-strain curve for concrete in compression, and those for structural steel or reinforcement, in tension or compression, are illustrated in Fig.2.8. Concrete reaches its maximum compressive stress at a strain of between 0.002 and 0.0035 . Normal concrete is very brittle in tension, having a strain capacity of only about 0.0001 (i.e. $0.1 \mathrm{~mm}$ per metre) before it cracks. The figure also shows that the maximum stress reached by concrete in a beam or column is little more than $80 \%$ of its cube strength. Steel yields at a strain similar to that given for crushing of concrete, but on further straining the stress in steel continues to increase slowly. Until the total strain is at least 40 times the yield strain.

\subsection{Composite Slab Behaviour}

Composite behavior is that occurred when the steel profile and the hardened concrete have combined and form the single structure element. This mean that it is capable of transmitted the longitudinal shear at the steel-concrete interface. The composite slab deflects and shear stress built up at the inter face under external load. This behavior depends mainly on the steel-concrete connection type such as shape, embossment, connector etc. Composite slab has two type of interaction (Fig. 2.9): 
Complete interaction: connection between the concrete and steel sheet is perfect and the longitudinal deformation are equal in the steel sheet and in the adjacent concrete. The two members then behaves as one, and slip and slip strain are everywhere zero.

Incomplete/partial interaction: deformation between the steel sheet and the adjacent concrete is not equal which results in the longitudinal displacement difference between the steel and adjacent concrete called slip.

The composite slab stiffness is highest at complete interaction and lowest at zero interaction. The link between the steel and concrete exists due to friction when micro slip appear, due to mechanical anchorage after the first slip occur and depends on the interface shape of steel-concrete.

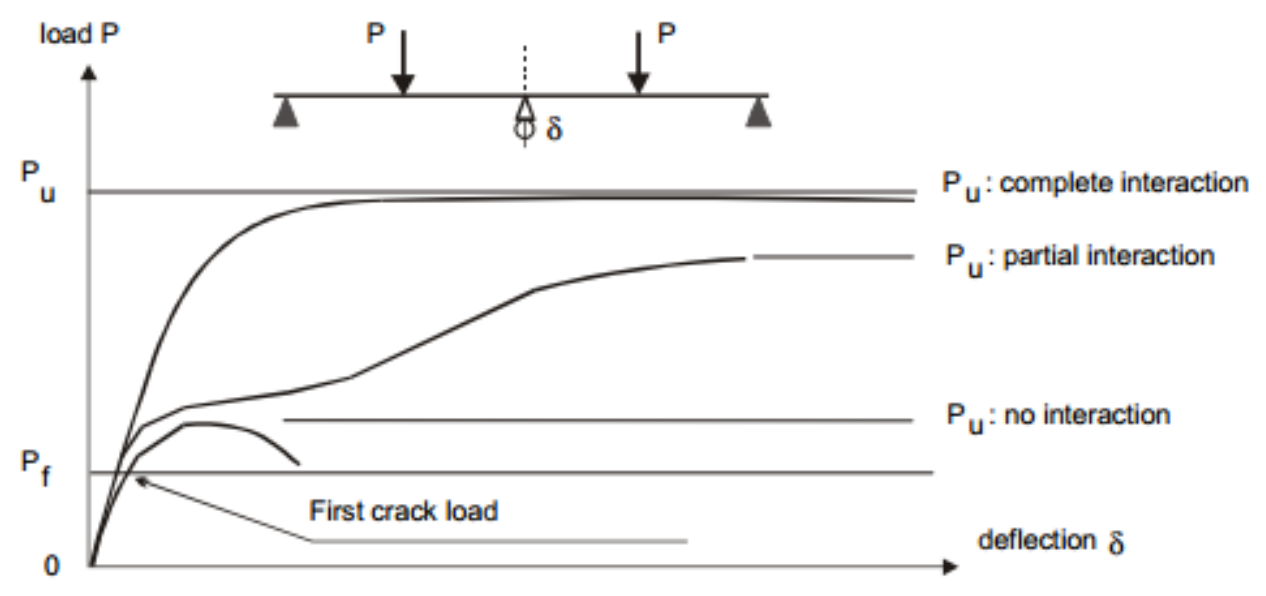

$P_{u}$ : ultimate load and $P_{f}$ : first crack load

Fig. 2.9:- Composite slab behavior (Ehlers, 2001)

Composite slab failure can be happened under one of these three failure modes (Fig. 2.10) which are flexure failure, vertical shear failure and longitudinal shear failure (Marimuthua et al. 2006).

Failure type I: The failure is due to the sagging moment (mode I) that is the bending resistance of the slab $\left(\mathrm{M}_{\mathrm{pl}, \mathrm{Rd}}\right)$. This type of failure is generally the critical mode for moderate to high spans with a high degree of interaction between the steel and concrete. However, it is not dominate type of failure because first the steel and concrete interactions is usually incomplete, second span length is limited by serviceability limit. Failure type II: The failure is due to longitudinal shear when the ultimate load resistance is reached at the steel-concrete interface. This happens in (mode II) along the shear span ( $\left.\mathrm{L}_{\mathrm{v}}\right)$. This type of failure mode is mostly happened in composite slab. The character of such type of failure is associated with the 
development of approximately diagonal tension crack at or near concentrated loads just before failure and followed by end-slip.

Failure type III: This failure is due to vertical shear near the support where vertical shear is important. This is only likely to be critical for slabs having short span length and subject to heavy and concentrated loads near the support.

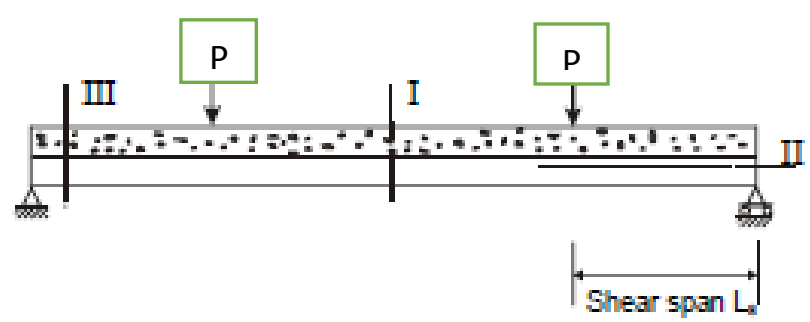

Fig. 2.10:- Composite slab failure mode types (Ehlers, 2001)

The composite slab failure mode may be classified as brittle and ductile. Brittle failure occurs suddenly. , Ductile failure happens progressively and gives significant deformation before totally collapse. The failure mode of the slab is said to be ductile if the failure load exceed the load causing first recorded end slip by more than 10\% (EN 1994-1-1:2004). The brittle type of failure should be avoided by profile deck producer by using various mechanical means, such as embossment or dovetail forms shear connector.

\subsection{Steel and Concrete Connections}

The profiled sheeting should be able to transfer longitudinal shear to concrete through the interface to ensure composite action of the composite slab. Composite action depends upon the adequacy of transfer this longitudinal shear forces. In addition to this horizontal shearing force, the bending action also leads to vertical separation between the concrete and the steel. The profile sheet has to be designed to resisted vertical separation in addition to transferring the longitudinal shear. Therefore, the adhesion of sheet and concrete by itself is not sufficient to create composite action that resisted all forces listed above. Composite behaviour between profiled sheeting and concrete shall be ensured by one or more of the following means, see Fig. 2.11 (Eurocode 4, 2004).

a) Mechanical interlock provided by deformations in the profile (indentations or embossments )

b) Frictional interlock for profiles shaped in a re-entrant form

c) Holes or incomplete perforation in the profile

d) Anchorage element fixed by welding and distributed along the sheet 
e) End anchorage provided by welded studs or another type of local connection between the concrete and the steel sheet, only in combination with (a) or (b)

f) End anchorage by deformation of the ribs at the end of the sheeting, only in combination with (b).
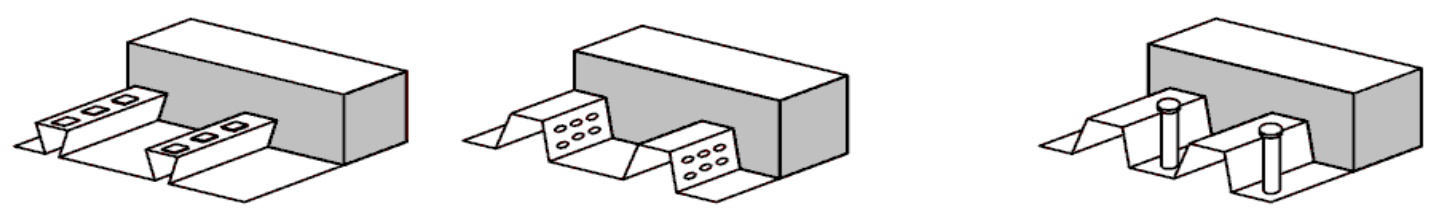

Mechanical Anchorage

End anchorage
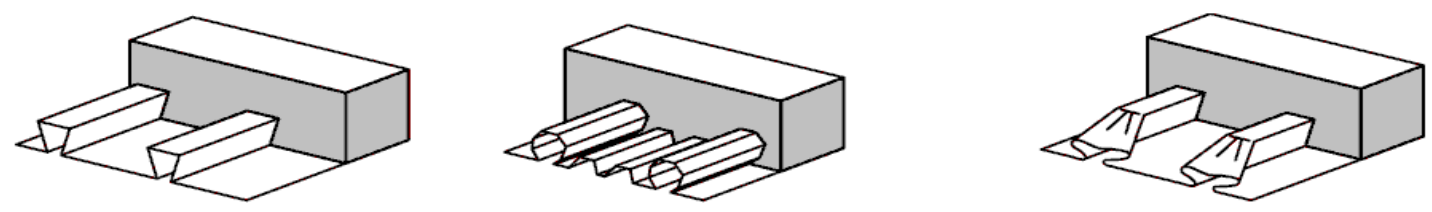

Frictional anchorage

End anchorage by end deformation

Fig. 2.11:- Typical forms of interlock in composite slabs (Eurocode 4, 2004)

\subsection{Design of Composite Slab}

Design of composite slabs is treated in chapter 9 of Eurocode 4. The minimum design slab thicknesses $\left(h_{c}\right)$ are classified in two different classes on the basis of the slab-beam behaviour as shown in the Table 2.1.

Table 2.1:- Slab-beam behaviour (Eurocode 4, 1994)

\begin{tabular}{|c|c|c|c|c|}
\hline & \multicolumn{2}{|c|}{$\begin{array}{c}\text { Composite slab-beam } \\
\text { behaviour } \\
\text { Or diaphragm use }\end{array}$} & \multicolumn{2}{c|}{$\begin{array}{c}\text { No-composite slab-beam } \\
\text { behaviour or no stabilising } \\
\text { function }\end{array}$} \\
\hline Overall depth of the slab & $h_{c} \geq$ & $90 \mathrm{~mm}$ & $h_{c} \geq$ & $80 \mathrm{~mm}$ \\
\hline $\begin{array}{c}\text { Thickness of concrete above } \\
\text { the mean flat surface of the top } \\
\text { of the ribs of type sheeting. }\end{array}$ & $h_{c} \geq$ & $50 \mathrm{~mm}$ & $h_{c} \geq$ & $40 \mathrm{~mm}$ \\
\hline
\end{tabular}

The scope of Eurocode 4 is limited to sheets with narrowly spaced webs. In clause 9.1.1(2) this is defined by an upper limit of the ratio $b_{r} / b_{s}=0.6$, and the minimum reinforcement required is $80 \mathrm{~mm}^{2} / \mathrm{m}$ in both directions, and the spacing between reinforcement bars should not exceed $2 \mathrm{hc}$ and $350 \mathrm{~mm}$ (Fig. 2.12). 


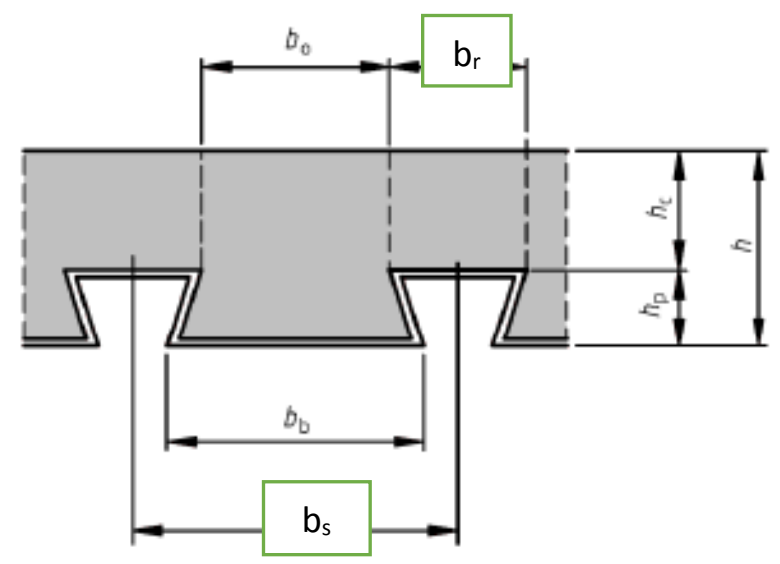

Re-entrant trough profile

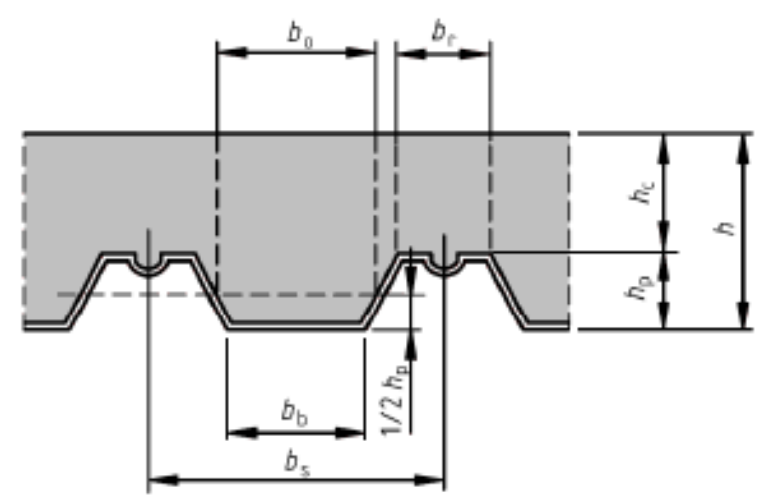

Open trough profile

Fig. 2.12:- Sheet and slab dimensions (Eurocode 4)

\subsubsection{Flexure in Composite Slab}

Flexural failure occurs when the plastic capacity of the slab is reached. This is possible if the resistance for the longitudinal shear transfer in the shear span is large enough to allow yielding of the entire cross section of the sheeting.

Case 1: The bending resistance of composite slab with the neutral axis above the sheeting is calculated as follows using stress distribution as shown In Fig. 2.13:

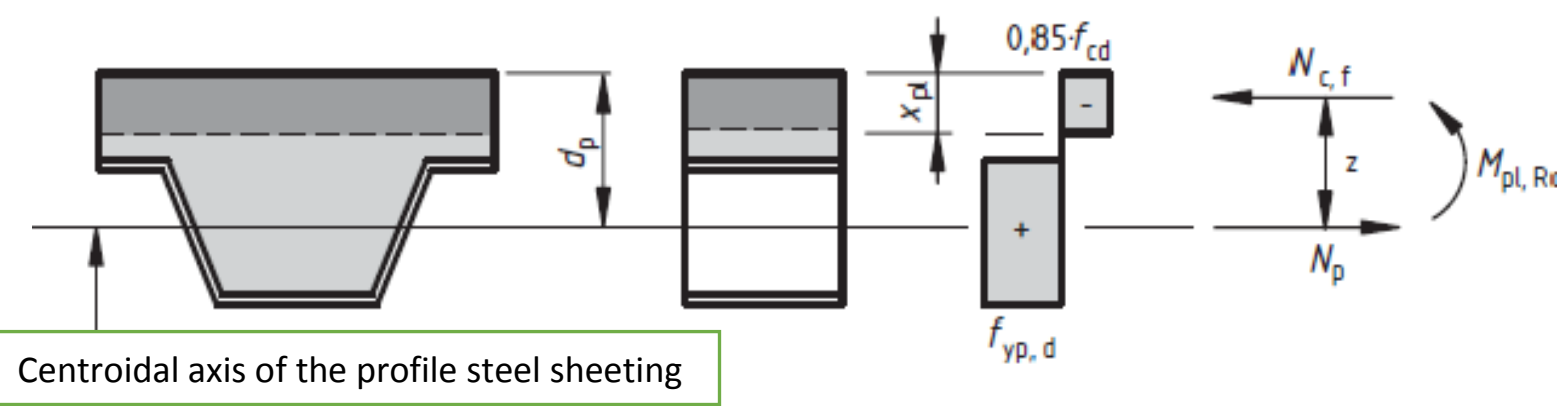

Fig. 2.13:- Stress distribution when neutral axis above the steel sheet (Penza, 2010)

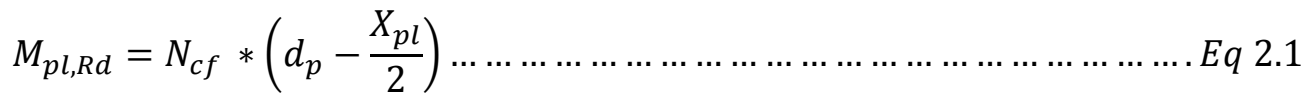

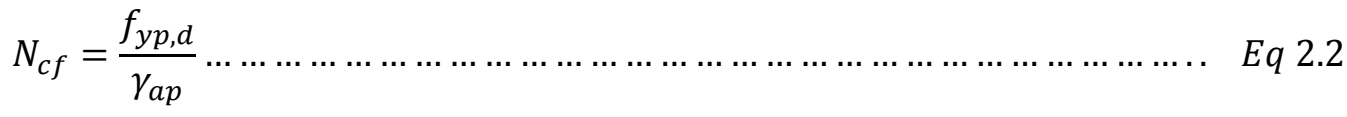

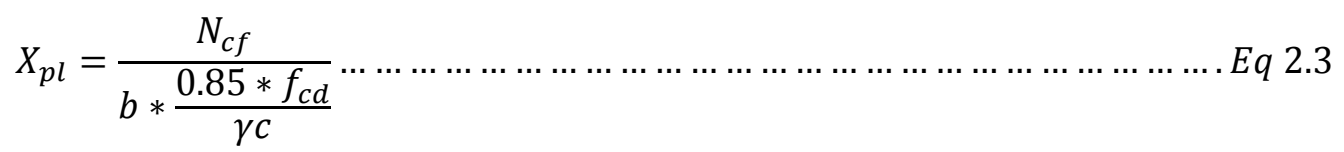


Where:

$M_{p l, R d}$ : Design value of the plastic resistance moment of the composite section with full shear connection

$\mathrm{N}_{c, \mathrm{f}}$ : Design value of the compressive normal force in the concrete flange with full shear connection $F_{c d}$ : Design value of the cylinder compressive strength of concrete

$A_{p}$ : is the effective area of the steel sheet in tension; the width of embossments and indentations in the sheet should be neglected

$\mathrm{f}_{\mathrm{yp}, \mathrm{d}}$ : design value of the yield strength of profiled steel sheeting

$d_{p}$ : is the distance from the top of the slab to the centroid of the effective area

$\mathrm{b}$ : is the width of the cross-section considered.

$X_{p l}$ : Distance between the plastic neutral axis and the extreme fibre of the concrete slab in compression

Case 2: The sagging bending resistance of a cross-section with the neutral axis in the sheeting should be calculated from the stress distribution in Fig. 2.14.

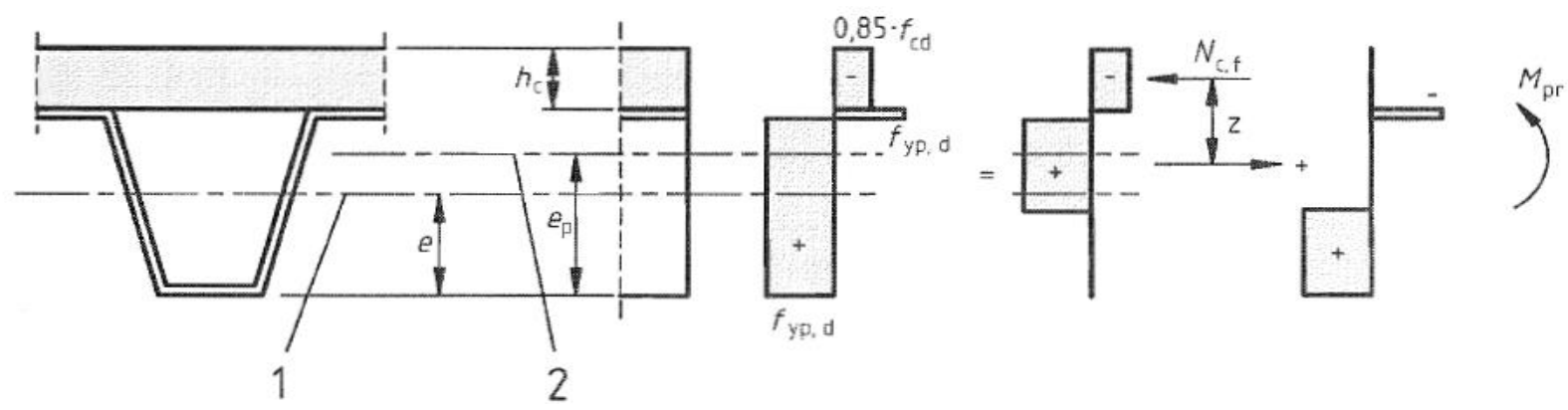

1 - Centroidal axis of the profiled steel sheeting; 2 - Plastic neutral axis of the profiled steel sheeting.

Fig. 2.14:- Stress distribution when neutral axis below the steel sheet (Penza, 2010)

If the plastic neutral axis intercepts the steel sheeting, a part of the steel sheeting section is in compression to keep the equilibrium in translation of the section. The bending resistance $\left(M_{p s, R d}\right)$ is calculated by the following expression:

$$
M_{p s, R d}=N_{c f} * z+M_{p r}
$$

Where

$\mathrm{z}$ is level arm, $\mathrm{M}_{\mathrm{pr}}$ is reduced plastic moment, and $\mathrm{N}_{\mathrm{cf}}$ is compression force in the concrete, may be determined with expressions: 


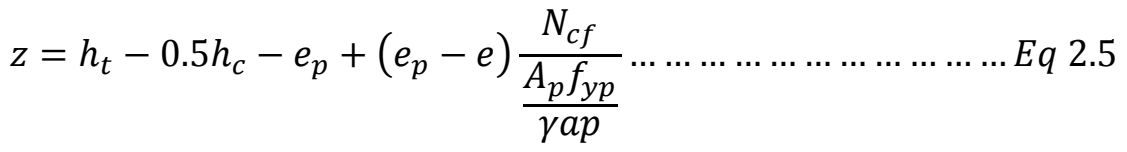

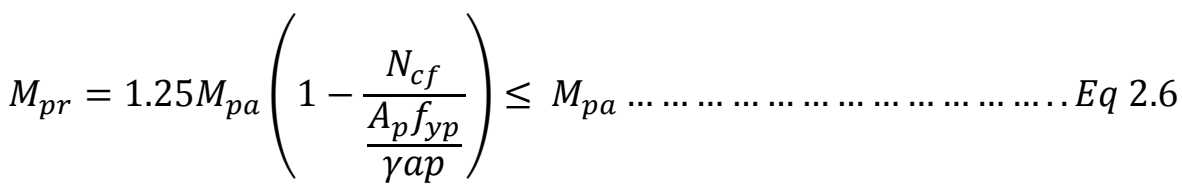

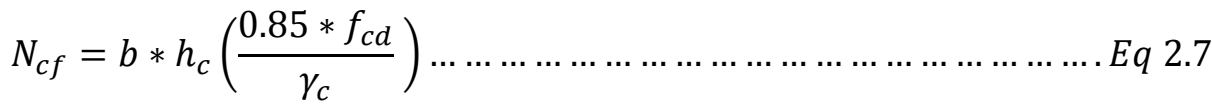

With:

$\mathrm{e}_{\mathrm{p}}$ : distance of the plastic neutral axis of the effective area of the sheeting to its underside.

e: distance from the centroidal axis of profiled steel sheeting to the extreme fibre of the composite slab in tension.

\subsubsection{Longitudinal Shear in Composite Slab}

Longitudinal shear failure occurs if the shear span is not sufficiently long for the mechanical interlocking strength to develop the plastic resistance. The method is to evaluate the average longitudinal shear resistance ' $\tau_{v}$ ' on shear span ' $L_{v}$ ' and compare this with the applied force. The resistance $\tau_{v}$ depends on the type of sheeting and must be established for all proprietary sheeting that is embossment or indentation orientation, surface condition etc. There are three types of shear connection between the steel sheet and concrete. The first one is depend on the natural connection between the two materials that is depend on only friction. This is not good unless use other thing prevent uplifting. Second one is creating the mechanical interlock between the two surfaces by using ribs, dimples, etc. The third one is creating end anchorage by welding the end sheet with steel beam or deformation of end sheet, etc. The design resistance against longitudinal shear should be determined by two different experimental methods:

- $\quad \mathrm{m}-\mathrm{k}$ Method and Partial connection Method.

\subsubsection{1 m-k Method}

The effectiveness of shear connection is studied by means of loading tests on simply-supported composite slabs. Specification of each tests given by Eurocode 4 (EN 1994-1-1, 2004). The length of each shear span, Lv is usually $L / 4$, where $L$ is the span length. There are three possible mode of failure. The expected mode of failure in a test depends on the ratio of Lv to the effective depth $d_{p}$ of the slab. As per Eurocode 4 , the 
results are plotted on a diagram with axes $V_{E} / b d_{p}$ and $A_{p} / b L_{v}$ (Fig. 2.15) for reasons that are now explained. At high $\mathrm{Lv} / \mathrm{dp}$, flexural failure occurs and at this time maximum bending moment $(\mathrm{Mu})$ is calculated by:

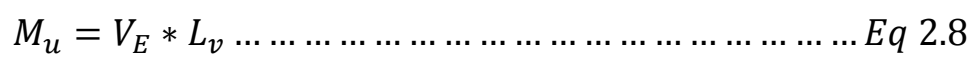

Where, $\mathrm{V}_{\mathrm{E}}$ is maximum vertical shear, assumed to be much greater than the self-weight of the slab. A test specimen of breadth $\mathrm{b}$ should include a member of complete wavelengths of sheeting of total crosssectional area $A_{p}$. Flexural failure is modeled by simple plastic theory, with all the steel at yield stress $f_{y p}$ and sufficient concrete at $0.85 f_{c}$ where $f_{c}$ is the cylinder strength for longitudinal equilibrium. The lever arm is a little less than $d_{p}$ but approximately (see fig 2.13).

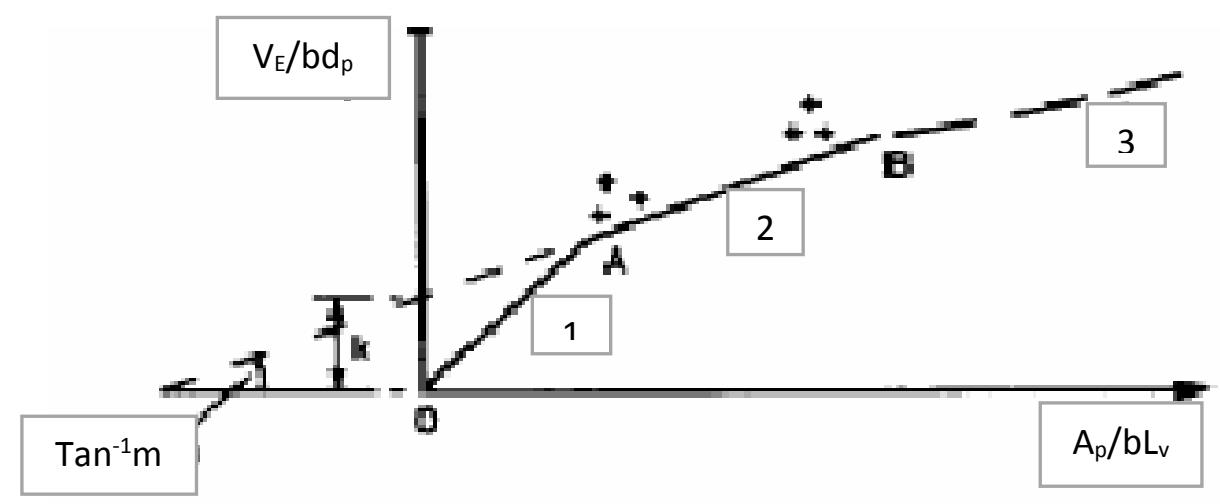

Fig. 2.15:- Plot showing m-k determination (Johnson \& Buckby, 1994)

The strength $f_{y p}$ is not varied during a series of tests and has no influence on longitudinal shear failure. It is therefore omitted from the axes on Fig.2.15 and equation 2.9 shows that flexural failure should plot as a straight line through the origin as shown by (1) in Fig. 2.15 .

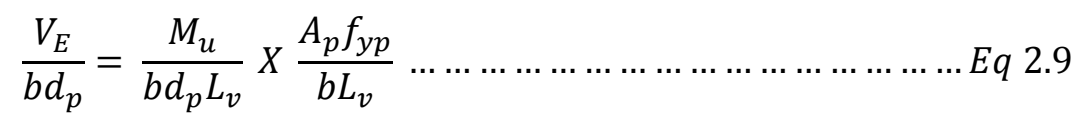

At low $L_{v} / d_{p}$, vertical shear failure occurs. The mean vertical shear stress on the concrete is roughly equal to $V_{E} / b d_{p}$. It is assumed the current codes that the ratio $A_{p} / b L_{v}$ has little influence on its ultimate value, so that vertical shear failure are represented by a horizontal line. However Patrick and Bridge (1993) have shown that this should be a rising curve indicated by (3) in Fig. 2.15. Longitudinal shear failure occur at intermediate values of $L_{v} / d_{p}$ and lie near the line. 


$$
\frac{V_{E}}{b d_{p}}=m\left[\frac{A_{p}}{b L_{v}}\right]+k
$$

As shown by $A B$ on Fig 2.15 where the $m$ and $k$ value are constant to be determined by testing. Design based on Equation 2.10 is one of the equation given by in Eurocode 4. Widely used " $m-k$ method "uses the following Equation:

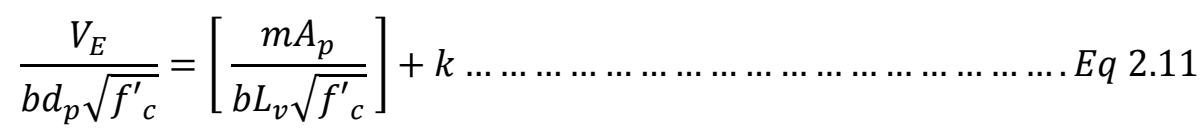

Where $f_{c}$ is the measured the cylinder or cube strength of the concrete. This equation can give unsatisfactory results for $m$ and $k$ when $f_{c}$ varies widely within a series of tests so $f_{c}$ has been omitted from equation 2.10. A comparison of the two methods has shown that this has little effect on $\mathrm{m}$; but the two equations give different values for $\mathrm{k}$ in different units.

A typical set of tests consists of a group of three with $L_{v} / d_{p}$ such that the results lie near point $A$ on Fig 2.15 and a second group with lower $L_{v} / d_{p}$ such that the results line near point $B$. Values of $m$ and $k$ are found for a line drawn below the lowest result in each group, at a distance that allows for the scatter of the test data.

\section{Defects of the m-k Method}

The method has proved to be an adequate design tool for profiles with short spans and rather brittle behavior, which have been widely used in North America. However, to exploit fully the ductile behavior of profile now available, with good mechanical interlock and longer spans, it is necessary to use a partialinteraction method, as explained later in the chapter. The defects of the $\mathrm{m}-\mathrm{k}$ method and of profiles with brittle behavior are as follows (Bode and born, 1993; Patrick and Bridge, 1990):

- The m-k method is not based on a mechanical model, so that conservative assumption has to be made in design when the dimensions, materials, of loading differ from those used in the tests.

- Many additional tests are needed before the range of application can be extended; for example, to include end anchorage or the use of longitudinal reinforcing bars.

- The method does not allow correctly for the beneficial effect of friction above support which exists in short spans. 
- The method of evaluation of test data is the same, whether the failure is brittle or ductile. The use in Eurocode 4 of a penalty factor of 0.8 for brittle behavior does not adequately represent the advantage of using sheeting with good mechanical interlock, because this increases with spans.

\subsubsection{Partial-Interaction Design ( $\tau_{v}$ Method)}

This method is an alternate method for $\mathrm{m}-\mathrm{k}$ method to calculate the longitudinal shear resistance of the composite slab. This method details listed Eurocode 4 EN 1994-1-1:2004 (E) Annex B and Annex E. This method takes more specific account for of the effects traction of near supports and can be more economical for short spans. This method should be used only for composite slabs with ductile behaviour.

The tensile force in the sheet $\mathrm{Np}$ can be calculated by:

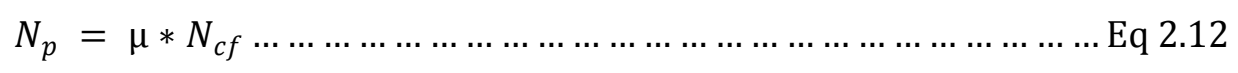

Which is equal to the compressive force of the concrete.

The moment $\mathrm{M}$ due to applied loads at a particular section can be calculated by:

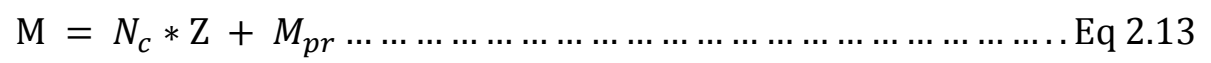

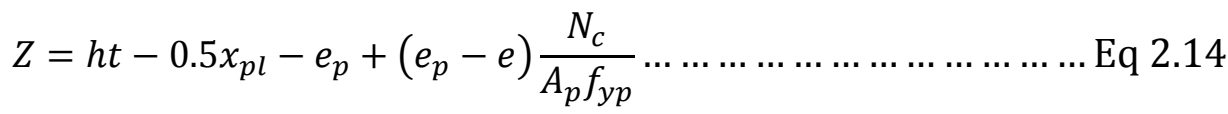

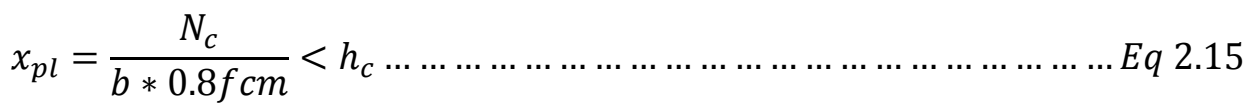

Where,

$\mathrm{e}=$ distance from the centroid of the effective area of sheeting to its underside.

$e_{p}=$ distance of the plastic neutral axis of the effective area of the sheeting to its underside.

$h_{t}=$ total depth of the slab

$\mathrm{h}_{\mathrm{c}}=$ height of concrete

$M_{p r}$ is the reduced plastic moment resistance of the sheet. It is calculated by; 


$$
M_{p r}=1.25 * M p a\left[1-\frac{N c f}{\frac{A p f_{y p}}{\gamma a p}}\right]<M_{p a}
$$

Where, $N_{c f}=h c * b *\left(0.85 \frac{f_{c k}}{\gamma_{c}}\right)$

$M_{p a}=$ plastic moment resistance of the effective area of the sheeting.

$\mathrm{N}_{\mathrm{C}}$ can be calculated by:

$$
N_{c}=\frac{-\left(h_{t}-e_{p}\right) \pm \sqrt{\left(h_{t}-e_{p}\right)-4 *\left(\frac{e_{p}-e}{A_{p} f_{y p}}\right)} *\left(M_{p r}-M\right)}{2 *\left(\frac{e_{p}-e}{A_{p} f_{y p}}-\frac{0.5}{b * 0.85 * f_{c m}}\right)}
$$

The degree of shear connection $\mu$ can be calculated by:

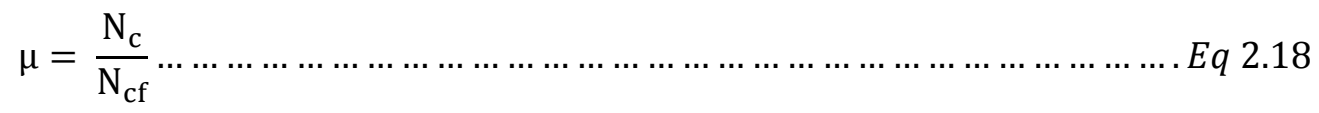

Where:

$\mu$ : the degree of sheer connection.

$\mathrm{N}_{\mathrm{c}}$ : is the design value of the compressive normal force in the concrete flange.

$\mathrm{N}_{\mathrm{cf}}$ : is the design value of compressive normal force in the concrete flange with full shear connection.

\section{For cases when:}

$\boldsymbol{\mu}=\mathbf{0}$ : Composite action between the steel sheet and the concrete does not exist and it is assumed that the bending resistance is provided only by the profiled steel sheet, equals Mpa, the design plastic resistance moment of the effective cross-section of the sheeting;

$\boldsymbol{\mu = 1}$ : Full shear connection exists such that the full tensile resistance of the sheet is developed;

$0<\boldsymbol{0}<1$ : The partial shear connection exists and this is typical for open trough profiled steel sheets.

The bending resistance of the composite slab is based on simple plastic theory using rectangular stress block for the concrete and profiled steel sheeting. It is also assumed that, before the maximum moment is reached, there is a complete redistribution of longitudinal shear stress at the interface between the sheet and the concrete such that a mean value for the longitudinal shear strength $\tau v$ can be calculated. 
The longitudinal shear stress calculated by

$$
\tau_{v}=\frac{\mu * N_{c}}{b *\left(L_{v}+L_{o}\right)}
$$

Where, $L_{o}$ is the length of overhang, $L_{v}$ is the shear span, $b$ is the width of the slab and $\mu$ is the degree of connection

\subsection{Criteria for the Testing of Composite Slabs according to CSSBI}

This design criteria for composite slabs made of a structural concrete placed permanently over composite steel deck is based on limit states as per Canadian Sheet Steel Building Institute (CSSBI). See CSSBI 12M Standard for Composite Steel Deck for information on the steel deck acting as a form during construction. See CSSBI S2-2008 Criteria for the Testing of Composite Slabs for information concerning testing of composite slabs. The full capacity of the composite slab is not achieved until the concrete has attained its specified compressive strength.

\subsubsection{Limit State of Strength}

The strength of a composite slab is usually limited by one of the following resistance limit states: (a) shearbond; (b) flexure of an under-reinforced section; (c) flexure of an over-reinforced section; and (d) punching shear with concentrated loads 2.8 Limit state of strength.

\subsubsection{Resistance Factors}

The following resistance factors shall apply:

$$
\begin{array}{ll}
\text { Shear-bond } & \phi_{\mathrm{v}}=0.70 \\
\text { Steel deck } & \phi_{\mathrm{s}}=0.90 \\
\text { Concrete } & \phi_{\mathrm{c}}=0.65
\end{array}
$$

\subsubsection{Shear-Bond Resistance}

The ultimate shear-bond resistance of a composite slab section shall be calculated using parameters determined from a testing program of full-scale slab specimens. The factored shear-bond resistance $\left(\mathrm{V}_{\mathrm{r}}\right)$ of a composite slab shall be determined by the following expression: 


$$
V_{r}=\phi_{v} V_{t}
$$

Where, $V_{r}=$ factored shear-bond resistance, $N / m$ of slab width

$V_{t}=$ tested shear-bond resistance, $N / m$ of slab width .

The basic equation used to determine the tested shear-bond resistance is one of the following:

$$
V_{t}=b d_{p}\left[k 5 / L_{v}+k 6\right]
$$

Where,

$b=$ unit width of compression face composite slab $(1000 \mathrm{~mm})$

$d_{p}=$ effective slab depth (distance from extreme concrete compression fiber to Centroidal axis of full cross-section of steel deck), $\mathrm{mm}$

$\mathrm{L}_{\mathrm{v}}=$ shear span, $\mathrm{mm}$; for uniform load, $\mathrm{Lv}$ is one quarter of the span

k5 and k6 are shear-bond coefficients obtained from a linear regression analysis of test data for one individual deck thickness.

Testing procedures used to determine the shear-bond coefficients are given in CSSBI S2-2008 Criteria for the Testing of Composite Slabs.

\subsubsection{Flexural Resistance}

Composite slabs subject to flexural failure are generally classified as under-reinforced or over-reinforced slabs depending on the compression depth ratio, $\left(c / d_{p}\right)$. Slabs with $\left(c / d_{p}\right)$ less than the balanced condition ratio $\left(c / d_{p}\right) b$ are considered under-reinforced, whereas slabs with $c / d_{p}$ greater than or equal to $\left(c / d_{p}\right) b$ are considered over-reinforcement.

The actual ratio:

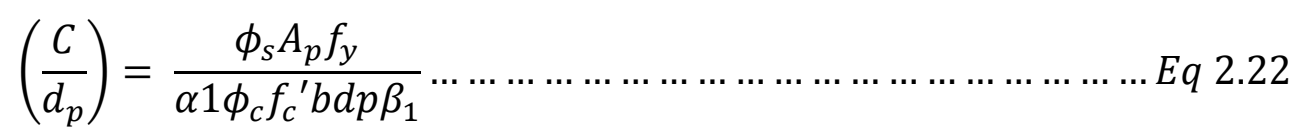

Whereas the ratio that denotes a balanced condition is:

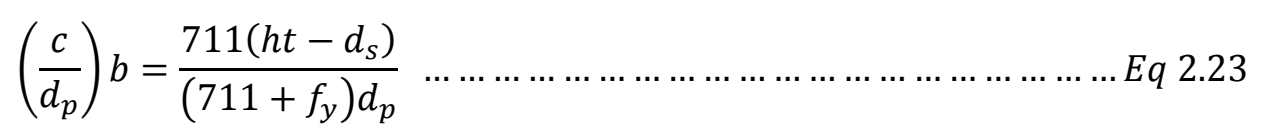

Where,

$A_{p}=$ area of steel deck, $\mathrm{mm}^{2} / \mathrm{m}$ of slab width 
$b=$ unit width of compression face composite slab $(1000 \mathrm{~mm})$

$\mathrm{c}=$ distance from extreme compression fiber to composite neutral axis, $\mathrm{mm}$

$d_{p}=$ distance from extreme compression fiber to centroid of steel deck, $\mathrm{mm}$

$d_{s}=$ overall depth of steel deck profile, $\mathrm{mm}$

$\mathrm{f}_{\mathrm{c}}^{\prime}=$ specified compressive strength of concrete, $\mathrm{MPa}$

$f_{y}=$ specified yield strength of steel deck, MPa

$h_{t}=$ nominal out-to-out depth of slab, $\mathrm{mm}$

$\alpha 1=0.85-0.0015 f c^{\prime} \geq 0.67$, and $\beta 1=0.97-0.0025 f c^{\prime} \geq 0.67$

\subsubsection{Under-Reinforced Slabs $\left(c / d_{p}\right)<\left(c / d_{p}\right) b$}

The factored moment resistance, in positive bending, of an under-reinforced composite slab shall be taken as:

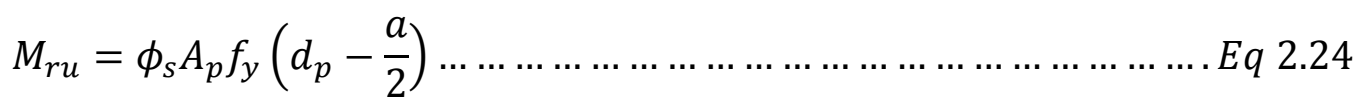

Where,

$$
a=\frac{\phi_{s} A_{p} f_{y}}{b \alpha_{1} \phi_{c} f_{c}}
$$

Equation 2.24 is valid only for composite slabs capable of developing the yield stress over the entire deck section. In some instances the strain compatibility of the slab cross-section or the ductility of the steel does not permit yielding over the entire deck section. Equation 2.24 does not account for steel reinforcement in addition to the steel deck and does not account for the case where a portion of the deck section lies on the compression side of the composite slab neutral axis. For those cases where equation 2.24 does not apply, the factored moment resistance shall be based on a detailed strain compatibility analysis. 


\subsubsection{Over-Reinforced Slabs $\left(c / d_{p}\right) \geq\left(c / d_{p}\right) b$}

The factored moment resistance, in positive bending, of an over-reinforced composite slab shall be determined by:

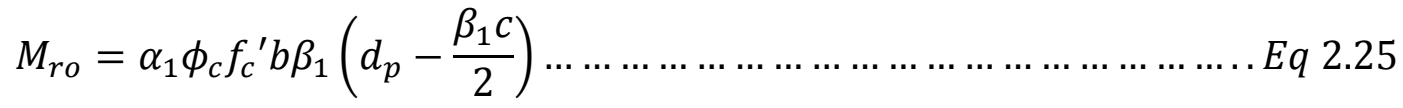

Where, $\mathrm{M}_{\mathrm{ro}}$ : factored over-reinforcement moment resistance.

$$
\begin{gathered}
c=d_{p}\left[\sqrt{\rho m+\left(\frac{\rho m}{2}\right)}-\frac{\rho m}{2}\right] \\
\rho m=\frac{A p}{b d p} ; \\
m=\frac{\phi_{s} E_{s} \varepsilon_{c u}}{\alpha_{1} \phi_{c} f_{c^{\prime}} \beta_{1}} \\
E_{S}=203000 \mathrm{Mpa} \quad \varepsilon_{c u}=0.0035
\end{gathered}
$$

Equation 2.25 is valid only for composite slabs where no part of the steel deck has yielded. If yielding of the steel deck does occur, $\mathrm{M}_{\text {ro }}$ may be determined by a detailed strain compatibility analysis and/or test.

\subsubsection{Continuous Slabs}

Where composite slabs are designed for continuity over supports, the factored moment resistance in negative bending shall be determined as in conventional reinforced concrete design in accordance with CSA-A23.3, Design of Concrete Structure. The contribution of the portion of the composite steel deck in compression may be neglected.

\subsubsection{Two-Way Action}

In slabs requiring two-way action for load distribution, the flexural resistance in the direction transverse to the deck corrugations needs to be calculated. The following two cases apply for the determination of this resistance:

- Where no supplementary transvers reinforcement is provided, the flexural strength shall be taken as that of the plain concrete section above the corrugations. Any contribution from the steel deck is neglected.

- Where supplementary transverse reinforcement is provided in the tension zone, equation (6) shall be used if the slab is under-reinforced. The area of steel, $A_{p}$, shall consist entirely of the 
supplementary reinforcement, and only the concrete section above the deck corrugations shall be considered effective, unless tests indicate conclusively that other assumptions are valid.

The effective width of the slab in the transverse direction shall be determined from tests or detailed analysis.

\subsubsection{Deflection Criteria}

\subsubsection{Flexural Properties for Deflection Calculations}

Composite flexural section properties needed to determine vertical deflections of composite slabs shall be computed in accordance with conventional elastic theory applied to reinforced concrete, transforming steel areas to equivalent areas of concrete.

1. Plane sections remain plane after bending

2. Stresses are proportional to strain in both concrete and steel at specified loads

3. The entire steel cross section is utilized except as reduced by holes

4. The moment of inertia used in deflection calculations, $I_{d}$, shall be taken as the average of the cracked, $I_{c}$, and un-cracked sections, $I_{u}$, using the design depth of the slab.

\subsubsection{Deflection Limitations}

Consideration needs to be given to both immediate and long-time loading. Computed maximum deflections shall be based on the assumptions of 2.8.6.1. Maximum permissible computed deflections are listed in Table 2.2. Additional deflection caused by creep shall be calculated by multiplying the immediate deflection due to the sustained load by the following factor:

2.0: for load duration of 3 months

2.2: for load duration of 6 months

2.4: for load duration of 1 year

3.0: for load duration of 5 years or more. 
Table 2.2:- Maximum permissible deflection (Canadian Sheet Steel Building Institute, 2008)

\begin{tabular}{|c|c|c|}
\hline Type of member & Deflection to be Considered & Deflection limitation \\
\hline $\begin{array}{l}\text { Flat roofs not supporting or } \\
\text { attached to nonstructural } \\
\text { elements likely to be damaged } \\
\text { by large deflections }\end{array}$ & $\begin{array}{l}\text { Immediate deflection due to } \\
\text { specified live load, L, or snow } \\
\text { load, S }\end{array}$ & Span/180 \\
\hline $\begin{array}{l}\text { Floors not supporting or } \\
\text { attached to nonstructural } \\
\text { elements likely to be damaged } \\
\text { by large deflections }\end{array}$ & $\begin{array}{l}\text { Immediate deflection due to } \\
\text { specified live load, } L\end{array}$ & Span/360 \\
\hline $\begin{array}{l}\text { Roof or floor construction } \\
\text { supporting or attached to } \\
\text { nonstructural elements likely to } \\
\text { be damaged by large deflections }\end{array}$ & \multirow{2}{*}{$\begin{array}{l}\text { That part of the total deflection } \\
\text { occurring after attachment of } \\
\text { nonstructural elements (sum of } \\
\text { the long-time deflection due to } \\
\text { all sustained loads and the } \\
\text { immediate deflection due to any } \\
\text { additional live load) }\end{array}$} & Span/480 \\
\hline $\begin{array}{l}\text { Roof or floor construction } \\
\text { supporting or attached to } \\
\text { nonstructural elements } \\
\text { not likely to be damaged by } \\
\text { large deflections }\end{array}$ & & Span/240 \\
\hline
\end{tabular}

Table 2.2 is a duplication of table 9-3of CSA-A23.3-04 Except for minor changes. The following applies for table2.2.

- Limit not intended to safeguard against ponding. Ponding should be checked by suitable calculations of deflection, including added deflections due to ponded water, and considering longtime effects of all sustained loads, and reliability of provisions for drainage

- Limit may be exceeded if adequate measures are taken to prevent damage to supported or attached element

- Long-time deflection are determined in accordance with Clause 9.8.2.5. Or 9.8.44 in CSA-A23.304 and may be reduced by the amount of deflection calculated to occur before the attachment of nonstructural element. This amount shall be determined on the basis of accepted engineering data relating to time-deflection characteristics of composite slab systems similar to those being considered.

\subsubsection{NBC Concentrated Load Criteria}

The National Building Code of Canada requires that floors be designed for a specified concentrated live load acting on an area of 750 by $750 \mathrm{~mm}$. With a composite slab system, there will be some lateral distribution of a concentrated load due to the steel deck acting as slab reinforcement. The exact extent 
to which a concentrated load is distributed depends on a number of factors; however, it can be assumed that the load is distributed down to the center of gravity of the steel deck. This will give a resulting load distribution area of $(750+2 \mathrm{~d})$ by $(750+2 \mathrm{~d}) \mathrm{mm}$. Figure 2.16 illustrates this loading condition.

\section{NBC Concentrated Load Condition}

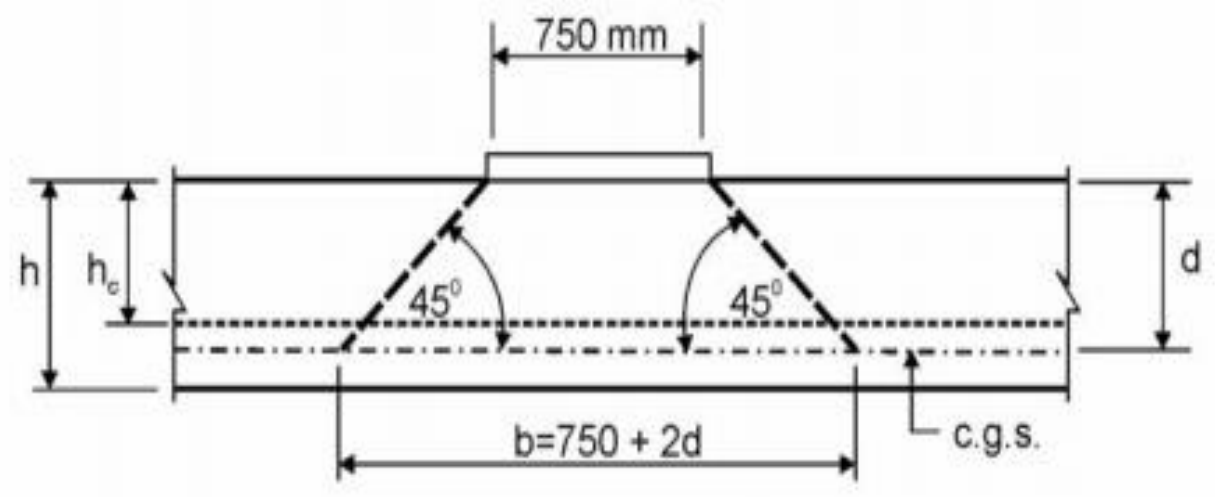

Fig. 2.16:- loading Condition (Canadian Sheet Steel Building Institute, 2008)

\subsubsection{Shrinkage and Crack Control Reinforcement}

Composite slabs shall have minimum shrinkage and temperature reinforcement in accordance with Table 2.3 unless a greater amount is required by the specified fire resistance rating. Where designed for continuity over structural supports, composite slabs shall have negative moment reinforcement as required in conventional reinforced concrete. When the composite slab is not designed for continuity over structural supports, the effects of cracking of the concrete shall be considered and adequate crack control measures shall be taken where necessary.

Table 2.3:- Minimum shrinkage and temperature reinforcement (Canadian Sheet Steel Building Institute, 2008)

\begin{tabular}{|c|c|}
\hline & $\begin{array}{l}\text { Minimum Area of Reinforcement Required } \\
\left(\mathrm{mm}^{2} / \mathrm{m} \text { of slab width }\right)\end{array}$ \\
\hline $\mathrm{h}_{\mathrm{c}} \leq 80$ & 60 \\
\hline $80 \geq \mathrm{h}_{\mathrm{c}} \leq 150$ & $\left(3 \mathrm{~h}_{\mathrm{c}}-180\right)$ \\
\hline $150 \leq \mathrm{h}_{\mathrm{c}}$ & $1.8 \mathrm{~h}_{\mathrm{c}}$ \\
\hline
\end{tabular}


The following notes are applied:

1. Shrinkage and temperature reinforcement alone is not intended to resist negative bending moments. Additional reinforcement must be provided as required by a structural design if negative bending is to be resisted.

2. The recommended minimum temperature and shrinkage reinforcement, usually in the form of welded wire mesh, if properly placed and if good concreting practices such as low water/cement ratio, low slump and proper curing are followed, will often be sufficient to cause the shrinkage and temperature stresses to be relieved in small local cracks rather than accumulating over greater distances. It is recommended that the mesh be placed approximately $25 \mathrm{~mm}$ below the top surface of the concrete, particularly in areas of negative moments, such as over supports where bending stresses in the top portion of the concrete add to the shrinkage.

3. For applications where a higher degree of crack control is required, the designer should refer to recognized standards of concrete practice and design such as CSA-A23.3.

\subsection{Review Conclusions}

Although structural performance of composite slabs with traditional concrete was the subject matter of numerous research studies, limited research has been conducted to envisage the behaviour of composite slabs with different profile steel sheeting and newly emerging high performance concrete (HPCs). Composite slabs with better structural performance can be obtained by using newly developed high performance concretes (HPCs) especially emerging highly ductile Engineered Cementitious Composite (ECC). There is an urgent need to conduct research on the structural performance of ECC based composite slabs compared to their traditional concrete counterparts and develop design specifications. The proposed research is a timely initiative to study the structural performance of the proposed ECC based new composite flooring system compared to conventional concrete. 


\section{CHAPTER 3: EXPERIMENTAL AND THEORETICAL INVESTIGATION}

\subsection{Introduction}

An experimental program consisting of full-scale composite slabs as per Eruocode 4, ASCE specification (1992) and BS5950: Part 4 (1994) was planned to evaluate the feasibility of ECC based composite slabs compared to their normal concrete counterparts based on key structural performance. Shear bond parameters ( $m$ and $k$ values) for both ECC and commercial SCC composite slabs are also evaluated from experimental results as per Code based specifications/procedures. A description of the specimen details, test arrangement and experimental and theoretical results are presented.

\subsection{Experimental Program}

A total of twelve full-scale composite slab specimens were cast and tested. The specimens were divided into two groups according to the two types of CANAM profiled steel sheets (P3623- Type B and P2432Type A) used in this project. The test parameters were: type of concrete (SCC and ECC), shear spans (three different shear spans) and types of steel sheets (two different geometry). The specimen identifications are shown in Table 3.1. Two types of concrete namely: an ECC (developed and produced at Ryerson) and a commercial self-consolidating concrete (supplied by King Packaged Materials). The different parameters used in the specimens are shown in Fig. 3.1.

The geometric dimensions including reinforcement details are also presented in Table 1 as well as shown in Fig. 3.2. All specimens were reinforced with $6 \mathrm{~mm}$ diameter bar in both directions (Fig. 4). The amount of reinforcement was $0.02 \mathrm{Ag}$. The clear cover of the reinforcement was $25 \mathrm{~mm}$. The total length of the slab was $1800 \mathrm{~mm}$ providing an effective span of $1500 \mathrm{~mm}$ between the supports. 
Table 3.1:- Details of composite slab specimens

\begin{tabular}{|c|c|c|c|c|c|c|c|c|c|c|}
\hline 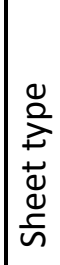 & 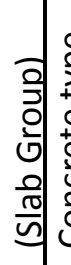 & 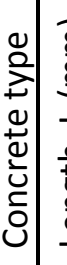 & 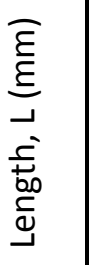 & 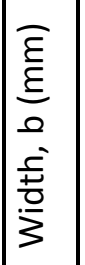 & 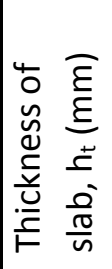 & 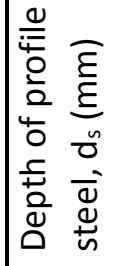 & 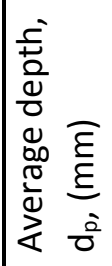 & 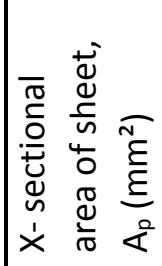 & 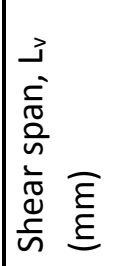 & 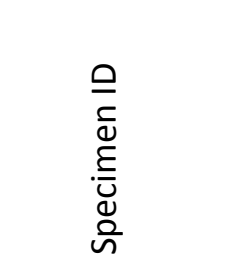 \\
\hline \multirow{6}{*}{ 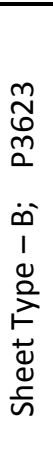 } & \multirow{3}{*}{\multicolumn{2}{|c|}{ 岕 }} & \multirow{3}{*}{1800} & \multirow{3}{*}{960} & \multirow{3}{*}{100} & \multirow{3}{*}{51} & \multirow{3}{*}{75} & \multirow{3}{*}{1016} & 300 & P3623-300-ECC \\
\hline & & & & & & & & & 450 & P3623-450-ECC \\
\hline & & & & & & & & & 600 & P3623-600-ECC \\
\hline & \multirow{3}{*}{\multicolumn{2}{|c|}{ U্ّ }} & \multirow{3}{*}{1800} & \multirow{3}{*}{960} & \multirow{3}{*}{100} & \multirow{3}{*}{51} & \multirow{3}{*}{75} & \multirow{3}{*}{1016} & 300 & P3623-300-SCC \\
\hline & & & & & & & & & 450 & P3623-450-SCC \\
\hline & & & & & & & & & 600 & P3623-600-SCC \\
\hline \multirow{6}{*}{ 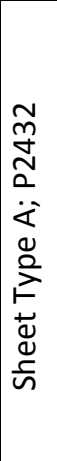 } & \multirow{3}{*}{\multicolumn{2}{|c|}{ 岕 }} & \multirow{3}{*}{1800} & \multirow{3}{*}{620} & \multirow{3}{*}{125} & \multirow{3}{*}{76} & \multirow{3}{*}{87} & \multirow{3}{*}{1131} & 300 & P2432-300-ECC \\
\hline & & & & & & & & & 450 & P2432-450-ECC \\
\hline & & & & & & & & & 600 & P2432-600-ECC \\
\hline & \multirow{3}{*}{ 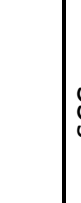 } & \multirow{3}{*}{$\mathrm{U}^{80}$} & \multirow{3}{*}{800} & \multirow{3}{*}{620} & \multirow{3}{*}{125} & \multirow{3}{*}{76} & \multirow{3}{*}{87} & \multirow{3}{*}{1131} & 300 & P2432-300-ECC \\
\hline & & & & & & & & & 450 & P2432-450-ECC \\
\hline & & & & & & & & & 600 & P2432-600-ECC \\
\hline
\end{tabular}

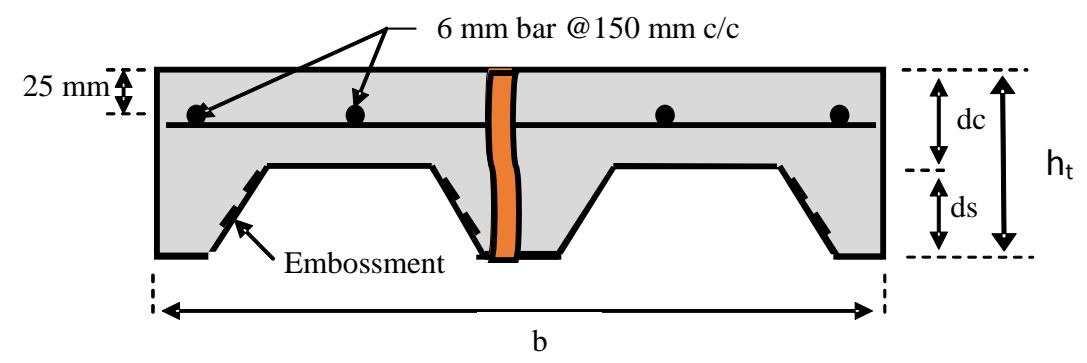

Fig. 3.1:- Geometric and dimensional parameters of composite slabs 


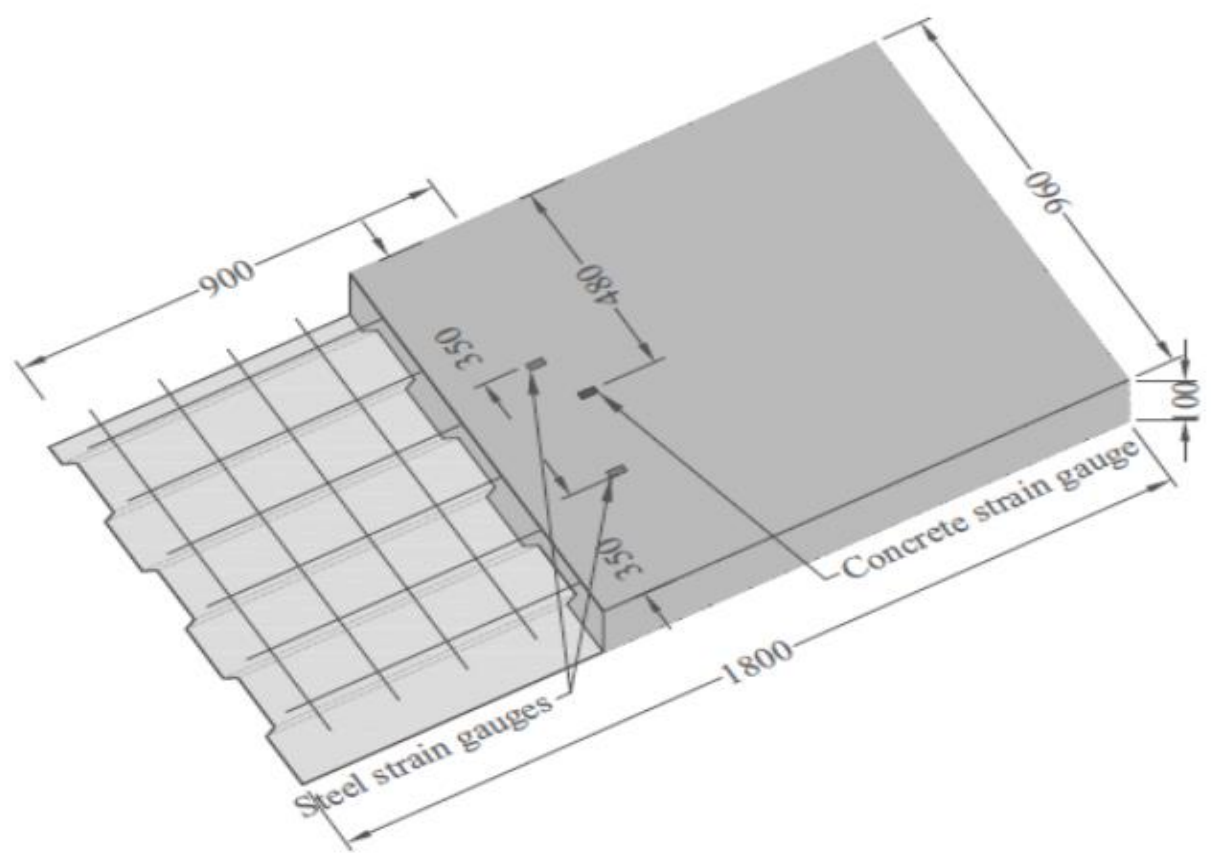

Fig. 3.2(a):- P3623 composite slab showing reinforcements and instrumentation

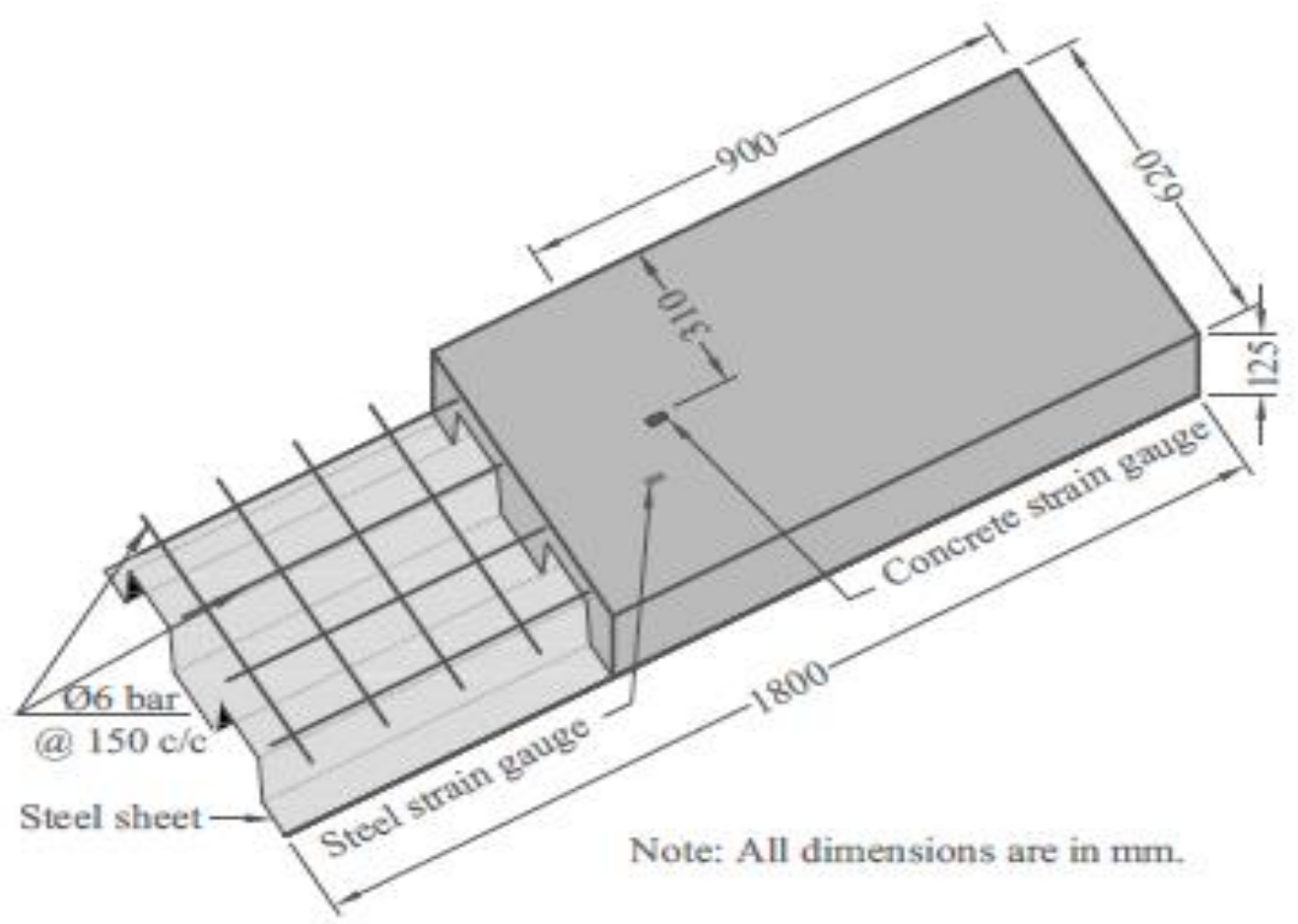

Fig. 3.2(b):- P-2423 composite slab showing reinforcements and instrumentation 


\subsubsection{Materials and Properties}

Two concrete mixtures have been used for the composite slabs - a Ryerson produced green Engineered Cementitious Composite (ECC) and a commercial Self-Consolidating Concrete (SCC) produced by King Packaged Materials. ECC was made of PVA fibers ( $8 \mathrm{~mm}$ length and diameter of $39 \mu \mathrm{m}$ diameter), local mortar sand (instead of silica sand), Portland cement, fly ash (as 55\% replacement of cement), admixtures and water to binder ratio of 0.27 . KING SCC is a pre-blended, pre-packaged, high performance, flowable concrete material containing Portland cement, silica fume, $10 \mathrm{~mm}$ stone and other carefully selected admixtures (King MS-S10 SCC, 2013). KING SCC is designed with natural normal-density non-reactive fine and coarse aggregates to eliminate potential alkali-aggregate reactivity (AAR). The strength properties of ECC and commercial SCC determined from control specimens at the age of testing (at 28 days) of composite slabs as per ASTM Standards (ASTM C39 2012; ASTM C78 / C78M 2010) are presented in Table 3.2.

Table 3.2:- Concrete strength properties

\begin{tabular}{lcc}
\hline Slabs & $\begin{array}{c}\text { Cylinder Concrete } \\
\text { strength }\left(\mathrm{f}^{\prime}{ }^{\prime}\right)(\mathrm{MPa})\end{array}$ & $\begin{array}{c}\text { Flexural strength } \\
(\mathrm{Mpa})\end{array}$ \\
\hline P3623-ECC & 64 & 7.1 \\
\hline P3623-SCC & 51 & 4.7 \\
\hline P2432-ECC & 66 & 7.0 \\
\hline P2432-SCC & 56 & 4.8 \\
\hline
\end{tabular}

The geometry and dimensional details of two types of embossed CANAM profiled steel sheets/decks (P3623 and P-2432) used to manufacture full-scale composite deck slabs are presented in Fig. 3.3. The sheet steels normally used to form CANAM steel deck profiles correspond to ASTM A 653M SS Grade 230. They have a yield strength of $230 \mathrm{MPa}$ and a tensile strength of $310 \mathrm{MPa}$ (CANAM 2014). 


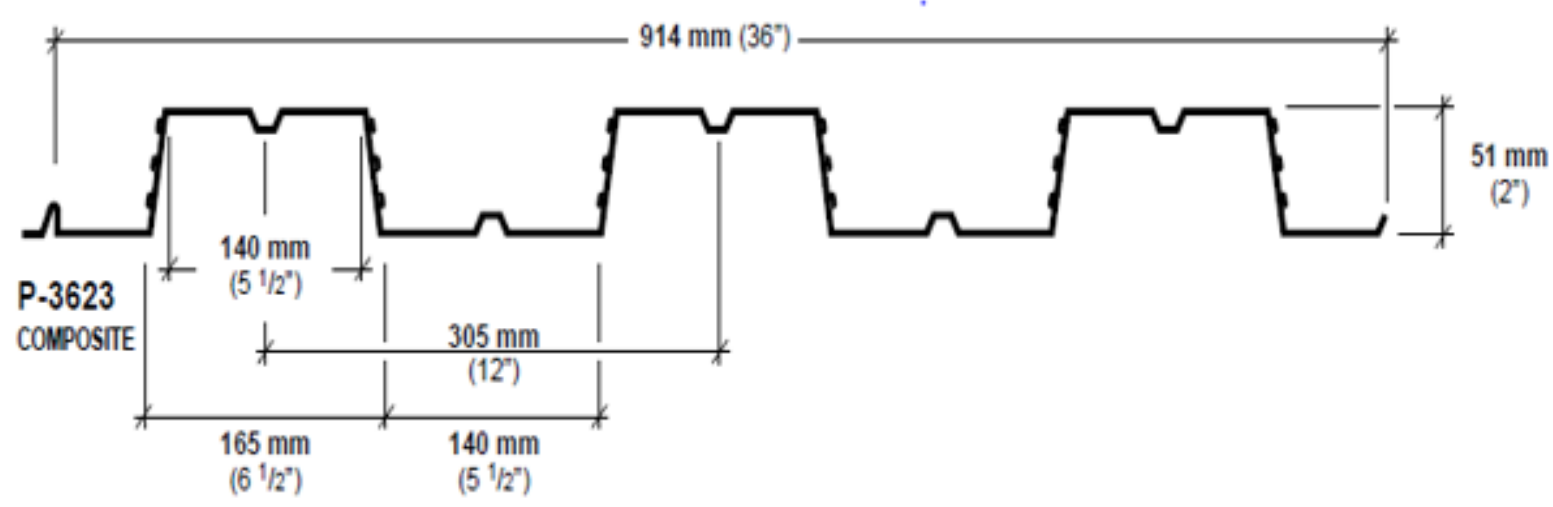

(a)

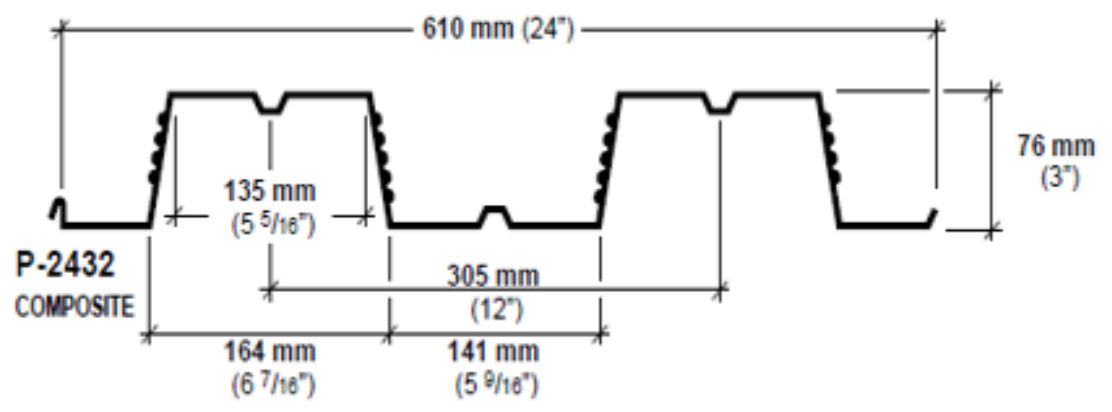

(b)

Fig. 3.3:- Profile sheets (a) P-3623 and (b) P-2432 (0.76 mm thick steel sheet)

\subsubsection{Casting and Curing of Composite Slabs}

During casting, profile steel decks were supported at the ends and the middle. The sheets were cleaned thoroughly before concreting. The specimens were cast using 400 liter capacity concrete mixer in the Structures laboratory of Ryerson University. Fig. 3.4 shows the concrete in the mixer machine. Two batches of concrete were used to cast three specimens in one day. Control specimens in the form cylinders and beams were cast from each batch to determine concrete compressive and flexural strengths. After casting, the slabs were covered with jute sheet and water cured for 2 to 3 days. Then the slabs were taken out of the formwork and stored at room temperatures until testing. Both SCC and ECC were flowable and cast without consolidation or manual compaction. Fig. 3.5 shows composite slab formwork before pouring concrete. Fig. 3.6 shows composite slab specimen after pouring concrete and during curing in the hardened state. 


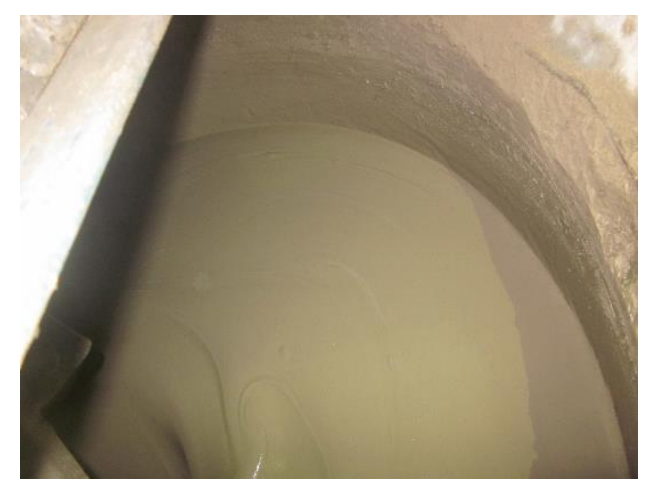

Fig. 3.4:- ECC production in the mixer machine

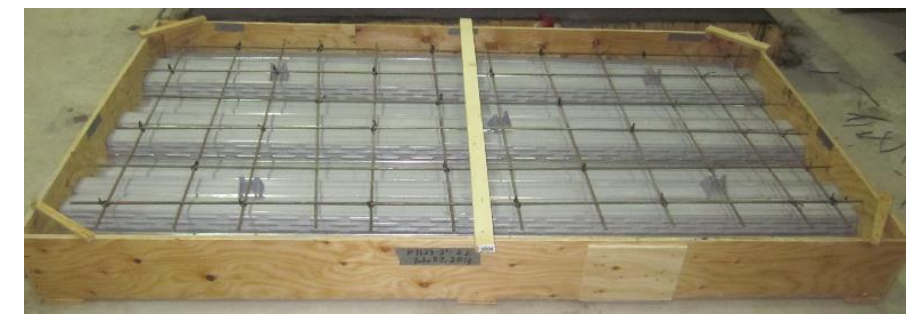

(a)

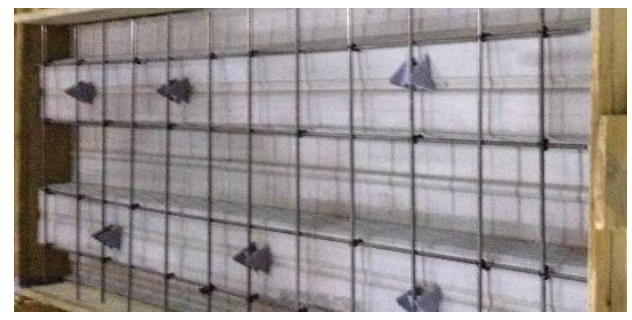

(b)

Fig. 3.5:- Composite slab forms and sheets in the formwork with reinforcement (a) P-3623, and (b) P-2432

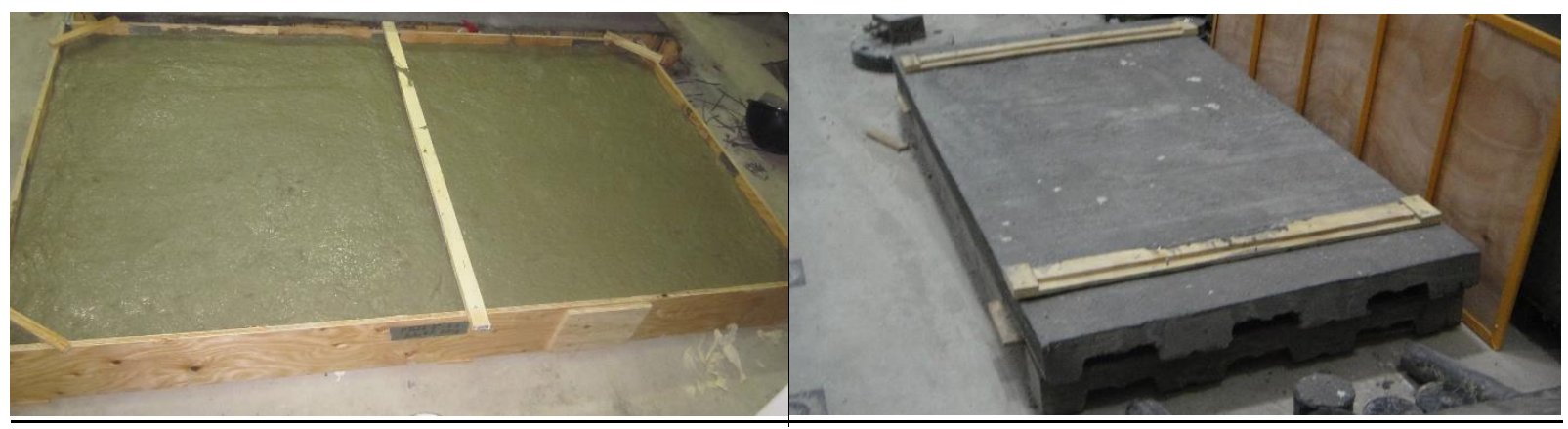

Composite slab after pouring concrete

Hardened composite slab waiting for testing

Fig. 3.6:- Composite sabs after pouring and in the hardened state 


\subsection{Test Set-up, Instrumentation and Testing Procedure}

Fig. 3.7 shows the test setup used in this study. The slabs were simply supported and tested under four point monotonic loading. Statically determinate system was ensured by adopting hinge and roller supports at the two ends. Each of the slabs was instrumented with two strain gauges and three LVDTs (Linear Voltage Displacement Transducers). One of the stain gauges was used to measure the steel strain (on the bottom surface) and the other strain gauge was used to measure concrete strain on top surface of the slab. Since P3623 sheet has two valleys at the bottom of the slab (as shown in Figure 3.7a-b), two steel strain gauges were installed in the steel sheet for these slabs. All the strain gauges were installed at the midspan of the slab. Figure 3.2 shows the arrangement of strain gauges in composite slabs. Figure 3.7(a) also shows the locations of strain gauges and LVDTs. One of the LVDTs was used to measure the midspan deflection and the other two (on the left and right) were used to measure the slip (between steel sheet and concrete) at the two ends of the slab. Strain gauge, LVDT and load channels were connected to a data acquisition system which connects to a personnel computer to store the data during testing. The test was done using a displacement control jack and the load was used at a rate of $2 \mathrm{~mm}$ movement per minute until the failure of the specimen. During testing failure modes, crack development/propagation and steel-concrete separation/slip were observed visually.

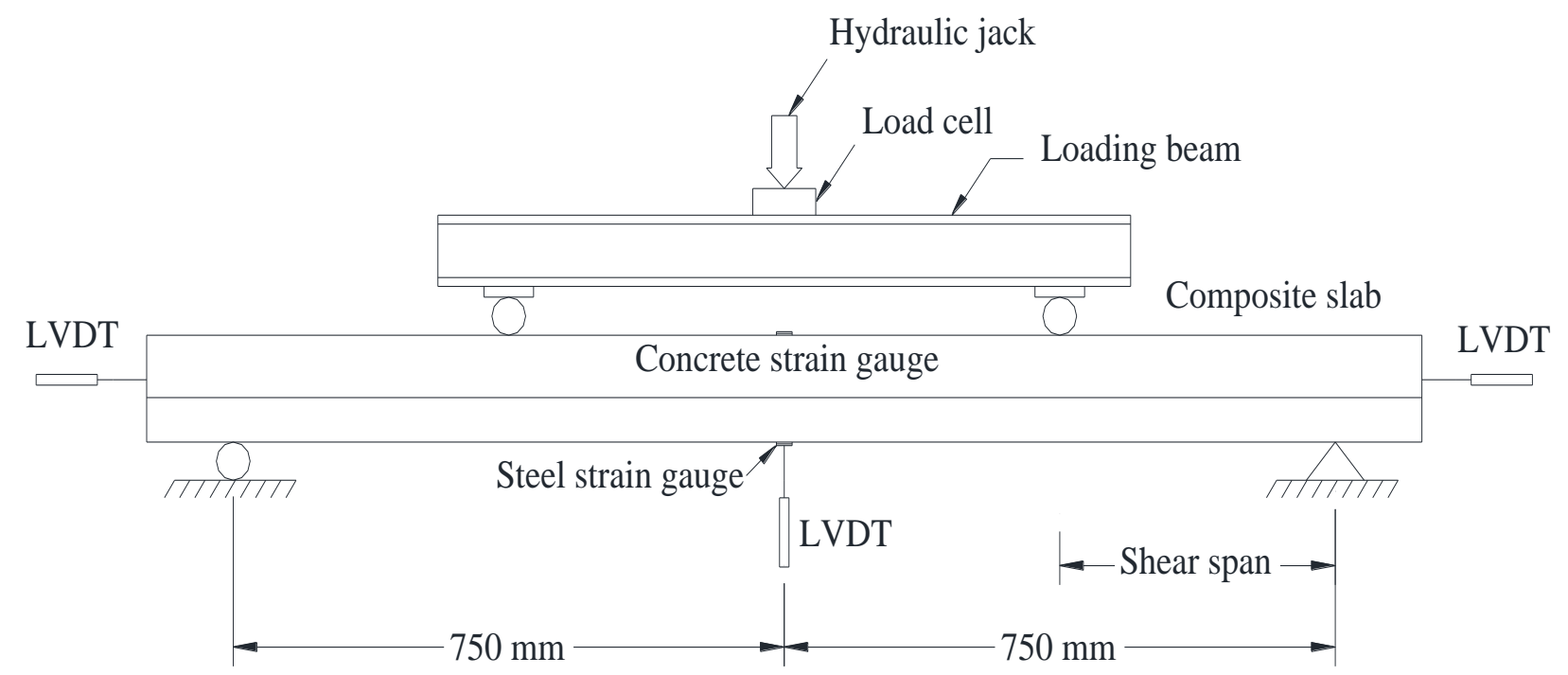

Fig. 3.7 (a):- Schematic diagram of test set-up 


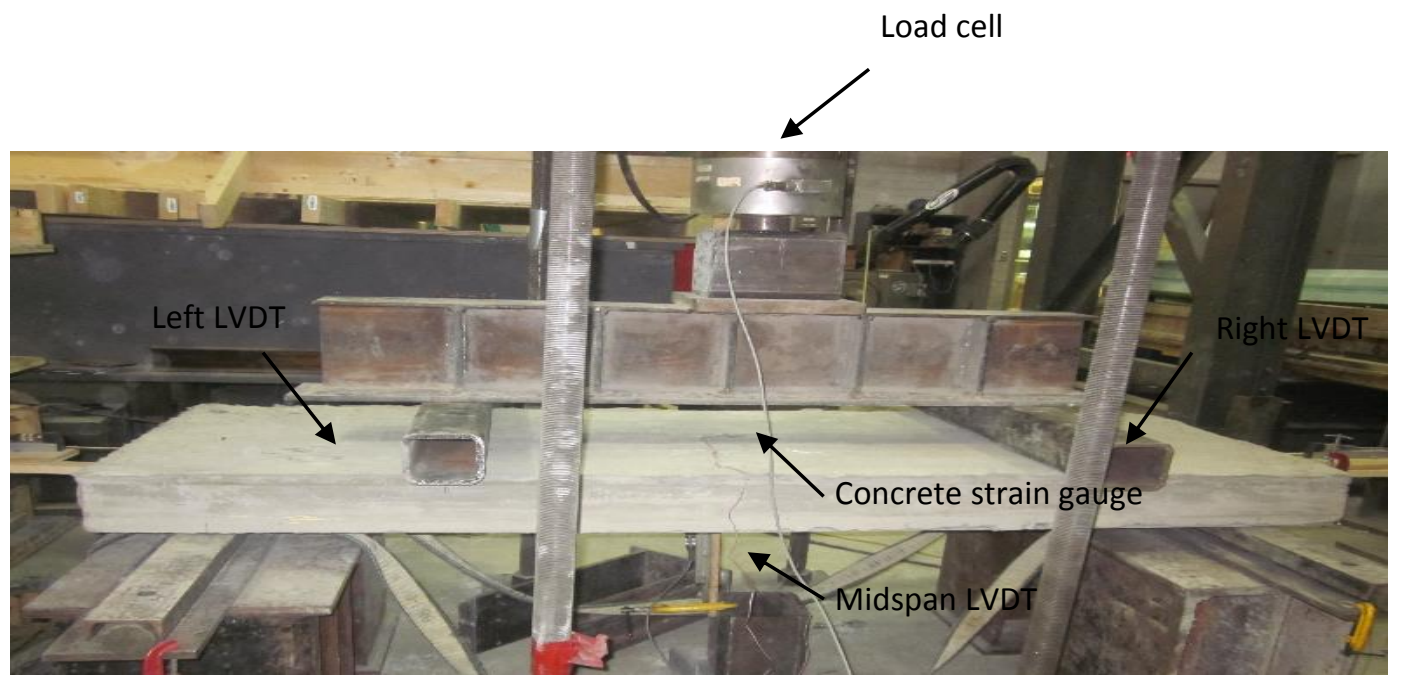

Fig. 3.7 (b):- Actual set-up with specimen and instrumentation

\subsection{Results and Discussion}

\subsubsection{General Observations}

With the continued increase in load during testing, the vertical deflection of slab increased and steelconcrete interface separation began to appear. Subsequently, concrete cracks started to form at the loading point from the bottom and continued to extend upward (Figure 3.8). Generally at the initial stage, the profiled sheet is subjected to tensile stresses and act compositely with concrete due to interface shear bond. With the increase in load, separation between the concrete and the profiled sheet was observed due to inadequate shear bond. At the final stage, the slabs failed due to excessive deflection accompanied by end slip (between steel and concrete) and concrete cracking. At failure, signs of flexural cracks were more obvious along with vertical shear cracks below the loading points. It was evident from the tests that all of the specimens failed in shear. 


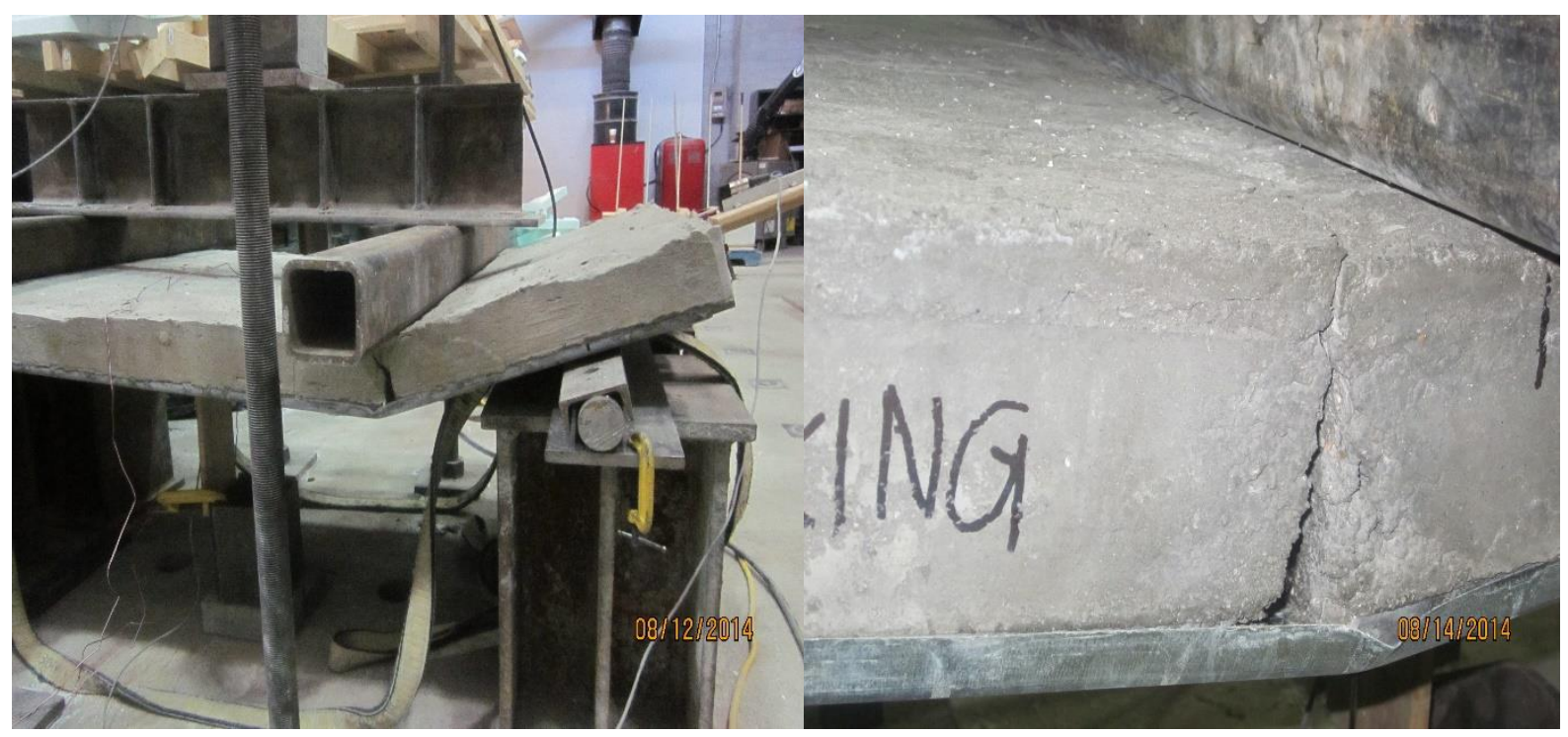

Fig. 3.8:- Cracking and steel-concrete separation of composite slab

\subsubsection{Load Deflection Behavior}

Load-central deflection responses of all composite slab specimens are presented in Fig. 3.9. Generally load increased with the increase of deflection and all the slabs showed similar trends of variation. In all slabs, loss of linear load-deflection behaviour or change in slope was identified at the onset of the development crack or longitudinal interface slip. The change in slope in the load-deflection response is an indicative of formation cracks, interface separation or slip initiation. According to Eurocode 4 (2004), the failure load can be taken as the load causing a mid-span deflection of span/50, unless failure has already taken place.

Generally load-deflection behavior can be characterized into three stages: pre-cracking, post-cracking and post-peak. All composite slabs showed similar trend in pre-cracking linear stage (Fig. 3.9). After cracking, the loss of linear behaviour was observed and continued up to the peak load. After the peak load, the degradation of the load carrying capacity of the slabs was observed and the deflection of the slabs increased. The post peak behaviour of ECC composite slabs is different than that observed in the SCC slabs. 


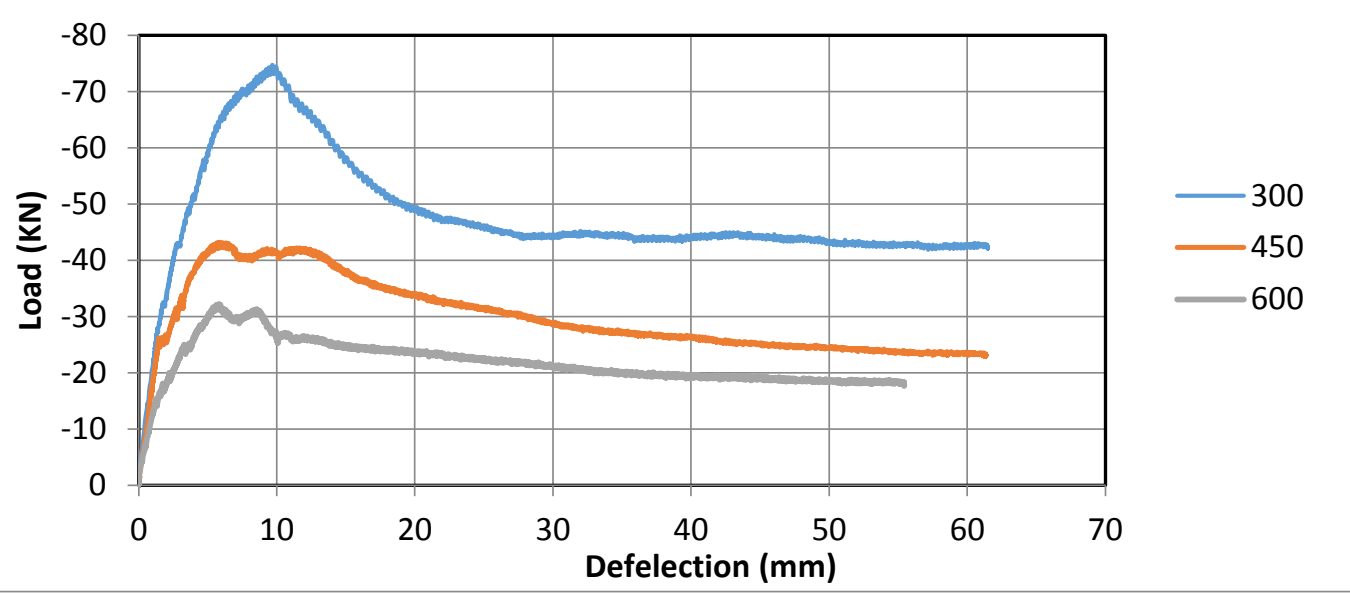

Fig. 3.9(a):- Load-deflection behaviour with different shear span (ECC - sheet A P-2432)

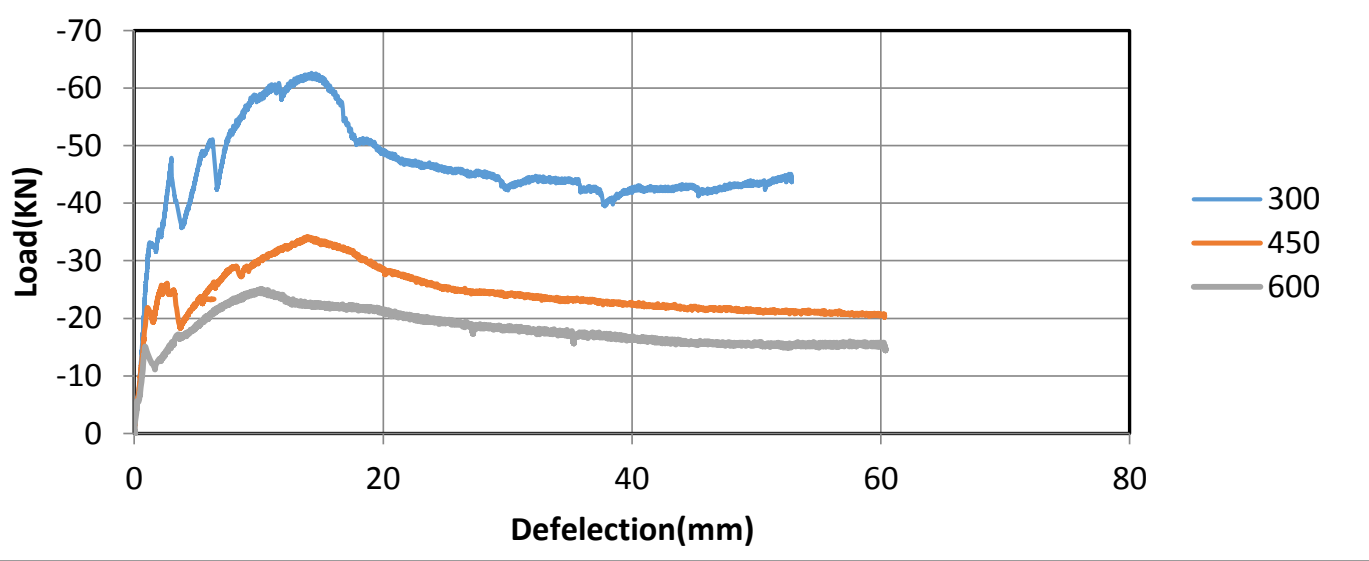

Fig. 3.9(b):- Load-deflection behaviour with different shear span (SCC - sheet A P-2432)

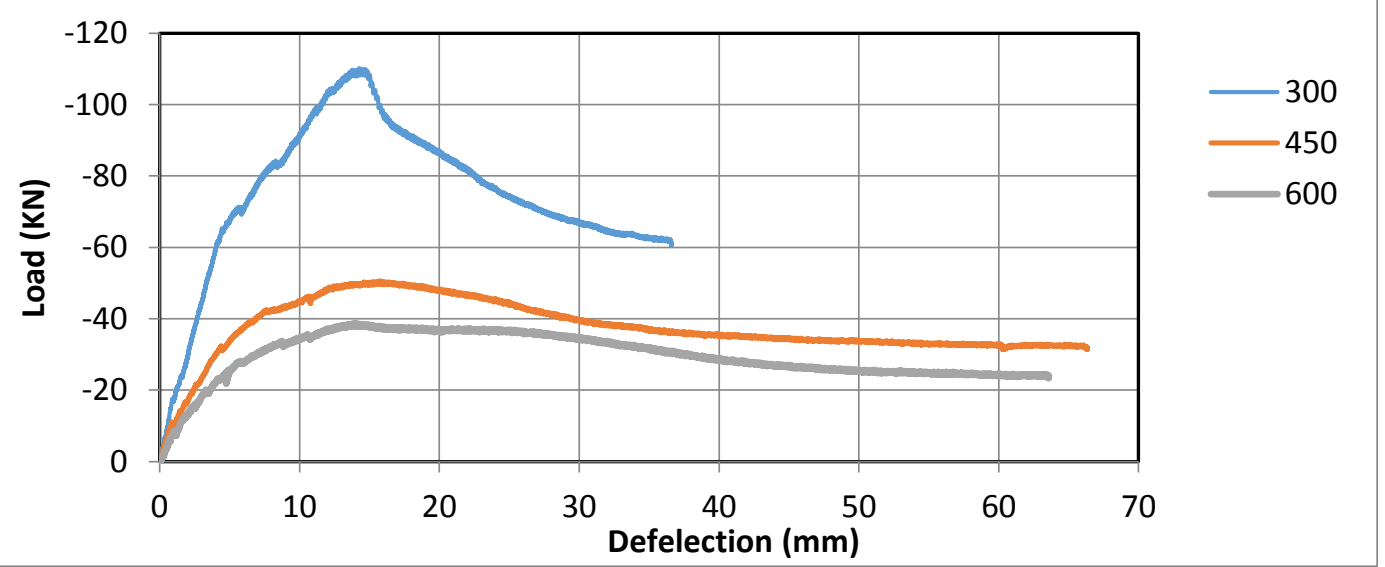

Fig. 3.9(c):- Load-deflection behaviour with different shear span (ECC - sheet B-P-3623) 


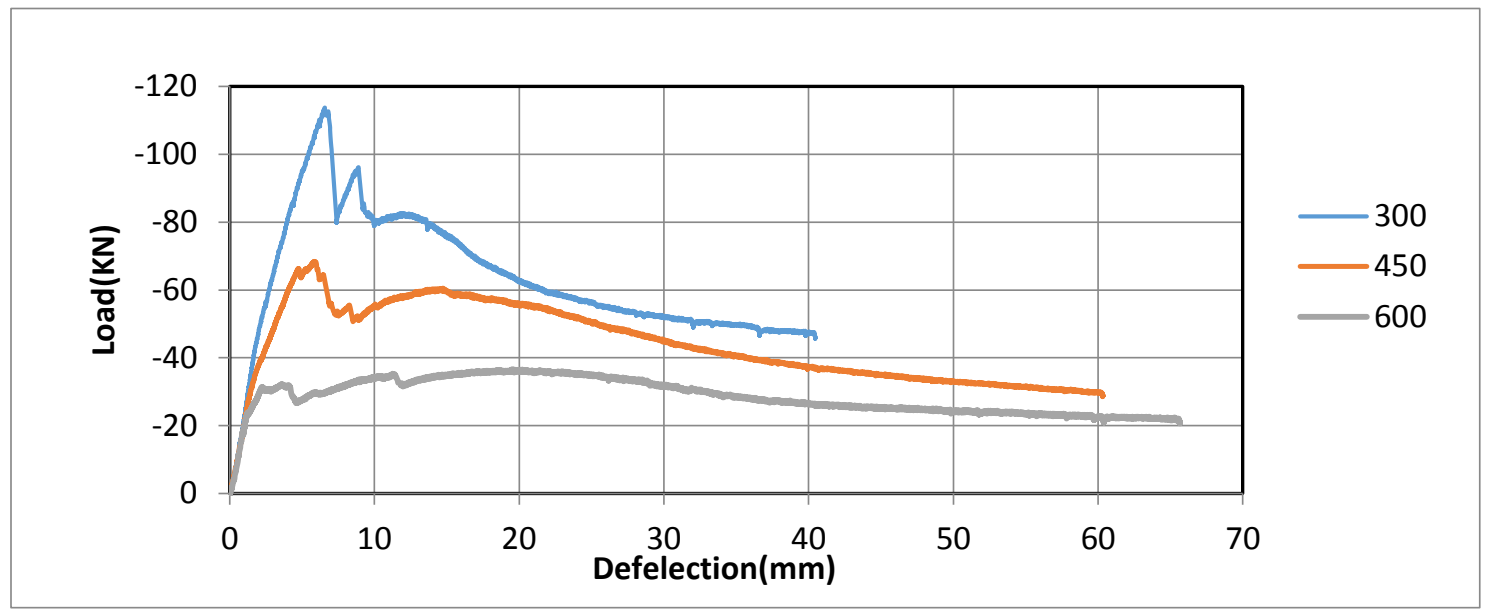

Fig. 3.9(d):- Load-deflection behaviour with different shear span (SCC - sheet B-P-3623)

In ECC slabs, the gradual drop in post-peak load with deflection was observed compared to sudden drop and rise in load in SCC slabs. Generally, the post peak behaviour of SCC slabs was characterized by several peaks (Fig. 3.9). In most of the SCC slabs, several peaks (rise and drop in load) were also observed before the peak load. The main advantages of using ECC is the smother load transfer between concrete and steel after cracking compared to SCC. This can be attributed to the better steel-concrete shear bond in ECC slabs compared to those with SCC. ECC's high strain capacity and crack resistant properties can develop higher shear bond through embossments present in both P3623 and P2432 steel decks. Failure load generally increased with the decrease of shear span for all composite slabs

\subsubsection{End Slip behavior of Slabs}

According to Eurocode 4 Part 1.1 (EN 1994-1-1, 2004) "The longitudinal shear behaviour may be considered as ductile if the failure load exceeds the load causing a recorded end slip of $0.1 \mathrm{~mm}$ by more than 10\%." All tested composite slab behaved in ductile manner according to Eurocode 4 requirement. 

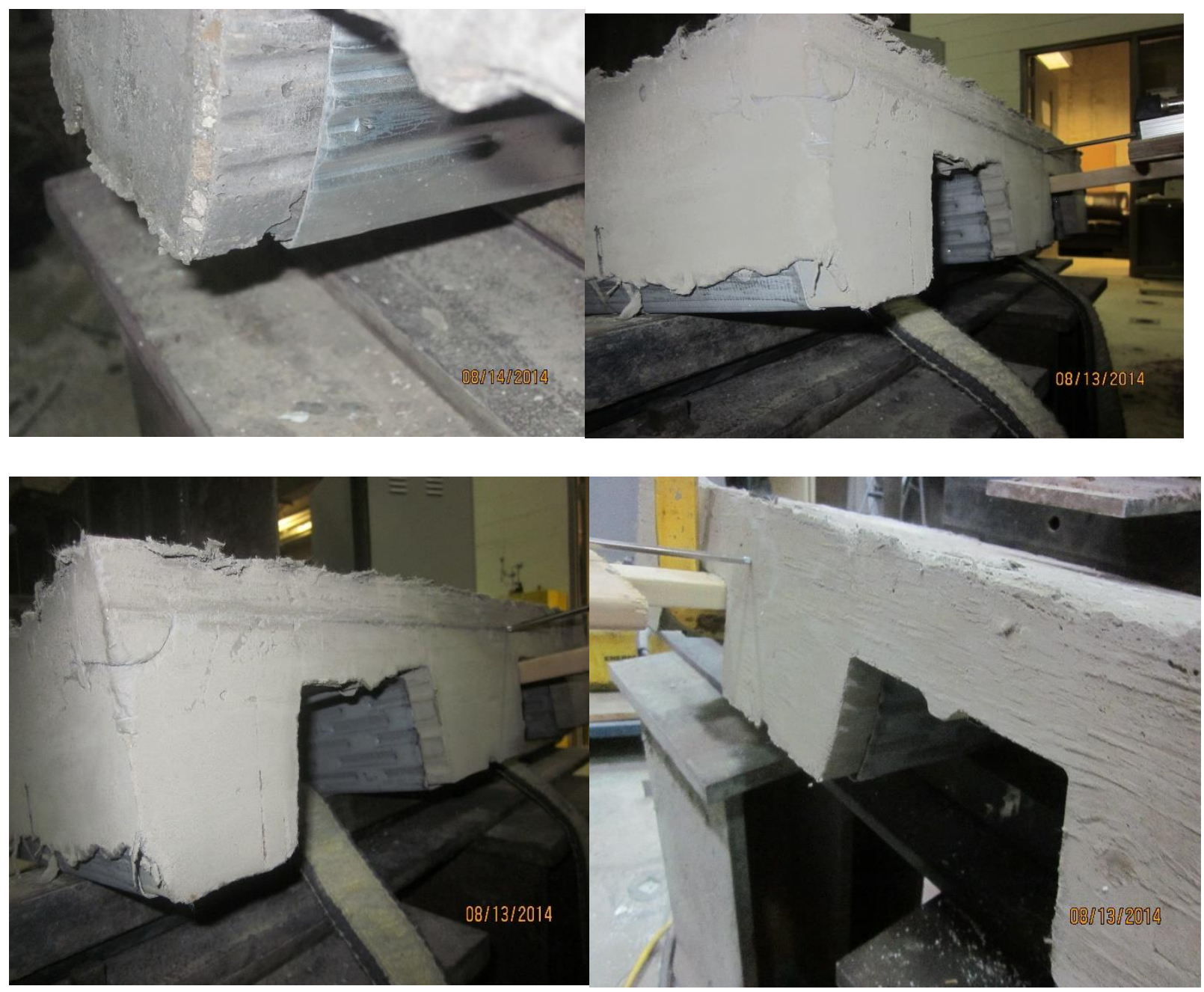

Fig. 3.10:- End slip between steel sheet and concrete in composite slabs

Typical end slips between the steel sheet and the concrete are shown in Fig 3.10. The slip in the initial (early stage) loading of all slabs were almost zero but after the slippage starts, the rate of slip got higher. According to Marimuthua, et al. (2006), the reverse direction of slippage at the development of the first crack (Fig.3.11a) showed the deterioration of bond between the steel sheet and the concrete. In all specimens, the slip was not started at early stage of the loading. This indicates that the embossment direction, depth and width which create the friction between the steel sheet and the concrete was good. 

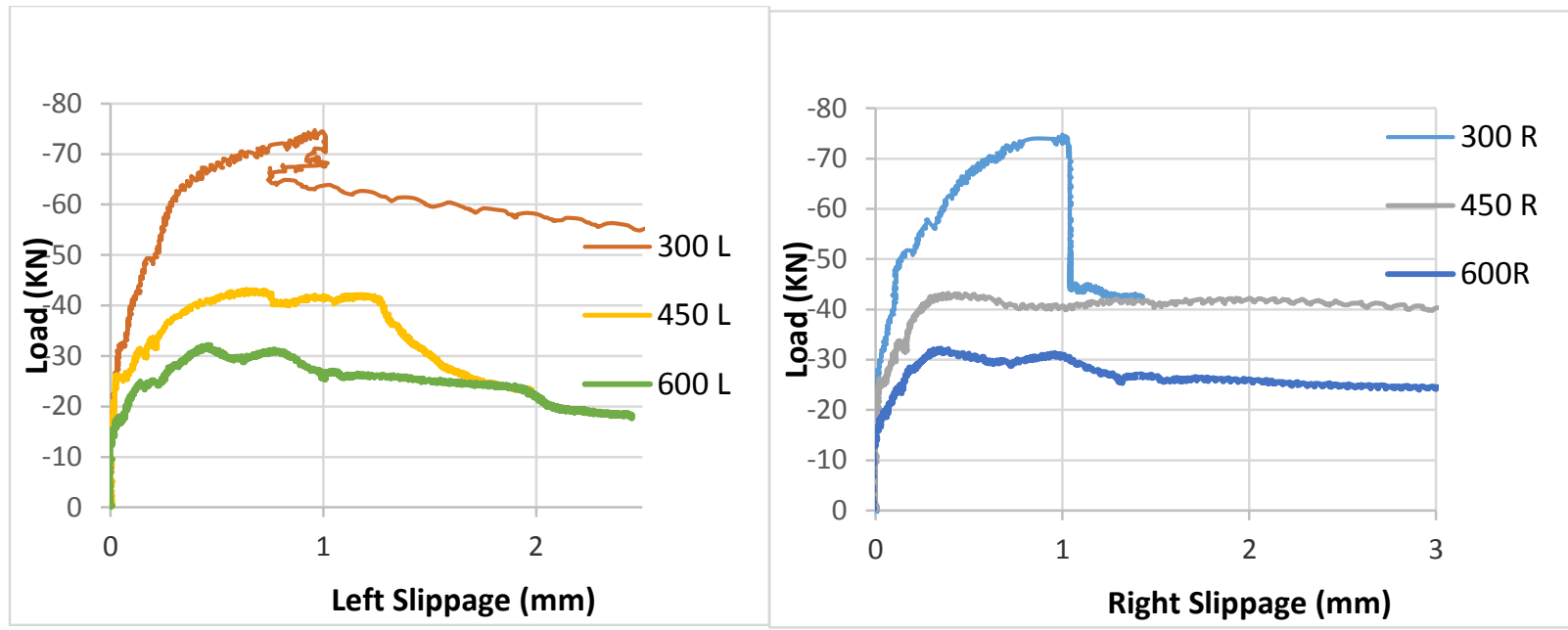

Fig. 3.11 (a):- Load-slip relation of composite slabs with different shear span (ECC - sheet A P-2432)
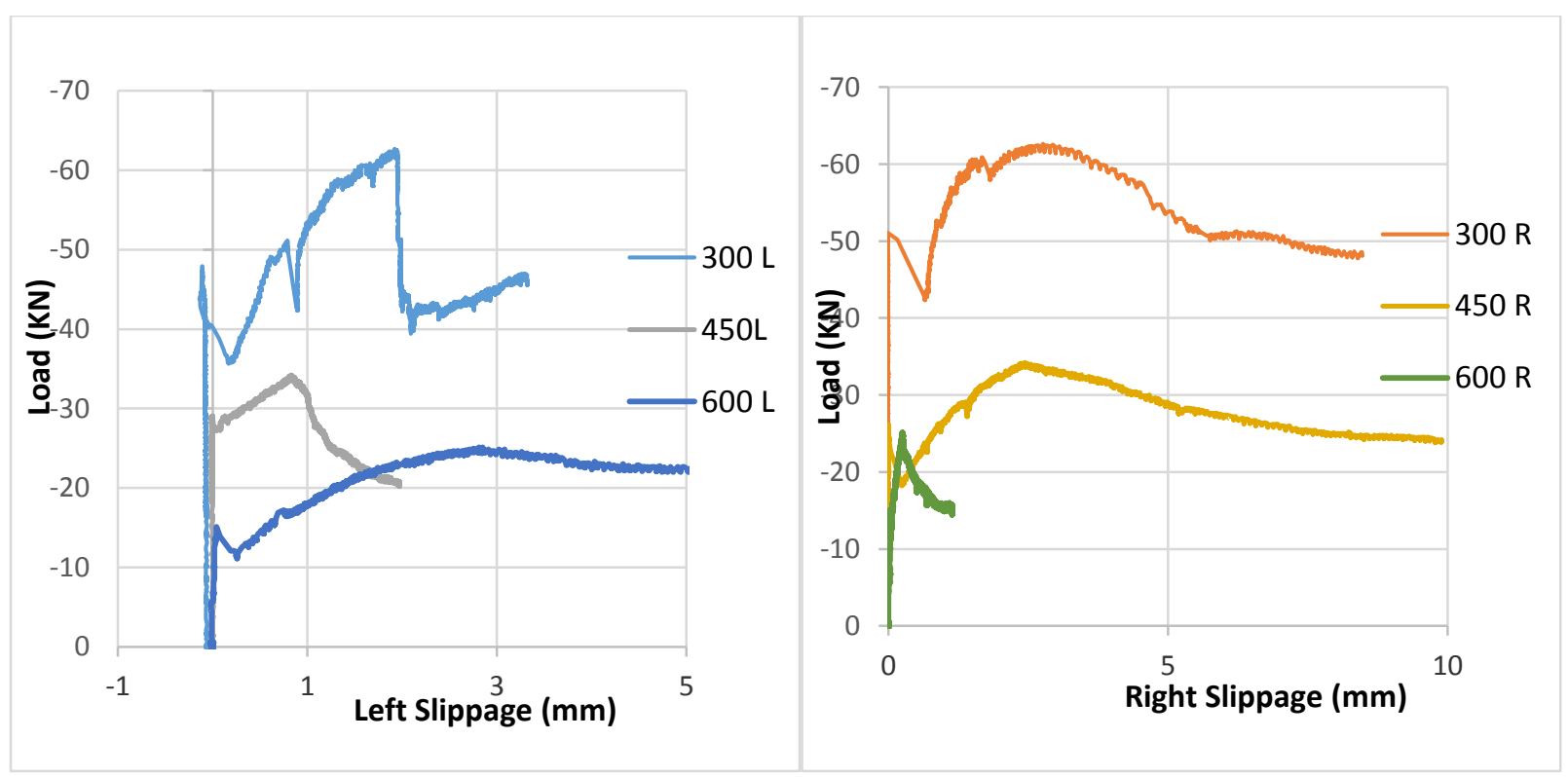

Fig. 3.11 (b):- Load-slip relation of composite slabs with different shear span (SCC - sheet A P-2432) 

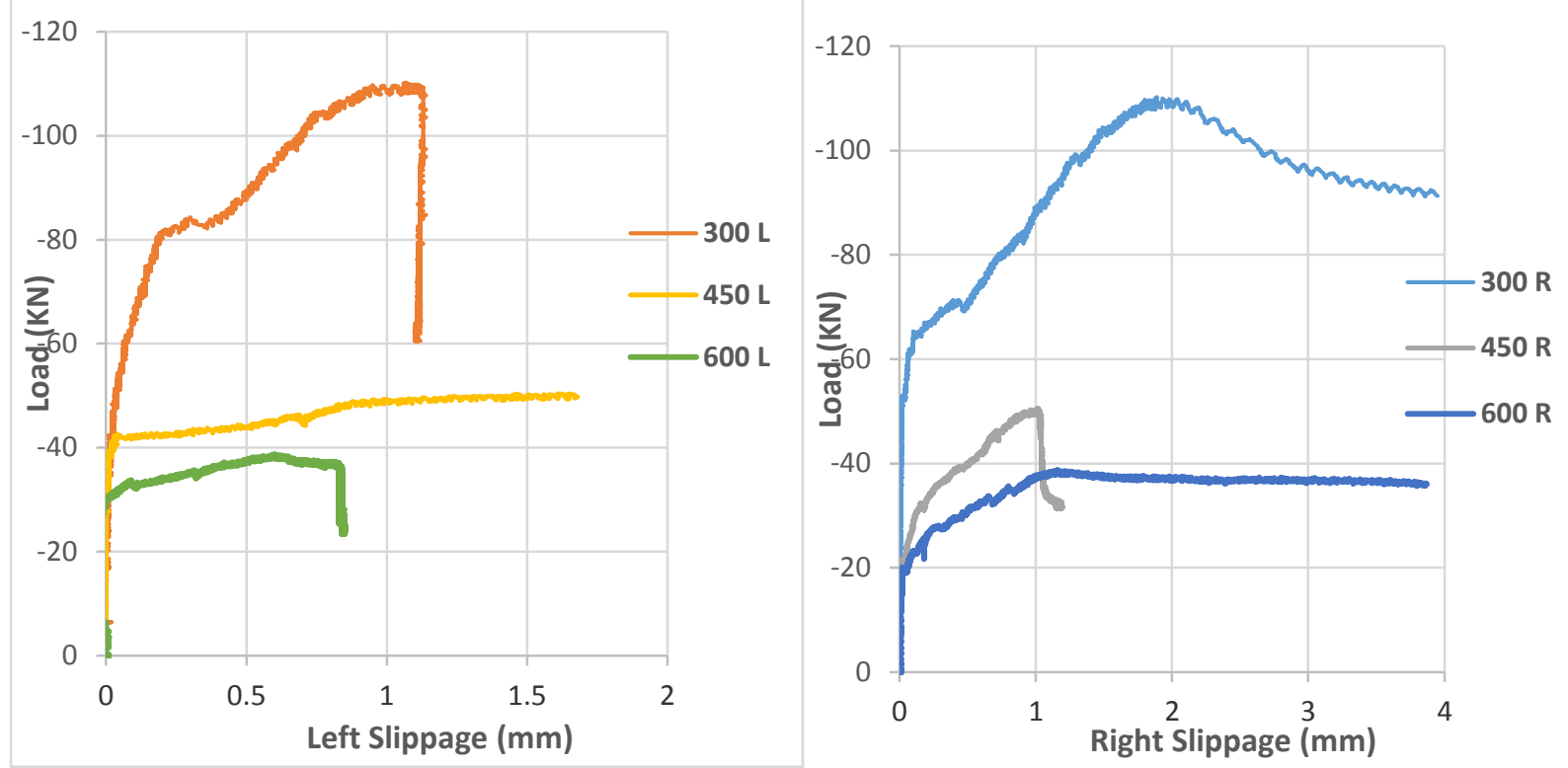

Fig. 3.11 (c):- Load-slip relation of composite slabs with different shear span (ECC-sheet B P-3623)

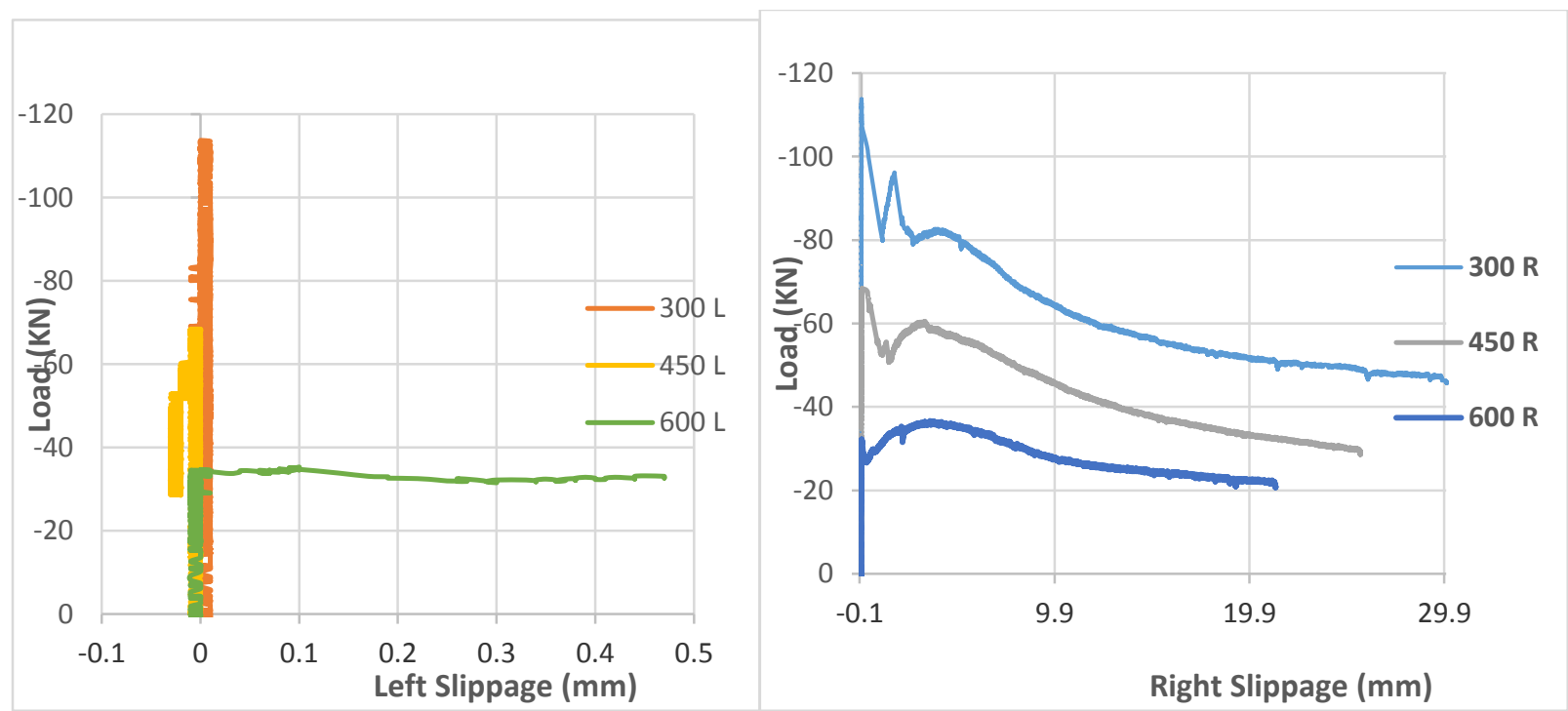

Fig. 3.11 (d):- Load-slip relation of composite slabs with different shear span (SCC- sheet B P-3623)

It has been observed from Fig 3.11, that slabs with shear span length of $300 \mathrm{~mm}$ showed more load resistance than those with $450 \mathrm{~mm}$ and $600 \mathrm{~mm}$ before slippage occurred. All slabs made with SCC had sudden drop in load when first slippage started. Slabs made with ECC carried more load after slippage. 
For the same shear span and same steel sheet, SCC composite slab had shown less slippages than ECC slabs at the failure load or first maximum load (Fig 3.12). That means the bond developed between the steel sheet and concrete in SCC is better than ECC before crack happened. That may be due to the big size aggregate used for SCC which made better mechanical interlock with embossment and also rough surfaces before slippage was started. From Fig.3.12 shows that all SCC slabs carried less load once slippage started whereas ECC slabs carried more loads even after starting of the slippage. This shows ductile behavior of ECC slabs.

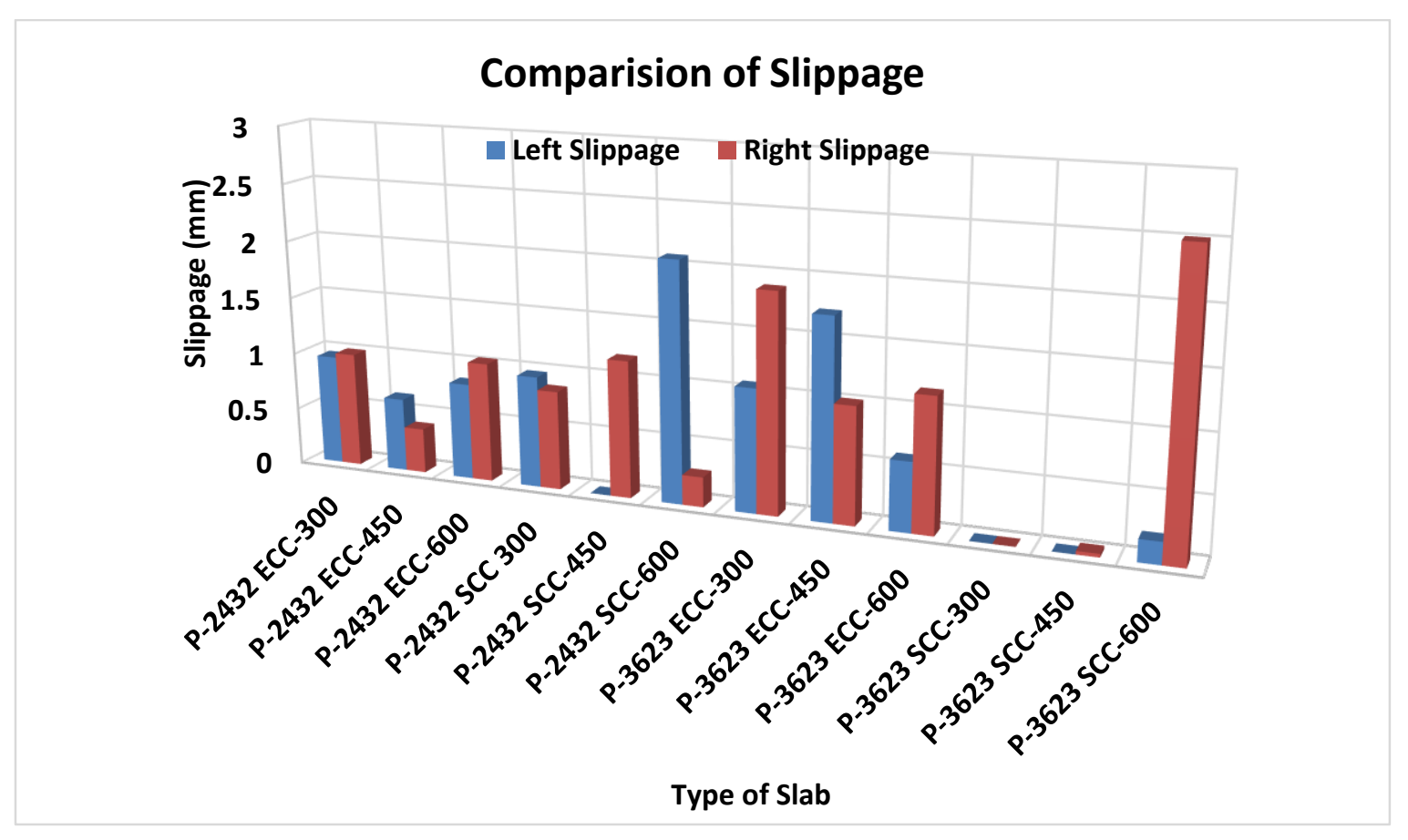

Fig. 3.12:- Comparison of end slippages

According to Eurocode 4 Part 1.1 (EN 1994-1-1, 2004) "The longitudinal shear behaviour may be considered as ductile if the failure load exceeds the load causing a recorded end slip of $0.1 \mathrm{~mm}$ by more than 10\%." As per column 9 of Table 3.3, the percentage of failure load at $0.1 \mathrm{~mm}$ slip was greater than $10 \%$ that means all tested composite slab behaved in ductile manner. 
Table 3.3:- Experimental Failure modes behavior, shear force different sabs respect to Euro-code 4

\begin{tabular}{|c|c|c|c|c|c|c|c|c|c|}
\hline $\begin{array}{l}\text { Concrete } \\
\text { Mix }\end{array}$ & $\begin{array}{c}\text { Sheet } \\
\text { type }\end{array}$ & $\begin{array}{l}\text { Sheer } \\
\text { Span Lv } \\
(\mathrm{mm})\end{array}$ & $\begin{array}{c}\text { Effective } \\
\text { depth } \\
\mathrm{d}_{\mathrm{s}} \\
(\mathrm{mm})\end{array}$ & $\begin{array}{c}\text { Concrete } \\
\text { comp. } \\
\text { Strength } \\
f_{\mathrm{cm}} \\
\left(\mathrm{N} / \mathrm{mm}^{2}\right)\end{array}$ & $\begin{array}{c}\text { cross } \\
\text { sectional } \\
\text { area of } \\
\text { sheet } \\
A_{p} \\
\left(\mathrm{~mm}^{2}\right) \\
\end{array}$ & $\begin{array}{c}\text { Sheer } \\
\text { Force } \\
@ 0.1 \mathrm{~mm} \\
\text { slip } \\
\frac{\mathrm{v} @ 0.1}{(\mathrm{KN})} \\
\end{array}$ & $\begin{array}{c}\text { Sheer } \\
\text { Force } \\
\mathrm{V}_{\mathrm{E}}(\mathrm{KN})\end{array}$ & $\frac{V @ 0.1}{\frac{V}{\underline{V_{E}}}}$ & Behavior \\
\hline \multirow{6}{*}{ ECC } & \multirow{3}{*}{$\begin{array}{c}P- \\
2432\end{array}$} & 300 & 87 & 66 & 1131 & 19.22 & 37.215 & 51.64584 & Ductile \\
\hline & & 450 & 87 & 66 & 1131 & 13.495 & 21.495 & 62.78204 & Ductile \\
\hline & & 600 & 87 & 66 & 1131 & 10.72 & 15.61 & 68.67392 & Ductile \\
\hline & \multirow{3}{*}{$\begin{array}{c}\text { P- } \\
3623\end{array}$} & 300 & 74.5 & 64 & 1016 & 32.05 & 54.99 & 58.28332 & Ductile \\
\hline & & 450 & 74.5 & 64 & 1016 & 21.05 & 25.16 & 83.66454 & Ductile \\
\hline & & 600 & 74.5 & 64 & 1016 & 16.11 & 19.385 & 83.10549 & Ductile \\
\hline \multirow{6}{*}{ SCC } & \multirow{3}{*}{$\begin{array}{c}P- \\
2432\end{array}$} & 300 & 87 & 56 & 1131 & 22.385 & 31.34 & 71.42629 & Ductile \\
\hline & & 450 & 87 & 56 & 1131 & 9.94 & 16.995 & 58.48779 & Ductile \\
\hline & & 600 & 87 & 56 & 1131 & 6.055 & 12.44 & 48.67363 & Ductile \\
\hline & \multirow{3}{*}{$\begin{array}{c}\text { P- } \\
3623\end{array}$} & 300 & 74.5 & 51 & 1016 & 51.82 & 56.875 & 91.11208 & Ductile \\
\hline & & 450 & 74.5 & 51 & 1016 & 34.05 & 34.215 & 99.51775 & Ductile \\
\hline & & 600 & 74.5 & 51 & 1016 & 14.38 & 18.105 & 79.4255 & Ductile \\
\hline
\end{tabular}

\subsubsection{Strain Development in Concrete Surface}

For all composite slabs strains were measured at the center on the top surface of concrete. As per Fig. 3.13, the shorter shear span slabs developed higher concrete strain compared to longer shear span ones. All ECC composite slabs developed higher strain and strain increase was much quicker compared to their SCC counterparts as shown in Fig.3.13 and Fig.3.14. This is attributed to the considerably higher ductility capacity of ECC compared to SCC. This shows ECC's more ductility and energy absorbing capacity. The ECC strain was closer to the ultimate compressive strain for slabs with longer shear span (600 $\mathrm{mm}$ ). However, most of the slabs failed before the concrete developed a compressive strain of 0.0035 (Fig. 3.13 and Fig. 3.14). 


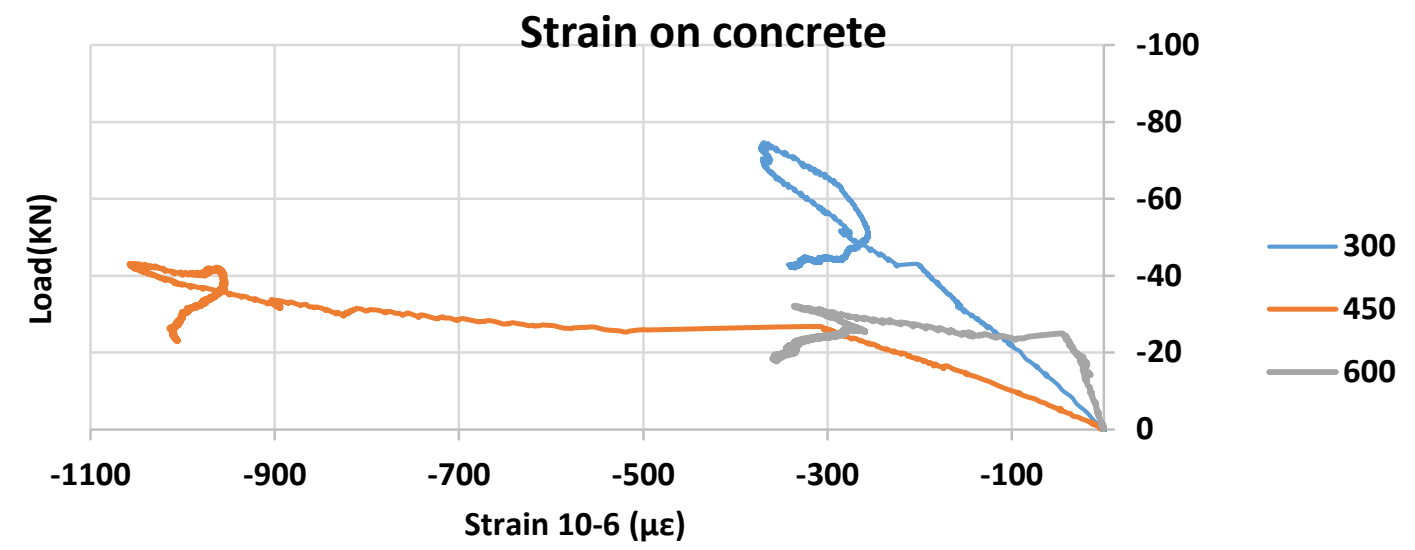

Fig. 3.13 (a):- Concrete strain development (ECC-sheet A P-2432)

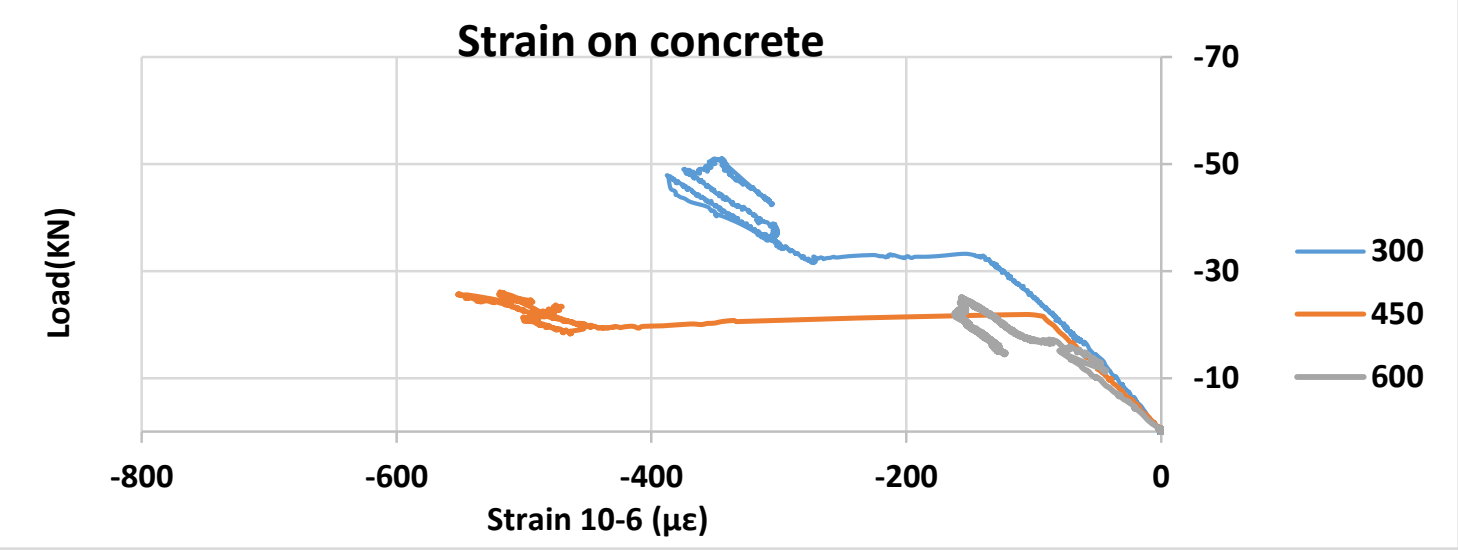

Fig. 3.13 (b):- Concrete strain development (SCC-sheet A P-2432)

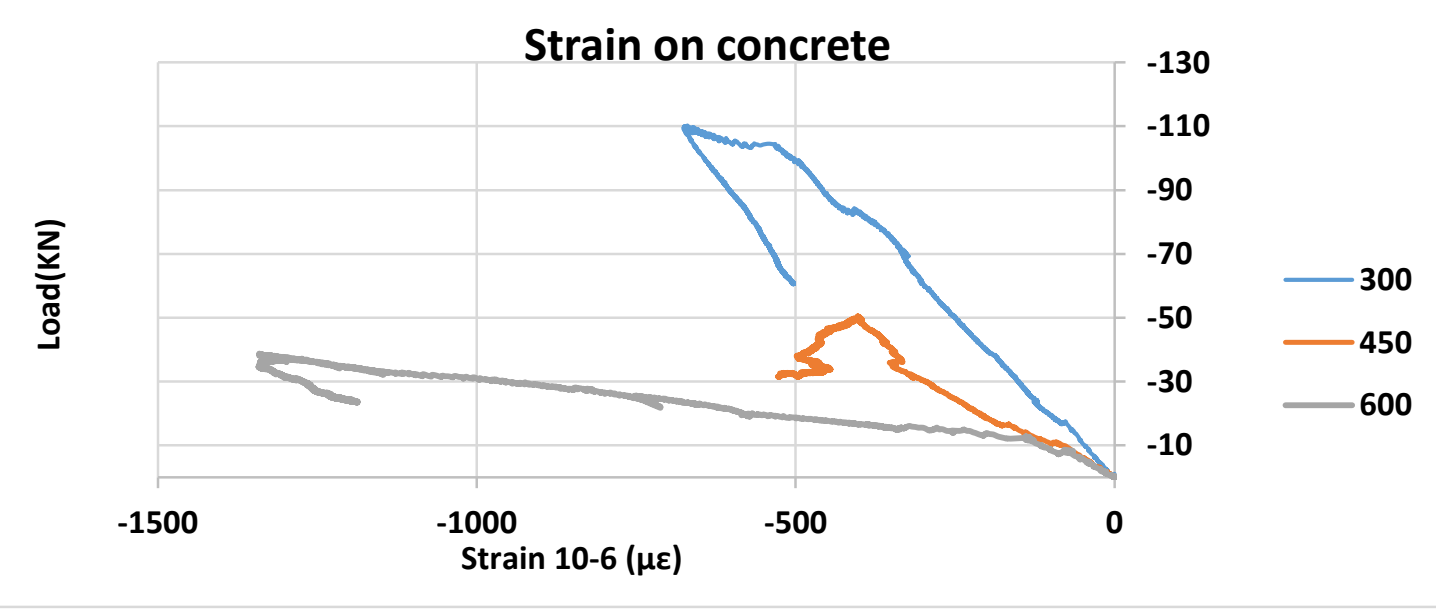

Fig. 3.13 (c):- Concrete strain development (ECC-sheet B P-3623) 


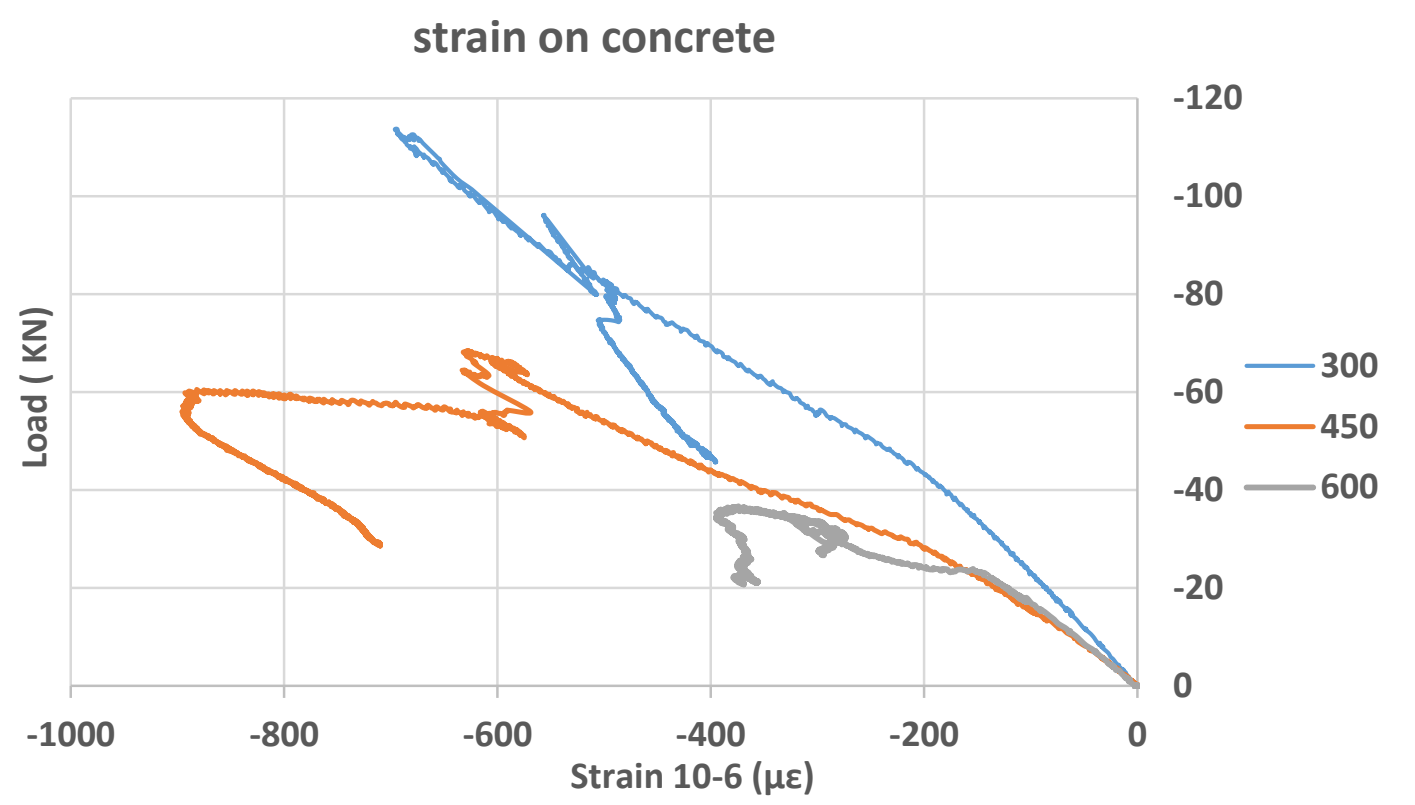

Fig. 3.13 (d):- Concrete strain development (SCC-sheet B P-3623)

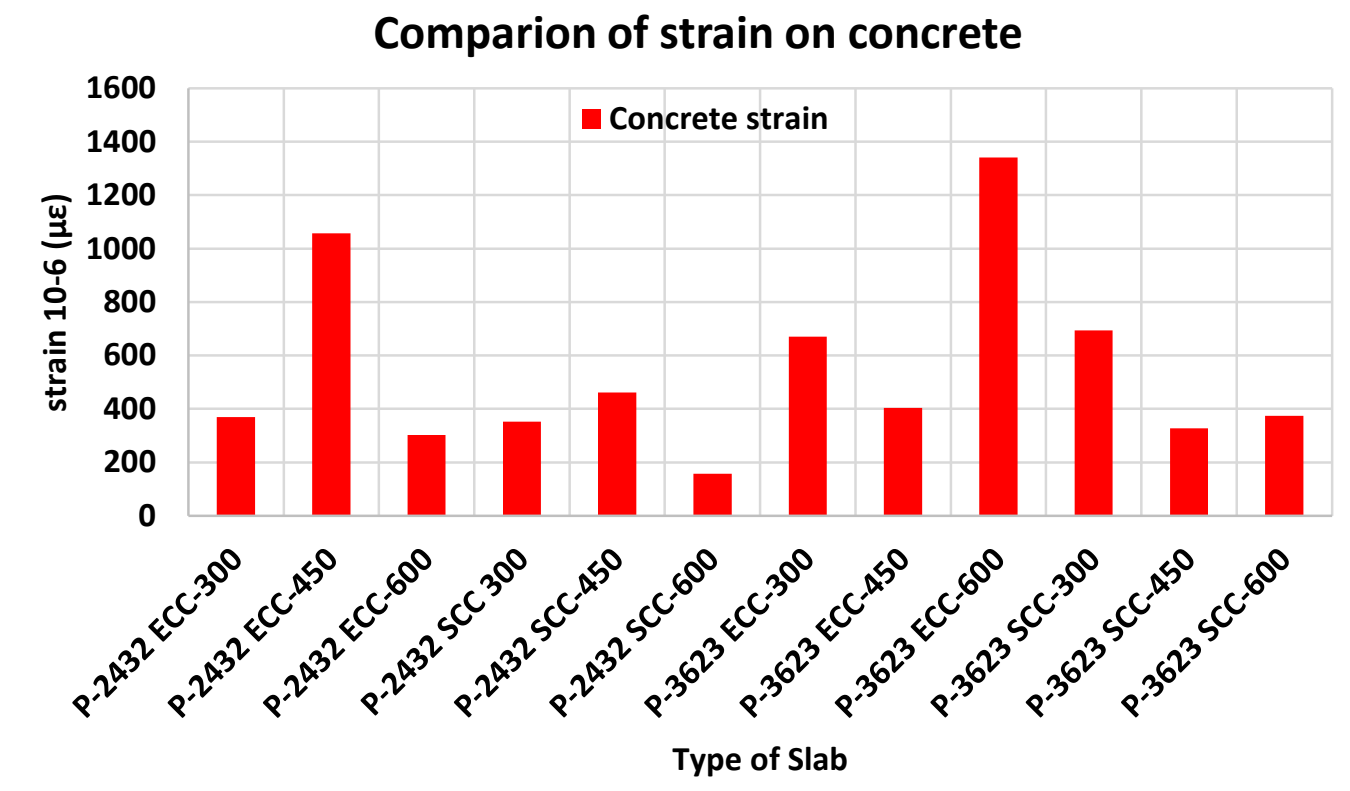

Fig. 3.14:- Comparison of compressive strains in concrete 


\subsubsection{Strain Development in Profile Steel Sheet}

Fig. 3.15 shows the tensile strain in developed linearly up to the concrete cracking as both concrete and profiled steel acted compositely. But after that a sudden strain increase indicated transfer of load to steel due to interface bond degradation. Fig.3.16 shows a comparison of steel strain in composite slabs made of different shear spans and concrete mix. Composite slab with sheet - B (P-3623) used two strain gages (St1 \& St2) because it had large width than those with sheet - A (P-2432) which used one strain gage (St1). Slabs with shorter shear span (like $300 \mathrm{~mm}$ ) attained higher steel strain compared to those with longer shear span. ECC slabs achieved higher strain compared to their SCC counterparts. This indicates that ECC slabs carried large load at the same amount of strain than SCC ones. This behavior can be credited to the high ductility of the ECC forming better composite action with the profiled steel sheeting. Composite slabs with both types of concrete made with the sheet $\mathrm{P}-3623$ yielded (tensile strain $>2000$ micro-strain) at the long shear span $(600 \mathrm{~mm})$.

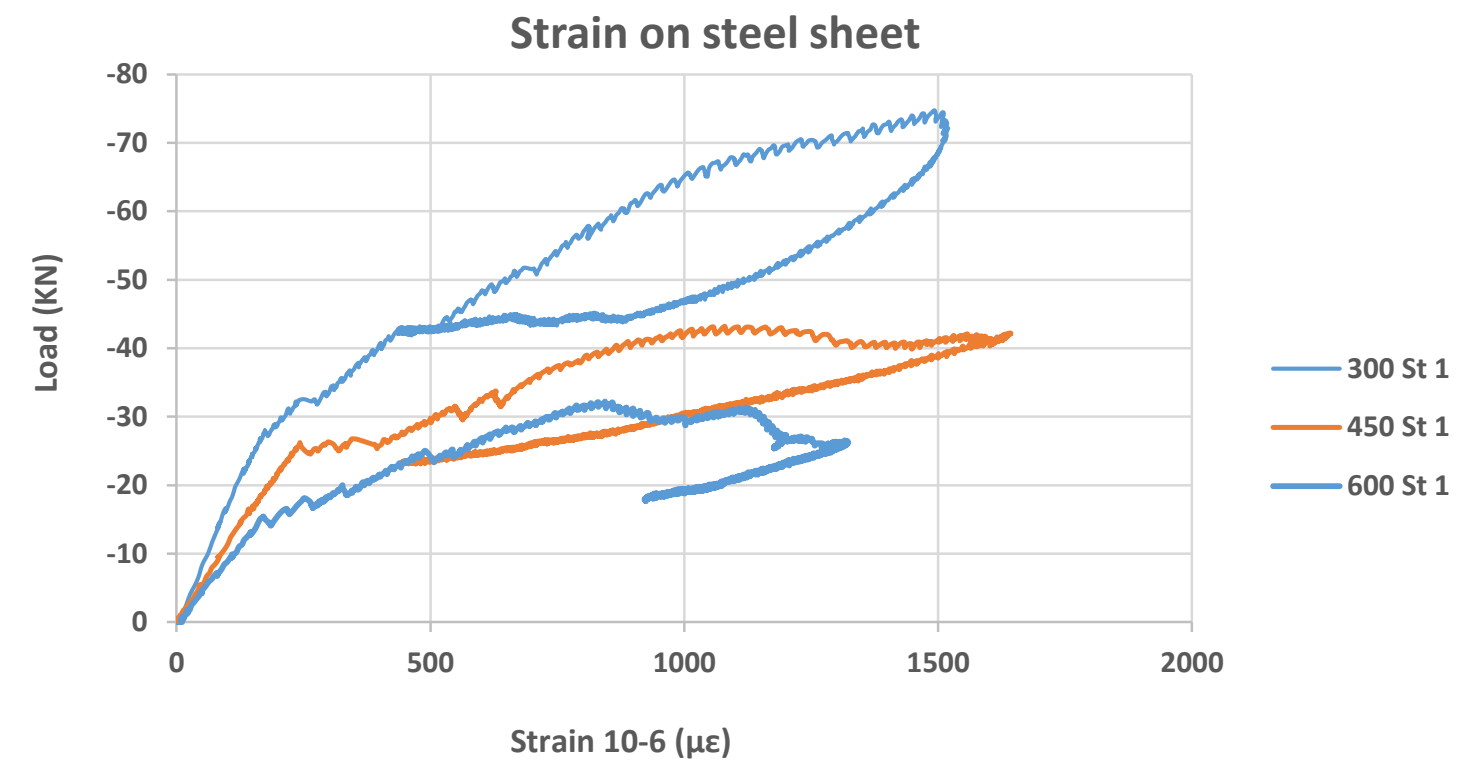

Fig. 3.15 (a):- Tensile steel strain development (ECC-sheet A-P-2432) 


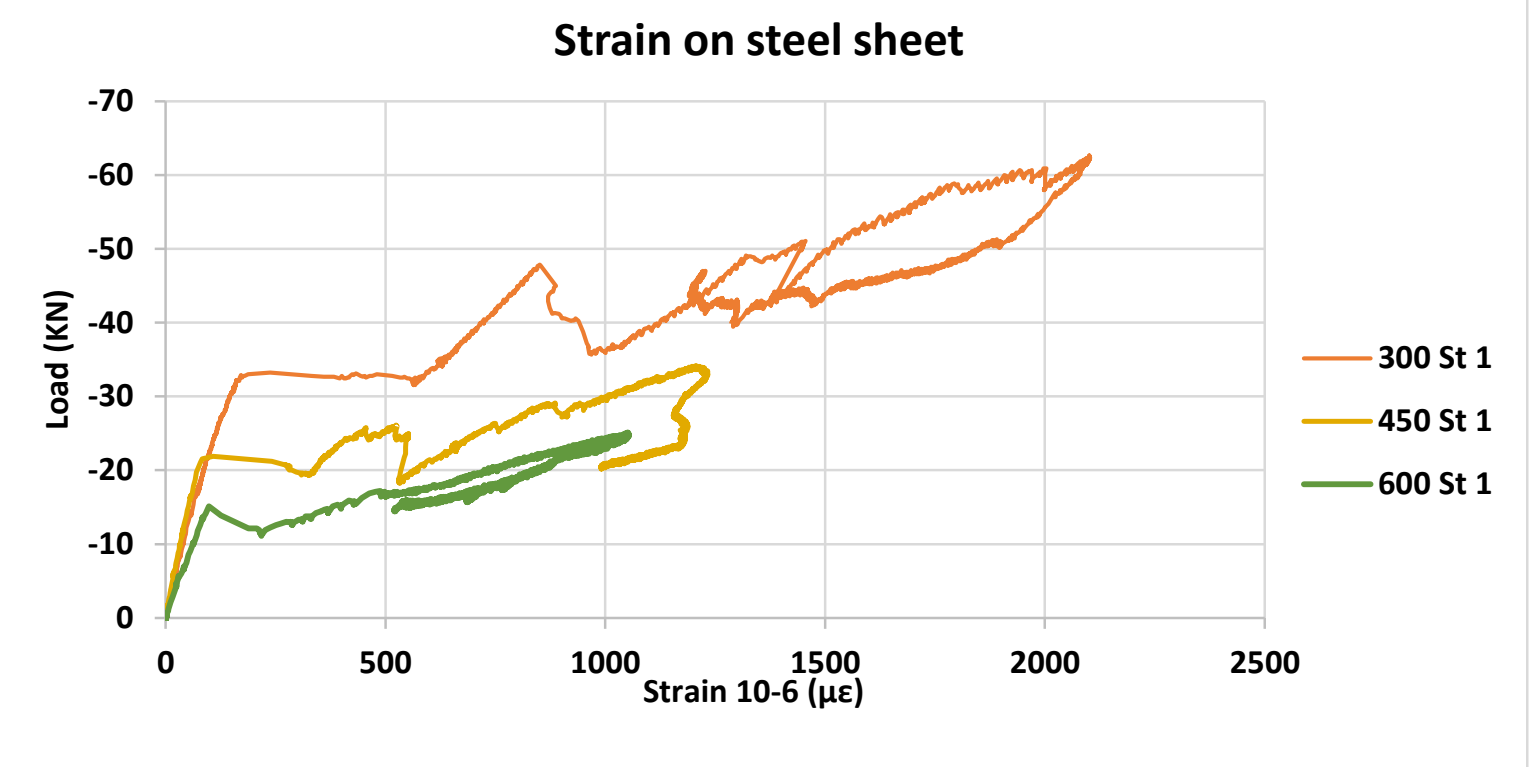

Fig. 3.15 (b):- Tensile steel strain development (SCC-sheet A-P-2432)

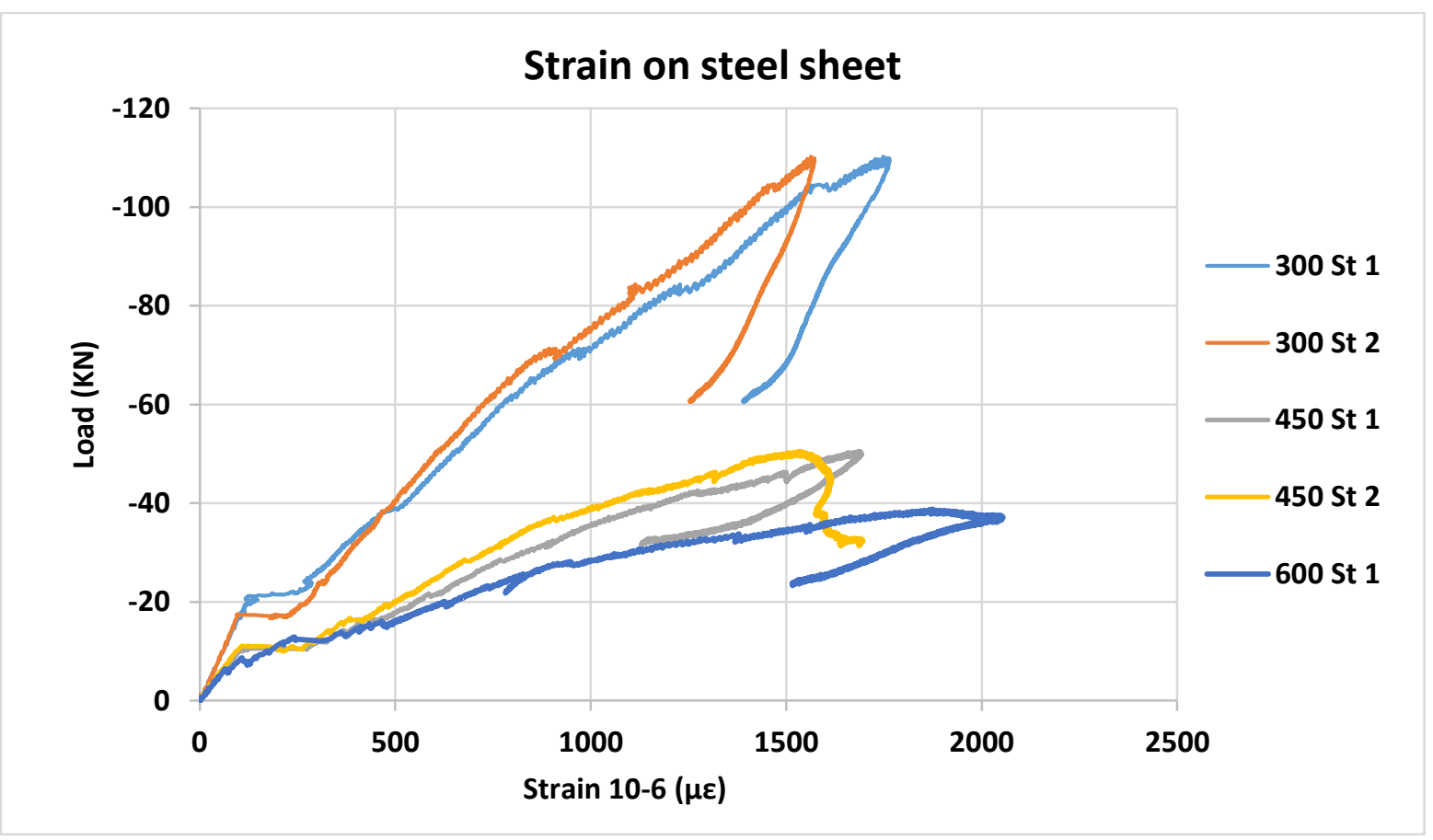

Fig. 3.15 (c):- Tensile steel strain development (ECC-sheet B-P-3623) 


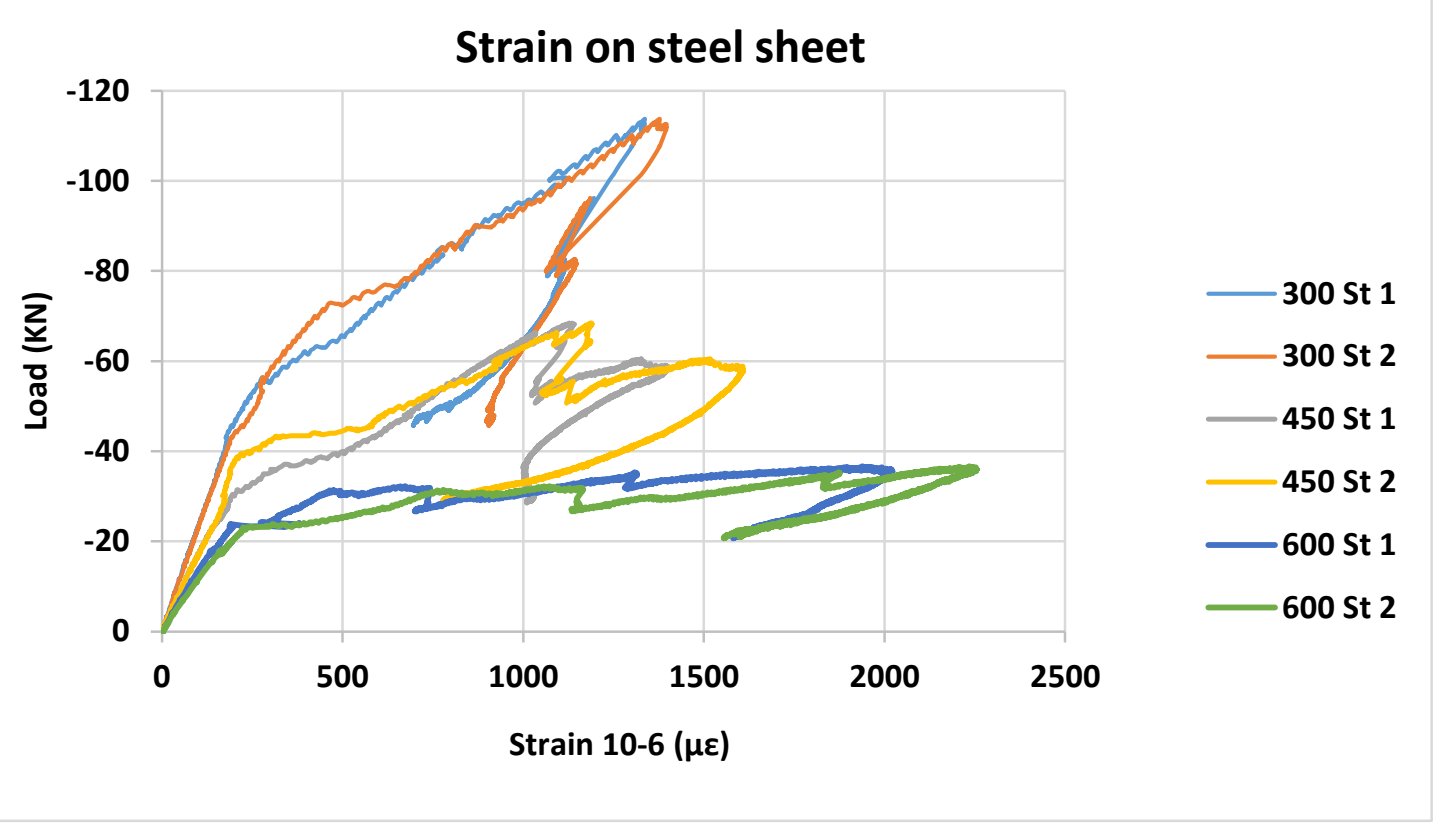

Fig. 3.15 (d):- Tensile steel strain development (SCC-sheet B-P-3623)

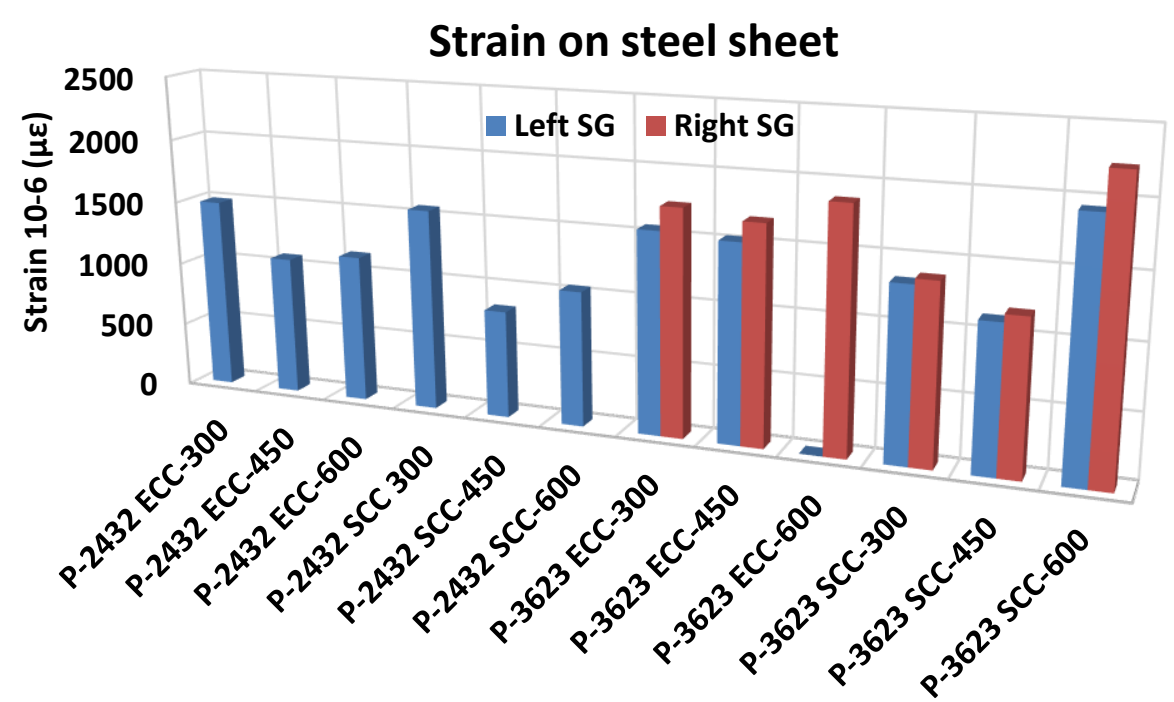

Type of Slab

Fig. 3.16:- Comparison of strain development in profile steel sheet 


\subsubsection{Evaluation of $\mathrm{M}$ - K Values and Shear Bond Capacity}

One of the main objective of the experimental investigation is to define the shear transferring capacity of the profile sheet by $m-k$ method. This method detailed in the (EN 1994-1-1, 2004) and (Mohammed, 2010) has been used to evaluate the $m$ and $k$ values which define the shear transfer capacity of the profiled sheet based on test results. $m$ represents the empirical value of mechanical interlocking between concrete and steel sheeting and $k$ represents for the empirical value for friction between the concrete and profile steel sheeting. Table 3.5 shows detail parameters to calculate the $\mathrm{m}$ and $\mathrm{k}$ values from the plotting of $\mathrm{m}-\mathrm{k}$ curve as shown in Fig. 3.17. According to Marimuthua et al. (2006), the recommended formula to calculate the shear bond capacity of composite slab is as follows:

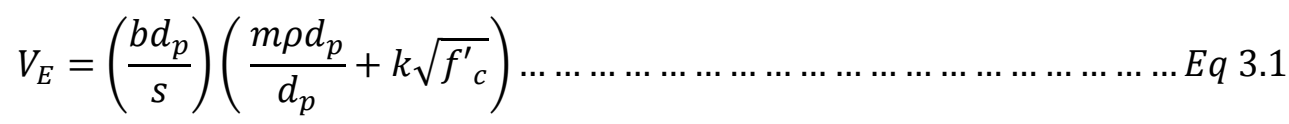

Where $s$ is the parameter depending on the type of shoring during casting.

Eq. 3.1 can be written as follows:

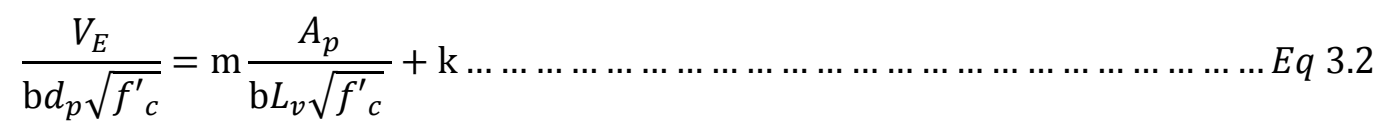

b is the width of the slab, Ap is the area of steel sheet, Lv is shear span, dp is the effective depth of slab to the centered of the profile steel sheeting, $f_{c m}$ is the average concrete cube strength (six cubes per mix) and VE is the maximum experimental shear force. Values of these parameters are listed in Table 3.4.

Eq. 3.2 represents the straight line of the form $y=m x+c$ that helps to calculate $m$ and $k$ value directly from plotting of test results. The angle of inclination of the line is $m$ value and the intersection of the $y$ axis is $k$ value. Fig. 3.17 shows the plotting of experimental data of composite slab for determining $\mathrm{m}$ and $\mathrm{k}$ values. 


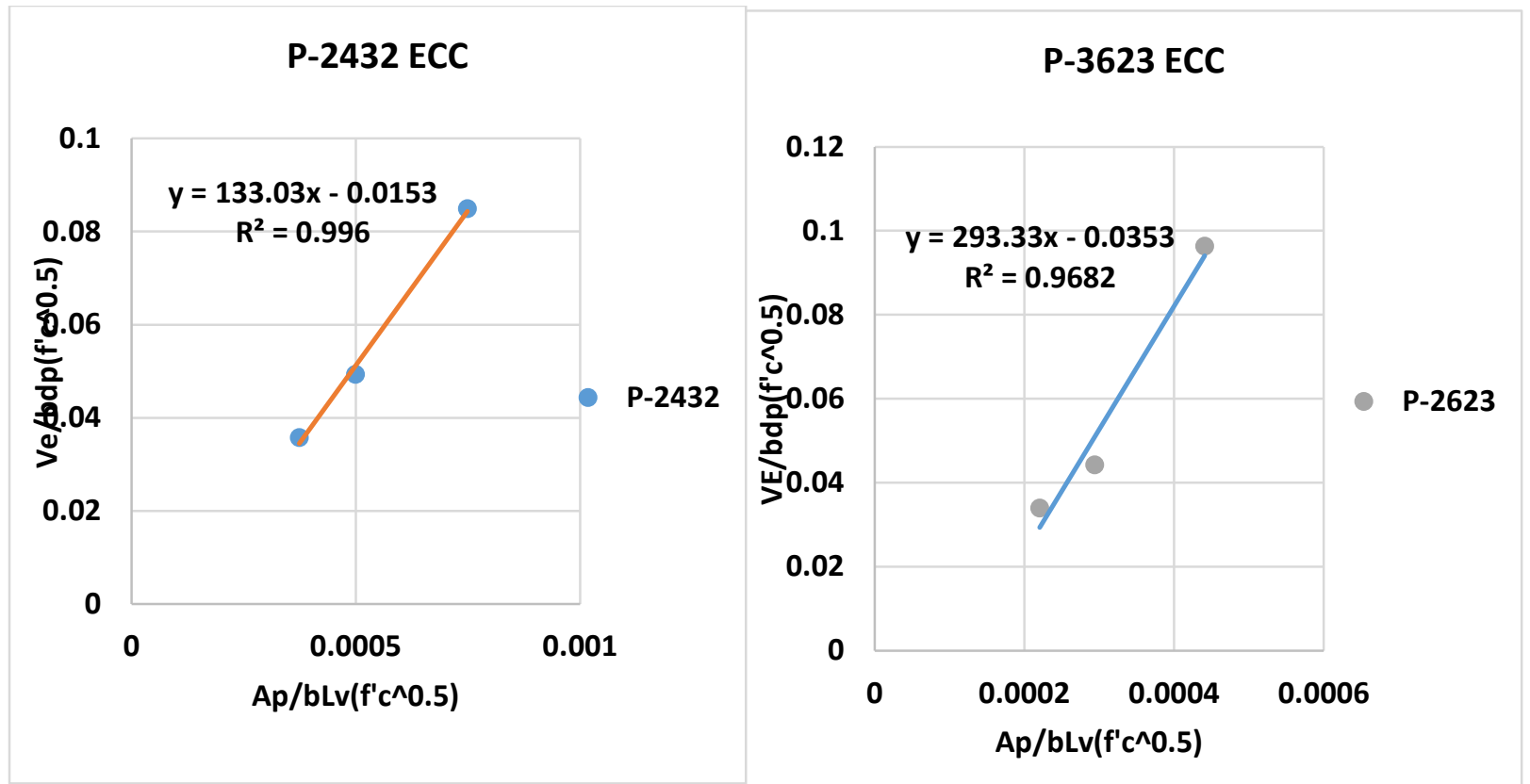

Fig. 3.17 (a):- $\mathrm{m}-\mathrm{k}$ plots of ECC slabs based on experimental results

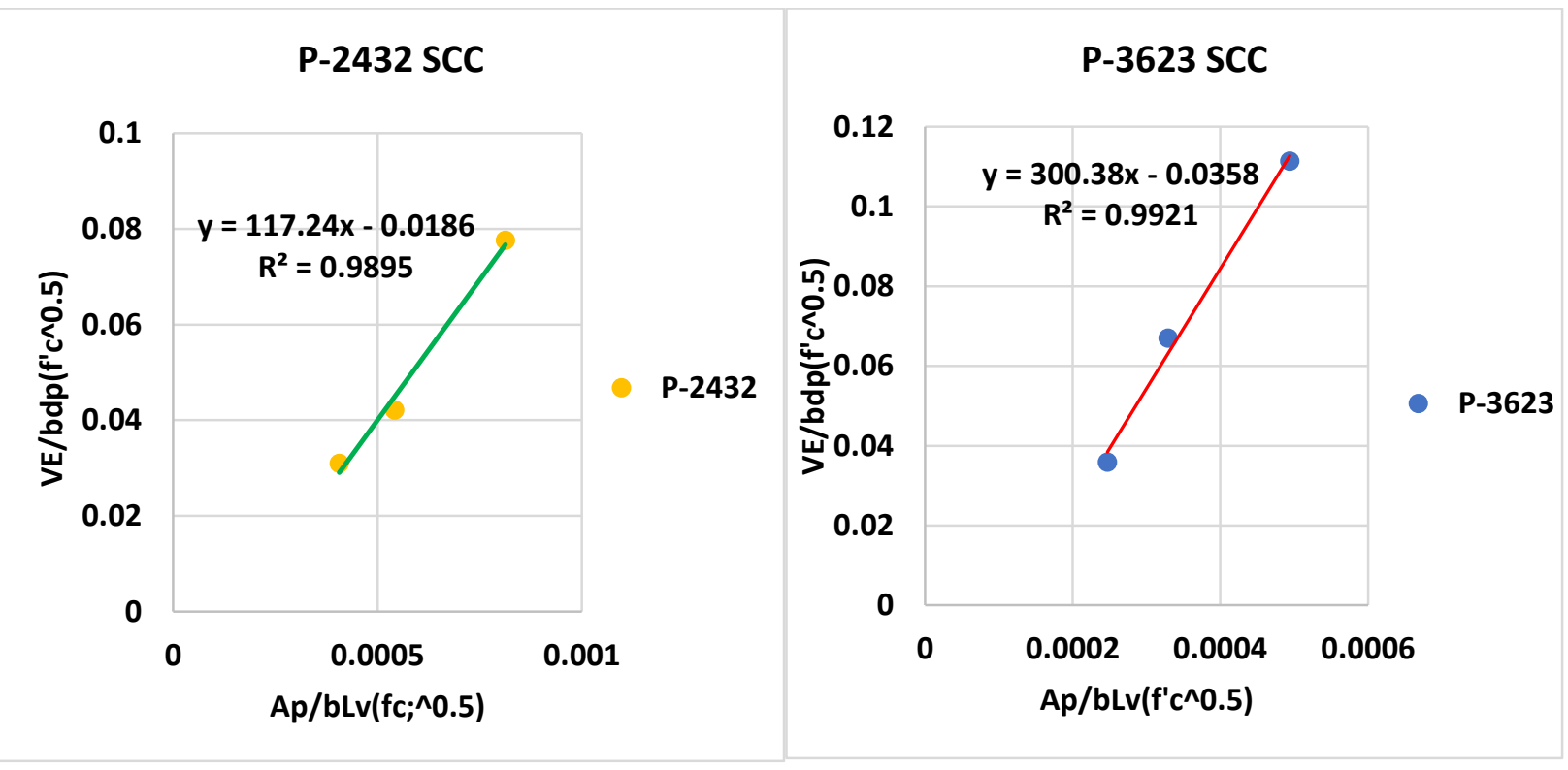

Fig. 3.17 (b):- $m-k$ plots of SCC slabs based on experimental results 
Table 3.4 (a):- Slab parameters

\begin{tabular}{|c|c|c|c|c|c|c|c|c|}
\hline $\begin{array}{c}\text { Concrete } \\
\text { Mix }\end{array}$ & $\begin{array}{c}\text { Sheet } \\
\text { Type }\end{array}$ & $\begin{array}{l}\text { Slab } \\
\text { No. }\end{array}$ & $\begin{array}{c}\text { b } \\
(\mathrm{mm})\end{array}$ & $\begin{array}{c}\text { Concrete } \\
\text { Mix }\end{array}$ & $\begin{array}{c}d_{p} \\
(\mathrm{~mm})\end{array}$ & $\begin{array}{c}\mathbf{f}_{\mathrm{cm}} \\
\left(\mathrm{N} / \mathrm{mm}^{2}\right)\end{array}$ & $\begin{array}{c}\mathrm{L}_{\mathrm{v}} \\
(\mathrm{mm})\end{array}$ & $\begin{array}{c}A_{p} \\
\left(\mathrm{~mm}^{2}\right)\end{array}$ \\
\hline \multirow{3}{*}{ ECC } & \multirow{3}{*}{$\begin{array}{l}\text { Sheet A } \\
(P-2432)\end{array}$} & 1 & 620 & 76 & 87 & 66 & 300 & 1131 \\
\hline & & 2 & 620 & 76 & 87 & 66 & 450 & 1131 \\
\hline & & 3 & 620 & 76 & 87 & 66 & 600 & 1131 \\
\hline \multirow{3}{*}{ ECC } & \multirow{3}{*}{$\begin{array}{l}\text { Sheet B } \\
(P-3623)\end{array}$} & 1 & 960 & 51 & 74.5 & 64 & 300 & 1016 \\
\hline & & 2 & 960 & 51 & 74.5 & 64 & 450 & 1016 \\
\hline & & 3 & 960 & 51 & 74.5 & 64 & 600 & 1016 \\
\hline \multirow{3}{*}{ SCC } & \multirow{3}{*}{$\begin{array}{l}\text { Sheet A } \\
(p-2432)\end{array}$} & 1 & 620 & 76 & 87 & 56 & 300 & 1131 \\
\hline & & 2 & 620 & 76 & 87 & 56 & 450 & 1131 \\
\hline & & 3 & 620 & 76 & 87 & 56 & 600 & 1131 \\
\hline & & & & & & & & \\
\hline \multirow{3}{*}{ SCC } & \multirow{3}{*}{$\begin{array}{l}\text { Sheet B } \\
(p-3623)\end{array}$} & 1 & 960 & 51 & 74.5 & 51 & 300 & 1016 \\
\hline & & 2 & 960 & 51 & 74.5 & 51 & 450 & 1016 \\
\hline & & 3 & 960 & 51 & 74.5 & 51 & 600 & 1016 \\
\hline
\end{tabular}

Table 3.4(b):- $m-k$ values and shear bond capacity $\left(\tau_{v}\right)$

\begin{tabular}{|c|c|c|c|c|c|c|c|c|}
\hline $\begin{array}{c}\text { Concrete } \\
\text { Mix }\end{array}$ & $\begin{array}{c}\text { Sheet } \\
\text { Type- }\end{array}$ & $\begin{array}{r}\text { Load } \\
(\mathrm{KN})\end{array}$ & $\begin{array}{c}V_{E} \\
\text { (KN) }\end{array}$ & $\begin{array}{c}V_{\mathrm{E}} / \\
\left(\mathrm{bd}_{\mathrm{p}}\right)^{*} \\
\left(\mathrm{f}_{\mathrm{cm}}\right)^{\wedge} .5\end{array}$ & $\begin{array}{c}A_{p} / \\
\left(b L_{v}\right)^{*} \\
\left(f_{c m}\right)^{\wedge} 0.5\end{array}$ & m & k & $\begin{array}{c}\tau_{v} \\
\left(\mathrm{~N} / \mathrm{mm}^{2}\right)\end{array}$ \\
\hline \multirow{3}{*}{ ECC } & \multirow{3}{*}{$\begin{array}{l}\text { Sheet A } \\
(P-2432)\end{array}$} & 74.43 & 37.215 & 0.085 & 0.000748 & 133.03 & 0.0153 & 0.933206 \\
\hline & & 43.21 & 21.605 & 0.049 & 0.000499 & 133.03 & 0.0153 & 0.66357 \\
\hline & & 31.33 & 15.665 & 0.036 & 0.000374 & 133.03 & 0.0153 & 0.528752 \\
\hline \multirow{3}{*}{ ECC } & \multirow{3}{*}{$\begin{array}{l}\text { Sheet B } \\
(\mathrm{P}-3623)\end{array}$} & 110.2 & 55.1 & 0.096 & 0.000441 & 293.33 & 0.0353 & 1.317203 \\
\hline & & 50.54 & 25.27 & 0.044 & 0.000294 & 293.33 & 0.0353 & 0.972269 \\
\hline & & 38.77 & 19.385 & 0.034 & 0.000220 & 293.33 & 0.0353 & 0.799802 \\
\hline \multirow{3}{*}{ SCC } & \multirow{3}{*}{$\begin{array}{l}\text { Sheet A } \\
(p-2432)\end{array}$} & 62.68 & 31.34 & 0.078 & 0.000813 & 117.24 & 0.0186 & 0.852084 \\
\hline & & 33.99 & 16.995 & 0.042 & 0.000542 & 117.24 & 0.0186 & 0.614453 \\
\hline & & 24.99 & 12.495 & 0.031 & 0.000406 & 117.24 & 0.0186 & 0.495637 \\
\hline \multirow{3}{*}{ SCC } & \multirow{3}{*}{$\begin{array}{l}\text { Sheet B } \\
(p-3623)\end{array}$} & 113.75 & 56.875 & 0.111 & 0.000494 & 300.38 & 0.0358 & 1.315337 \\
\hline & & 68.43 & 34.215 & 0.067 & 0.000329 & 300.38 & 0.0358 & 0.962112 \\
\hline & & 36.66 & 18.33 & 0.036 & 0.000247 & 300.38 & 0.0358 & 0.7855 \\
\hline
\end{tabular}


The $\mathrm{m}$ and $\mathrm{K}$ vales or composite slabs are summarized in Table 3.4 and compared in Fig. 3.18. The mechanical interlock represented by $m$ value is found to be significantly different between ECC and SCC composite slab especially for sheet $-\mathrm{A}$ (P-2432). This shows that ECC creates more mechanical interlock than SCC that helps to resist more load before failure. The value of friction between the concrete and steel sheet represented by $k$ value is found to be slightly higher for SCC slightly $r$ than ECC. That may be due to the presence of large aggregate in SCC than ECC and the roughness of concrete.

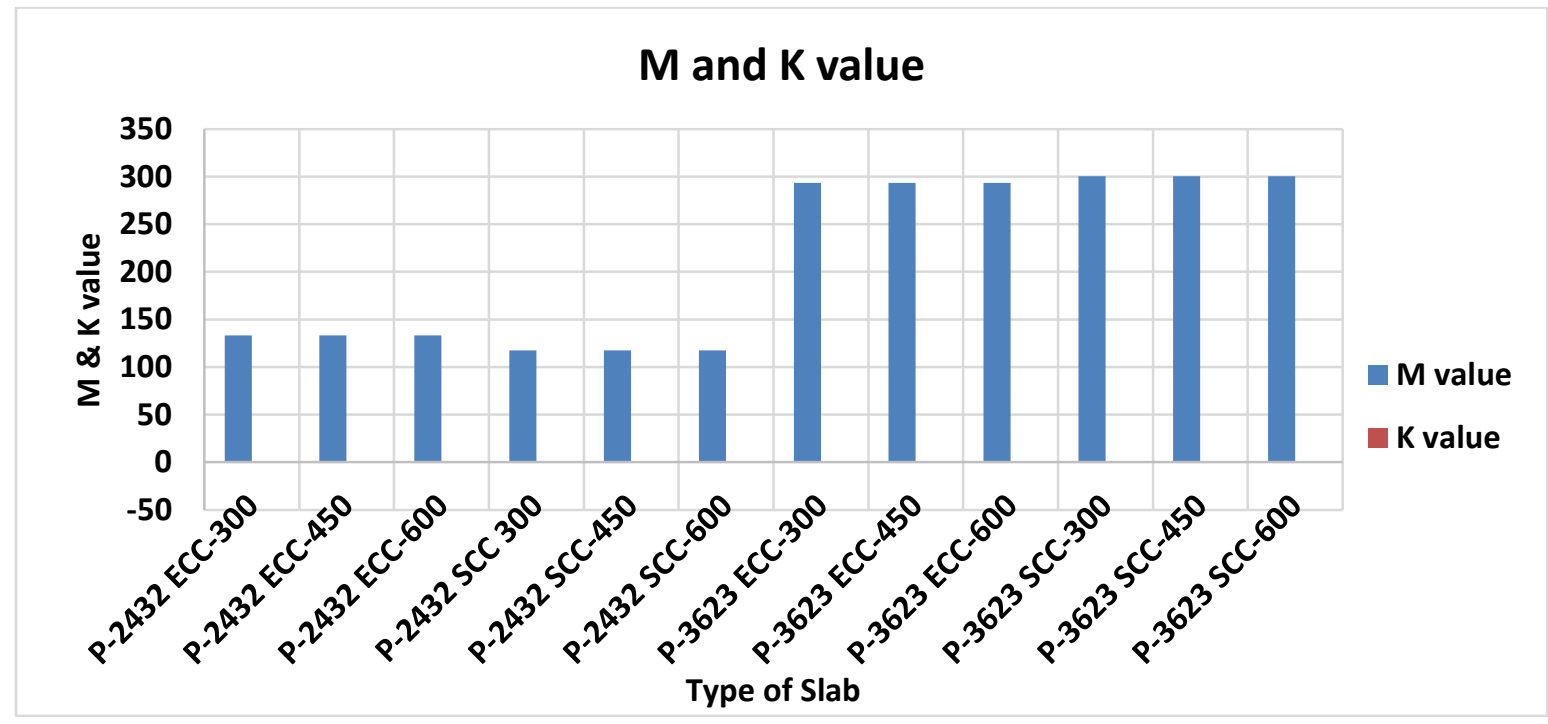

Fig. 3.18:- Comparison of $\mathrm{m}$ and $\mathrm{k}$ values

After $m$ and $k$ values were obtained, the shear bond capacity $\left(\tau_{v, R d}\right)$ of composite slabs are calculated by the design equations (Eq. 3.3 and eq. 3.4) found from Eurocode 4. The shear bond capacity of all composite slabs are listed in Table 3.5.

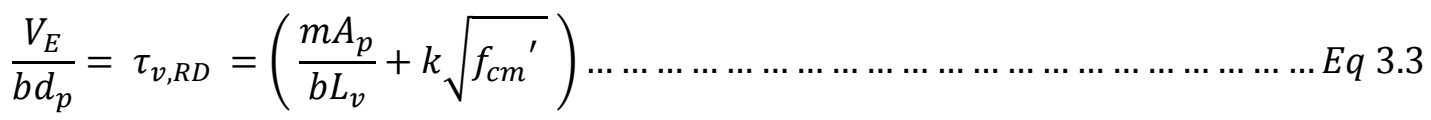

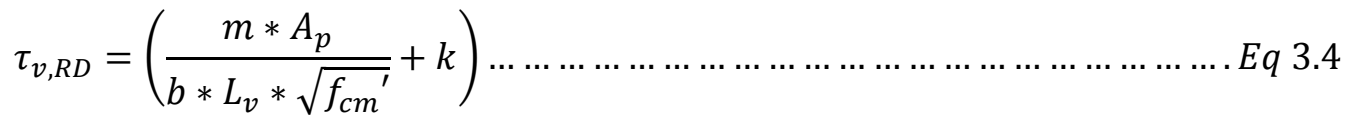

The comparison of shear bond capacitywith different shear span is shown in Fig.3.19. Shorter shear span slabs had produced better shear bond capacity. The slabs made with ECC have developed better shear bond capacity compared to their SCC counterparts. This indicates $\mathrm{m}-\mathrm{k}$ method produce better result and more suitable for slabs with shorter spans (predominantly for shear bond failure) than those with longer spans. 


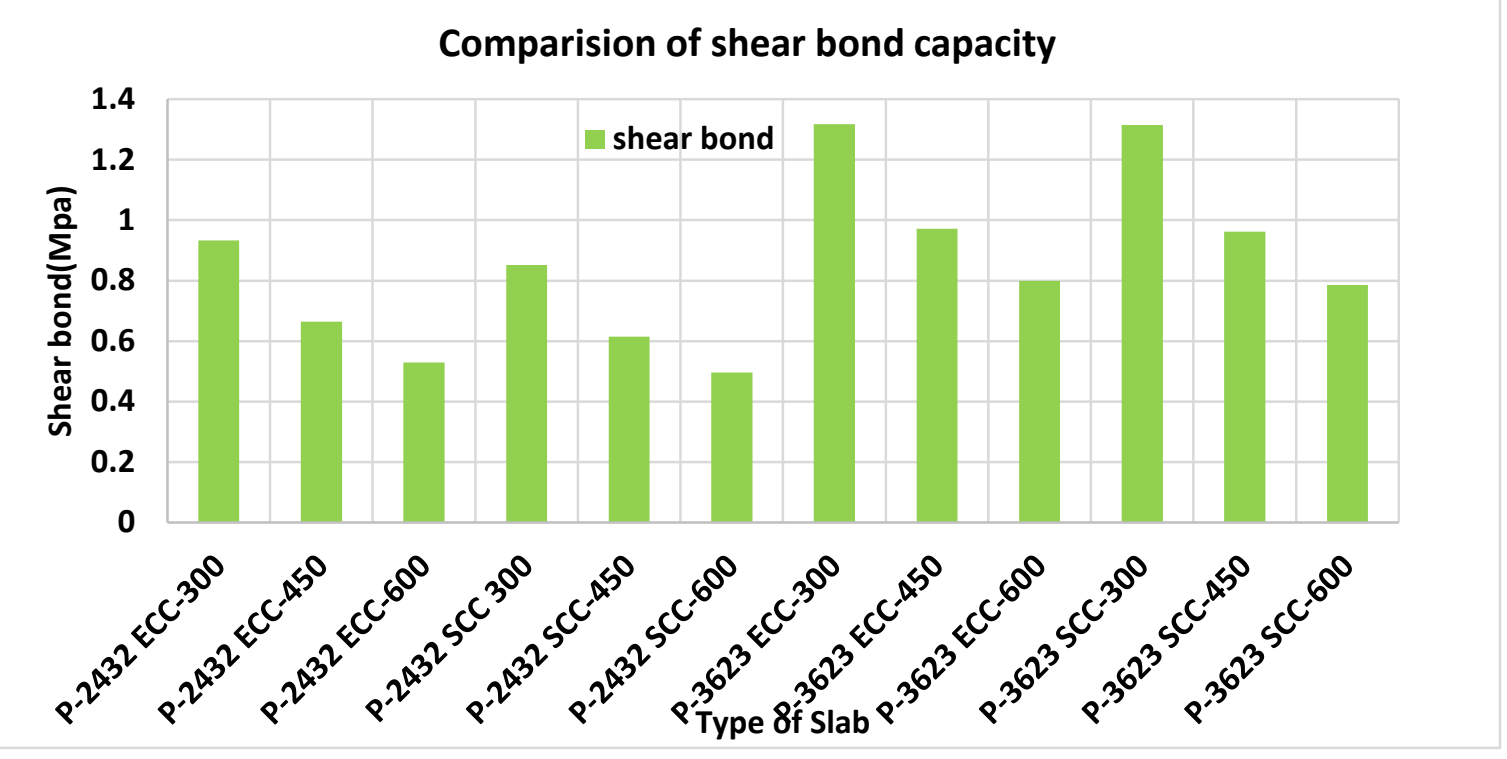

Fig. 3.19:- Comparison of Shear bond capacity (in Mpa) by $\mathrm{M}$ - K value method.

\subsection{7 $\tau_{v}$ Method}

This method is an alternate method for $\mathrm{m}-\mathrm{k}$ method to calculate the longitudinal shear resistance of the composite slab. This details of this method is presented in Eurocode 4 (EN 1994-1-1, 2004) Annex B and Annex E.

As per this method, the tensile force $(\mathrm{Np})$ in the sheet can be calculated by:

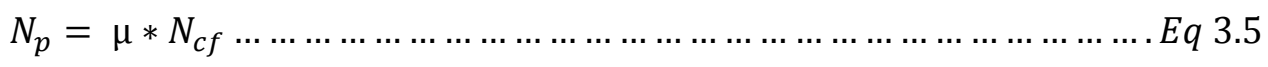

Which is equal to the compressive force of the concrete.

The moment $\mathrm{M}$ due to applied loads at a particular section can be calculated by:

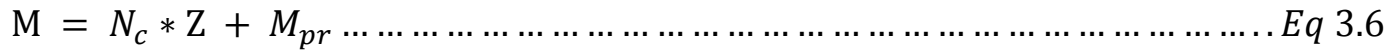

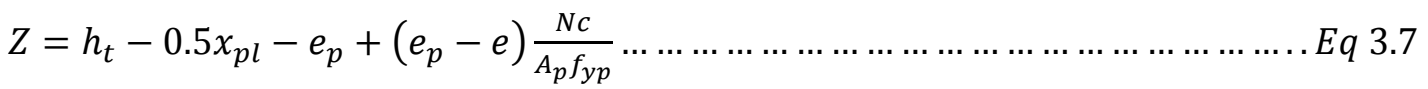

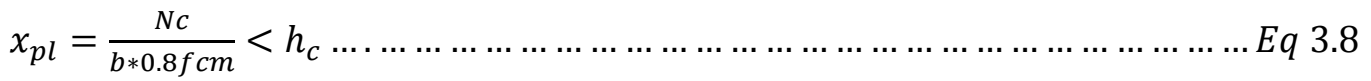

Where, $\mathrm{e}=$ distance from the centroid of the effective area of sheeting to its underside.

$e_{p}=$ distance of the plastic neutral axis of the effective area of the sheeting to its underside.

$h_{t}=$ total depth of the slab 
Mpr is the reduced plastic moment resistance of the sheet. It calculated by:

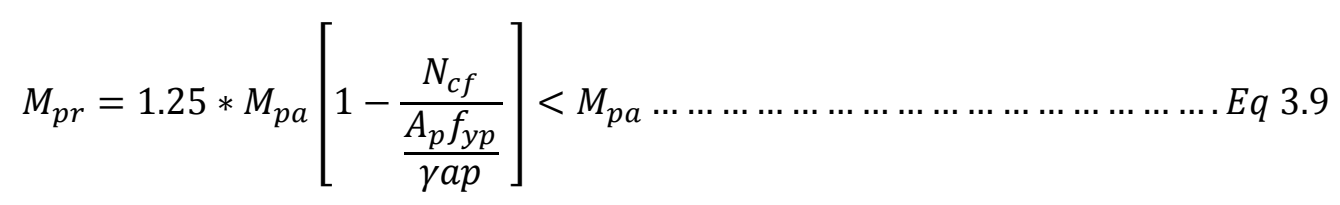

Where, $N_{c f}=h c * b *\left(0.85 \frac{f_{c k}}{\gamma_{c}}\right)$

$M_{p a}=$ plastic moment resistance of the effective area of the sheeting.

The degree of steel-concrete interface shear connection $\mu$ can be calculated by:

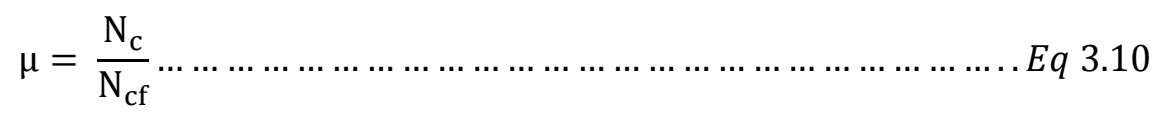

The longitudinal shear stress can be calculated by:

$$
\tau_{v}=\frac{\mu * N_{c f}}{b *\left(L_{v}+L_{o}\right)}
$$

Where, Lo is length of overhang, $\mu$ is the degree of connection, $L v$ is the shear span and $B$ is width of the slab.

\subsubsection{Sample Calculation of Shear Bond Strength ( $\left.\tau_{v, R d}\right)$ for ECC Composite Slab (P-2432)}

Calculate the neutral axis and check if it is above the sheet or below. If the neutral axis is above the sheet $\mathrm{N}_{c}$ should be equal to $\mathrm{Np}$.

$$
\begin{aligned}
& \text { That mean, } \quad x_{p l} * b * 0.85 * f^{\prime}{ }_{c}=A_{p} * f_{y p} \\
& x_{p l}=\frac{A_{p} f_{y p}}{b * 0.85 * f_{c}^{\prime}}=\frac{1131 * 230}{620 * 0.85 * 66}=11.38 \mathrm{~mm}<h_{c} \ldots o k
\end{aligned}
$$

This result shows that the neutral axis is above the sheeting (Fig. 3.21). The sagging bending resistance of a cross-section with neutral axis above the sheeting is calculated by the following stress distribution (Fig. 3.20). 


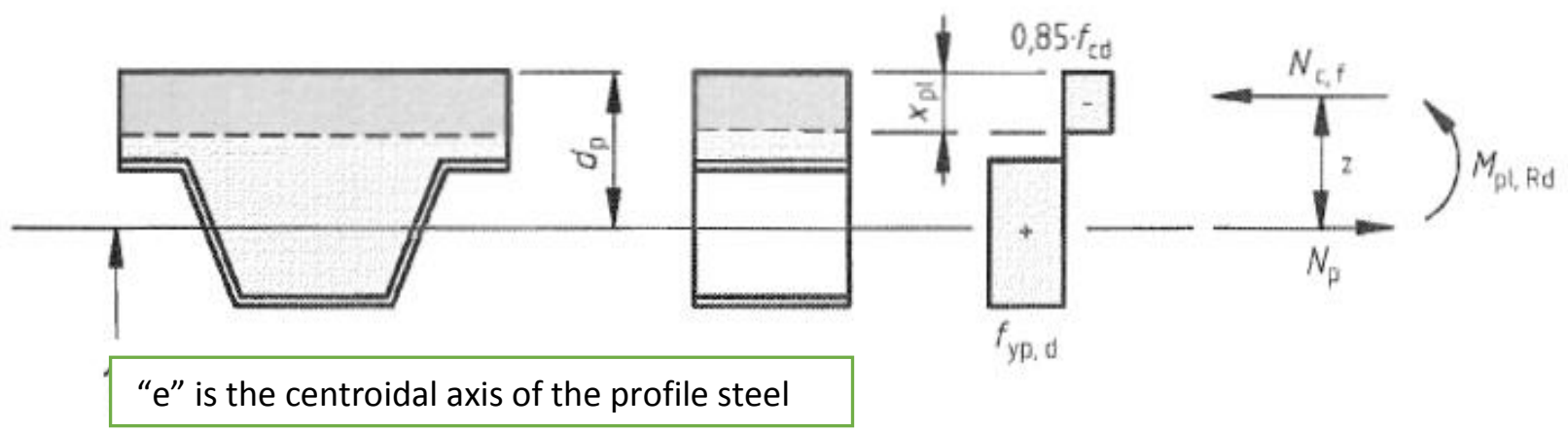

Fig. 3.20:- Stress distribution for sagging bending moment if the neutral axis is above the steel sheeting.

Calculate the distance from the plastic natural axis of the effective area of sheeting to its underside "ep" is equal to " $\mathrm{e}$ " which is the distance from the centroid of the effective area of sheeting to its underside.

$$
\begin{aligned}
& (2 * 135)+4 *\left(77.37-1.02 e_{p}\right)=(2 * 141)+\left(4 * 1.02 e_{p}\right) \\
& 579.48-4.08 e_{p}=282+4.08 e_{p} \\
& e_{p}=36.46 \mathrm{~mm}=e
\end{aligned}
$$

Then calculate the plastic moment resistance (Mpa) of the effective area of the sheeting above the neutral axis all piece of sheet as follows:

$$
\begin{aligned}
\mathrm{M}_{\mathrm{pa}}= & ((2 * 135 * 0.76 * 39.13)+(4 * 40.18 * 0.76 * 19.38)) * 230 \\
= & 10,404.12 \mathrm{~mm}^{3} * 230 \mathrm{M}_{\mathrm{pa}} \\
= & 2.39 \mathrm{KN} . \mathrm{m} \\
N_{c f}=h_{c} * b * 0.85\left(\frac{f_{c k}}{\gamma_{c}}\right) & \\
= & 11.38 * 620 * 0.85 *(66 / 1.5) \\
& =263.88 \mathrm{KN} \\
M_{p r} & =1.25 * M_{p a}\left[1-\frac{N_{c f}}{\frac{A_{p} f_{y p}}{\gamma_{a p}}}\right]<M_{p a} \\
& =1.25 * 2.39 \mathrm{KN} . \mathrm{m}(1-263.88 / 359.86)<2.39 \mathrm{KN} . \mathrm{m} \\
& =2.99 *(1-0.733)=0.797 \mathrm{KN} . \mathrm{m}<2.39 \mathrm{KN} . \mathrm{m} . \ldots \ldots \ldots \ldots \ldots \ldots \ldots \ldots \ldots \ldots \ldots . . .0 k
\end{aligned}
$$




$$
\begin{aligned}
Z= & h_{t}-0.5 x_{p l}-e_{p}+\left(e_{p}-e\right) *\left(\frac{N_{c}}{A_{p} f_{y p}}\right) \\
& =125-(0.5 * 11.38)-(76 / 2)+0 \\
& =81.31 \mathrm{~mm} \\
M & =N_{c} * Z+M_{p r} \\
& =(11.38 * 620 * 0.85 *(66 / 1.5) * 81.31+0.797 \mathrm{KN} . \mathrm{m} \\
& =263.879 \mathrm{KN} * 0.0813+0.797 \mathrm{KN} \cdot \mathrm{m} \\
& =21.45 \mathrm{KN} . \mathrm{m}+0.797 \mathrm{KN} . \mathrm{m} \\
& =22.247 \mathrm{KN} . \mathrm{m}
\end{aligned}
$$

The degree of shear connection $\mu$ is calculated by:

$$
\mu=\frac{N c}{N c f}
$$

Where,

$$
\begin{gathered}
N_{c}=\frac{-\left(h_{t}-e_{p}\right) \pm \sqrt{\left(h_{t}-e_{p}\right)-4 *\left(\frac{e_{p}-e}{A_{p} f_{y p}}\right) *\left(M_{p r}-M\right)}}{2 *\left(\frac{e_{p}-e}{A_{p} f_{y p}}-\frac{0.5}{b * 0.85 * f_{c m}}\right)} \\
N c=\frac{-87 \pm \sqrt{\left(87^{2}-4\left(0-\frac{0.5}{620 * 0.85 * 66}\right) *(0.797-21.46)\right.}}{2 *\left(0-\frac{0.5}{620 * 0.85 * 66}\right)} \\
\quad N c=\frac{-87 \pm \sqrt{6334.57}}{-0.000029}=\frac{-87 \pm 79.59}{-0.000029} \\
\therefore \quad \frac{N c}{N c f}=\frac{257.633 K N}{263.88 K N}=0.976 \quad \begin{array}{c}
N c=257.633 K N \\
N
\end{array}
\end{gathered}
$$


The degree of shear connection has the same value for the same slab with different shear spans. The longitudinal shear stresses for different shear span of sheet -A (P-2432) ECC composite slabs are calculated as follows:

For 300mm shear span;

$$
\tau_{v}=\frac{\mu * N_{c f}}{b *\left(L_{v}+L_{o}\right)}=\frac{0.976 * 263.88}{620 *(300+150)}=0.923 M P a \ldots \ldots \ldots \text { for } 300 \mathrm{~mm} \text { shear span } .
$$

For 450mm shear span;

$$
\tau_{v}=\frac{\mu * N_{c f}}{b *\left(L_{v}+L_{o}\right)}=\frac{0.976 * 263.88}{620 *(450+150)}=0.655 \mathrm{MPa} \ldots \ldots \ldots \ldots \text { for } 450 \mathrm{~mm} \text { shear span } .
$$

\section{For $600 \mathrm{~mm}$ shear span;}

$$
\tau_{v}=\frac{\mu * N_{c f}}{b *\left(L_{v}+L_{o}\right)}=\frac{0.976 * 263.88}{620 *(600+150)}=0.554 M p a \ldots \ldots \ldots \ldots \text { for } 600 \mathrm{~mm} \text { shear span }
$$

Where, $L_{v}$ is the shear span and $L_{o}$ is the length of overhang.

The longitudinal shear bond stresses calculated by this method for all composite slabs are listed in Table 3.6. Table 3.6 and Fig. 3.21 compares the shear bond stress calculated based on $\mathrm{m}-\mathrm{k}$ method and $\tau_{\mathrm{v}}$ method. The shear bond stress calculated based on tV method are found to be significantly lower compared to those obtained by m-k method especially for slabs made with P-3623 steel sheeting. For slabs with P-2432 type profiled steel sheet, the shear bond stress calculated by m-k method is found to be relatively close compared to those obtained of partial shear connection method ( $\tau_{v}$ method). 
Table 3.5:- Comparison of $m-k$ and $\tau_{v}$ methods

\begin{tabular}{|c|c|c|c|c|}
\hline & & & \multicolumn{2}{c|}{ Shear bond stress } \\
\hline Slab & $\mathbf{m}$ & & $\begin{array}{c}\mathbf{\tau}_{\mathbf{v}} \\
(\mathbf{m}-\mathbf{k} \text { method }) \\
\left(\mathbf{N} / \mathbf{m m}^{2}\right)\end{array}$ & $\begin{array}{c}\boldsymbol{\tau}_{\mathbf{v}} \text { method } \\
\left(\mathbf{N} / \mathbf{m m}^{2}\right)\end{array}$ \\
\hline P-2432 ECC-300 & 133.03 & 0.0153 & 0.933206 & 0.923 \\
\hline P-2432 ECC-450 & 133.03 & 0.0153 & 0.66357 & 0.655 \\
\hline P-2432 ECC-600 & 133.03 & 0.0153 & 0.528752 & 0.554 \\
\hline P-2432 SCC 300 & 117.24 & 0.0186 & 0.852084 & 0.916 \\
\hline P-2432 SCC-450 & 117.24 & 0.0186 & 0.614453 & 0.687 \\
\hline P-2432 SCC-600 & 117.24 & 0.0186 & 0.495637 & 0.55 \\
\hline P-3623 ECC-300 & 293.33 & 0.0353 & 1.317203 & 0.538 \\
\hline P-3623 ECC-450 & 293.33 & 0.0353 & 0.972269 & 0.404 \\
\hline P-3623 ECC-600 & 293.33 & 0.0353 & 0.799802 & 0.323 \\
\hline P-3623 SCC-300 & 300.38 & 0.0358 & 1.315337 & 0.537 \\
\hline P-3623 SCC-450 & 300.38 & 0.0358 & 0.962112 & 0.403 \\
\hline P-3623 SCC-600 & 300.38 & 0.0358 & 0.7855 & 0.322 \\
\hline
\end{tabular}

\section{Comparsion of shear bond strength}

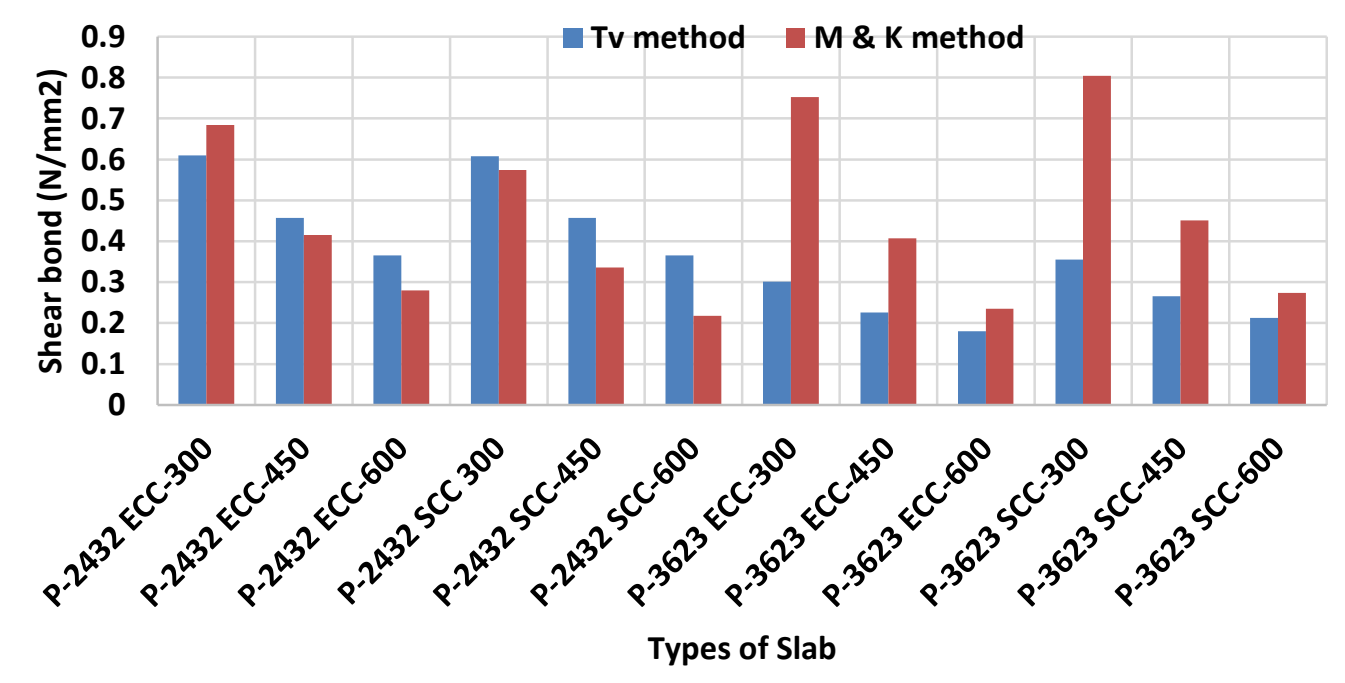

Fig. 3.21:- Comparison of shear bond capacity by $m-k$ and $\tau_{v}$ method 


\subsubsection{Energy Absorbing Capacity of Composite Slab}

Energy absorbing capacity of tested composite slabs were calculated by the area under load-deflection curve up to the peak load. Energy of composite slabs are presented and compared in Table 3.6 and Fig. 3.22. The energy absorption capacity of ECC composite slab is significantly greater compared to their SCC counter parts for both type of steel sheet profile. The energy absorbing capacity of slabs with shorter shear span is greater than those with longer span. This confirms that the ECC can be useful in producing structures with high energy absorbing capacity. Structures subjected to impact may also take advantage of the isotropic energy absorption behavior of ECC, such as highway pavements, bridge decks, and blastresistant building core elements (Herber \& Li, 2013).

Table 3. 6:- Energy absorbing capacity of composite slabs

\begin{tabular}{|c|c|c|c|}
\hline & & \multicolumn{2}{|c|}{ Energy Absorbing Capacity } \\
\hline $\begin{array}{c}\text { Type of } \\
\text { concrete }\end{array}$ & $\begin{array}{c}\text { Shear span } \\
(\mathbf{m m})\end{array}$ & $\begin{array}{c}\text { P-2432 Slab } \\
(\mathbf{J})\end{array}$ & $\begin{array}{c}\text { P-3623 Slab } \\
(\mathbf{J})\end{array}$ \\
\hline \multirow{2}{*}{ ECC } & 300 & 507.22 & 1020.55 \\
& 450 & 173.23 & 575.16 \\
& 600 & 204.77 & 373.92 \\
\hline & & & \\
\hline \multirow{2}{*}{ SCC } & 300 & 294.40 & 427.43 \\
& 450 & 163.01 & 254.57 \\
& 600 & 180.97 & 328.60 \\
\hline
\end{tabular}
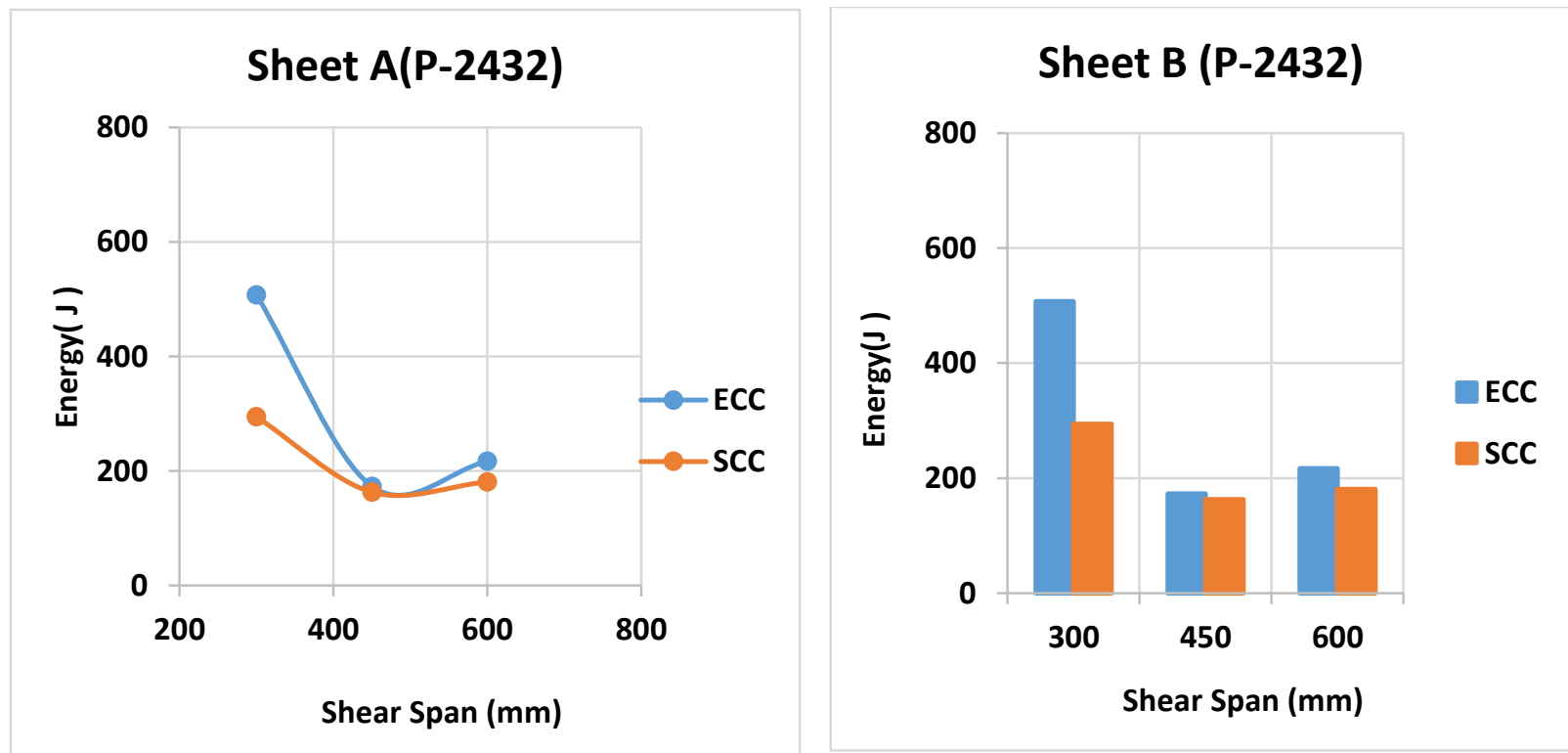

Fig. 3.22 (a):- Comparison of energy absorbing capacity 

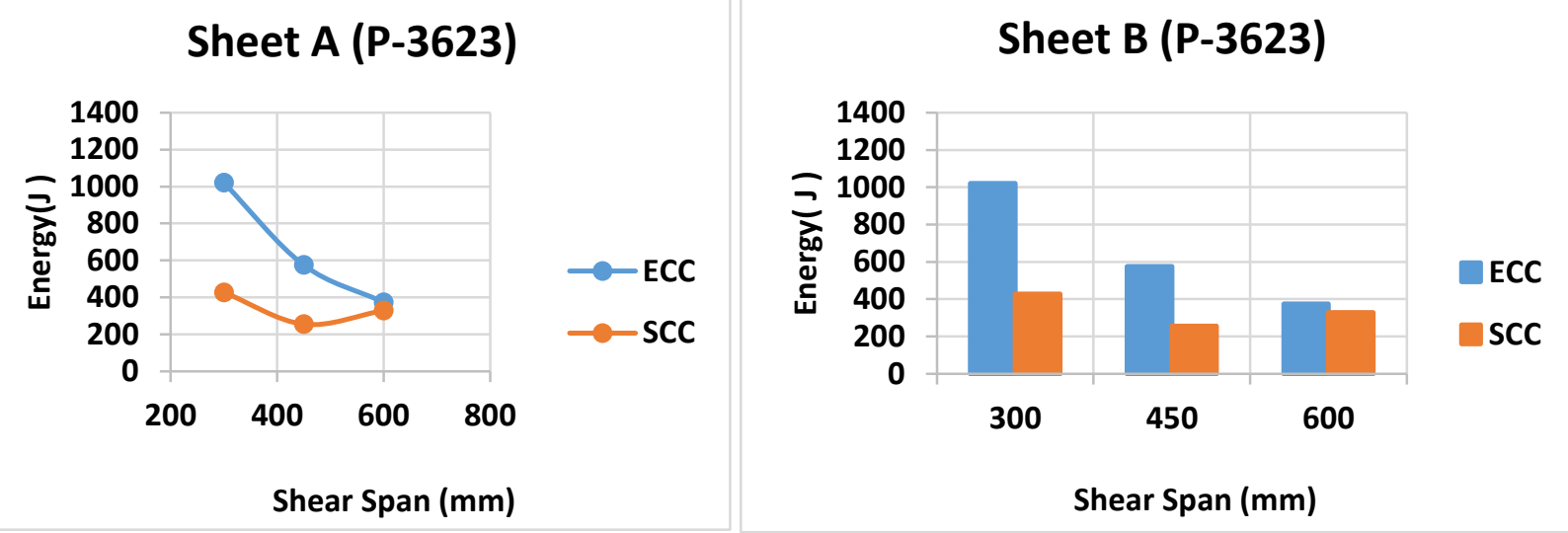

Fig. 3.22 (b):- Comparison of energy absorbing capacity
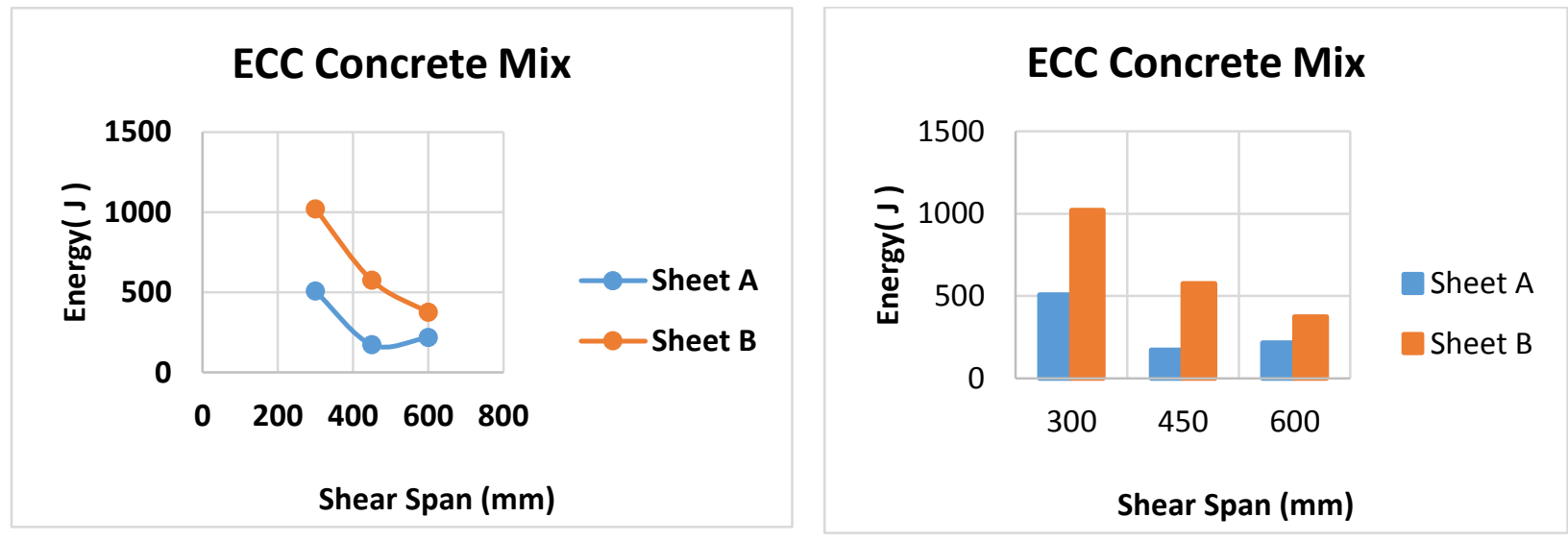

Fig. 3.22 (c):- Comparison of energy absorbing capacity
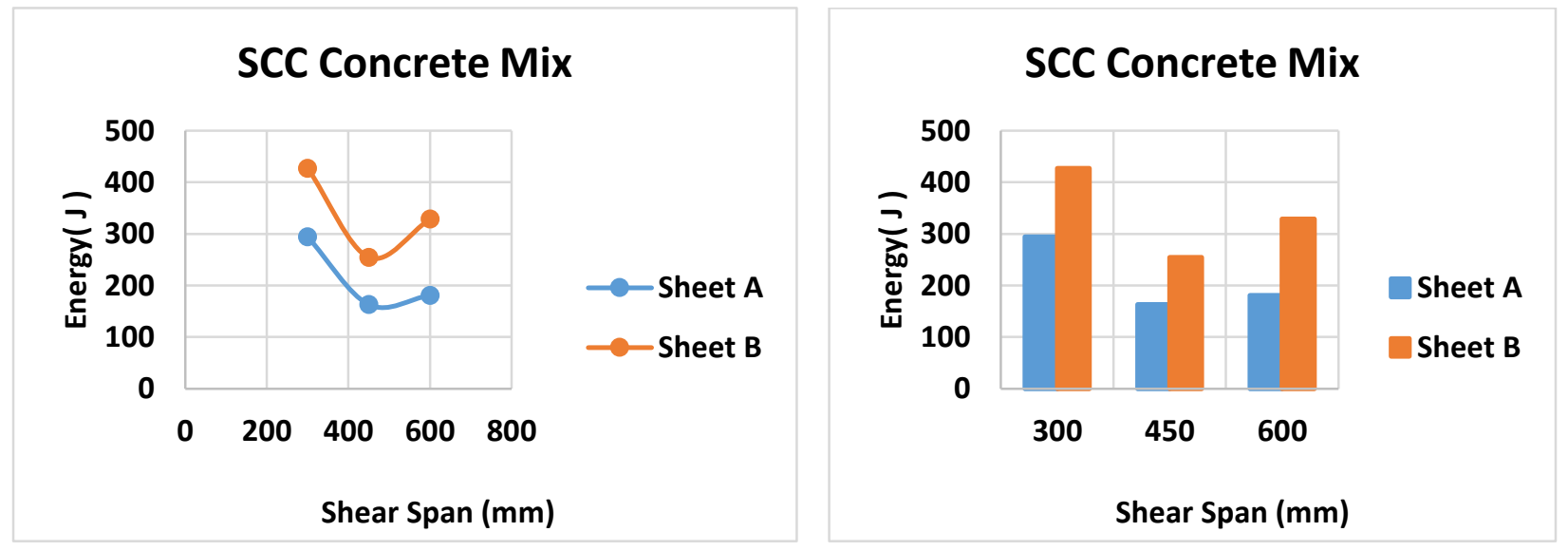

Fig. 3.22 (d):- Comparison of energy absorbing capacity 


\section{CHAPTER 4: CONCLUSIONS AND RECOMMENDATIONS FOR FURTHER RESEARCH}

\subsection{Introduction}

The structural performance of composite slabs made with a green engineered cementitious composite (ECC) compared to their commercial self-consolidating concrete (SCC) counterparts was studied through experimental and theoretical investigations. The effect of different profiled steel sheets (two types of CANAM embossed profiled steel decks - P-3623 and P-2432) and variable shear span length (three different shear spans) on load-deflection response, shear/moment resistance, ductility, energy absorbing capacity, stress-strain development in concrete/steel, cracking/crack propagation, steel-concrete interface slip, failure modes and shear bond characteristics were investigated.

\subsection{Conclusions}

The following conclusions were drawn from this study:

- Both SCC and ECC ensured uniform self-consolidation during casting and produced good quality concrete with smooth surface finish and without voids, bleeding or segregation. ECC was more flowable than SCC and its casting process was easy, quick and less labour intensive compared with SCC.

- Composite slabs with longer shear span developed greater stress/strain in steel sheet compared to those of shorter shear spans. However, in majority of the composite slabs, the steel strain did not reach yield strain. In general, ECC slabs developed higher steel strain compared to their SCC counterparts. The use of studs in P3623 slabs (both SCC and ECC) reduced the strain development in pre-peak load response although the effect of stud in the post-peak strain development was not conclusive. ECC slabs also developed higher concrete strain before failure compared to SCC exhibiting higher strain hardening capacity of ECC.

- Load-deflection responses of ECC and SCC slabs also differed. Both pre-peak and post-peak behaviours of ECC slabs were characterized by smooth ascending and descending branches, respectively while sudden drop and rise in loads were observed for SCC slabs. This could be attributed to the higher steel-concrete shear bond development in ECC slabs.

- Failure load generally increased with the decrease of shear span for all composite slabs. Strength increase (in terms of shear or moment capacity) was higher for ECC slabs compared to their SCC 
counterparts. This can be attributed to the ECC's superior ability to produce better steel-concrete composite action through embossments and shear studs.

- According to Eurocode 4 (2004), the behavior of all composite slabs was ductile based on end slip criteria and all slabs achieved the ductility requirements of Eurocode 4 before failure in shear. In general, the energy absorbing capacity and ductility of ECC composite slabs were higher compared to those made with SCC.

- Values of shear bond parameters ( $m$ and $k$ ) of ECC slabs were higher compared to their SCC counterparts. This was an indication that ECC was more capable of generating higher mechanical interlock and friction at steel-concrete interface.

- The shear bond capacity decreased with the increase of shear span. ECC composite slabs developed higher shear bond compared to their SCC counterparts.

- The shear bond stress calculated based on $\tau_{v}$ method are found to be lower in most cases compared to those obtained by $\mathrm{m}-\mathrm{k}$ method. Suggested values of shear bond parameters ( $\mathrm{m}$ and k) can be used in Code based design procedures to predict the design shear bond capacity of ECC/SCC composite slabs.

- Overall, ECC composite slabs showed better performance compared to their SCC counterparts through the development of better shear bond resistance, higher ductility and enhanced strength.

- The result of this investigation is very promising and confirms the viability of the production of high performance ECC based composite slabs for construction applications.

\subsection{Recommendations for Further Research}

Future research can be directed in the following directions:

- Carry out experimental investigations of ECC and traditional concrete composite slabs with shear connectors in combination with embossments.

- Study of the fire resistance of composite slabs with ECC compared to traditional concrete.

- Study the structural performance of ECC composite slabs under fatigue loading.

- Development of comprehensive design guidelines and performance based specifications for ECC based composite slabs. 


\section{Reference}

Abdullah, R., \& Easterling, W. S. (2006). Elemental Bending Test and Modeling of Shear Bond in Composite Slabs, Faculty of Civil Engineering, Skudai.

ASCE 1992. Standard for the structural Design of composite slabs. ANSI/ ASCE 3-91. American Society of Civil Engineers, New York.

ASTM C39 (2012). Standard method for Compressive Strength of Cylindrical Concrete Specimens. Annual Book of ASTM Standard, ASTM International, West Conshohocken, PA, USA.

ASTM C78 / C78M (2010). Standard Test Method for Flexural Strength of Concrete. Annual Book of ASTM Standard, ASTM International, West Conshohocken, PA, USA.

British Standard Institution. (1993). Design of steel structures, part 1-1 General rules and rules ofor buildings. London: British Standard Institution.

BS 5950 Part 4 (1994). Code of practice for design of floors with profiled steel sheeting. British Standards Institution, London.

Canadian Sheet Steel Building Institute. (2008). Criteria for the Design of Composite Slabs. Canadian Sheet Steel Building Institute, Cambridge.

CANAM (2014), CANAM Steel Deck. http:// steeldeck@canam.ws (Accessed date: 14-03-2014).

Chen, S. (2003). Load carrying capacity of composite slabs with various end constraints. Journal of Constructional Steel Research, 59, 385-403.

Ehlers, P. (2001). Composite Slabs with Profiled Steel Sheeting. Engineering College of Aarhus, Arhus Retrieved from http://www.ssedta.com

Eurocode 3. (2005). Design of steel structures-The European Standard EN 1993-1-8:2005 has the status of a British Standard. European Committee for Standardization, Brussels.

Eurocode 4. (2004). Design of composite steel and concrete structures - Part 1-1: General rules and rules for buildings. European Committee for Standardization, Brussels:

Hedaoo, N. A., Gupta, L. M., \& Ronghe, G. N. (2012). Design of composite slabs with profiled steel decking: a comparison between experimental and analytical studies. International Journal of Advanced Structural Engineering 2012 3:1., 2008-6695.

Herber, E. N., \& Li, V. C. (2013). Self-Healing of Microcracks in Engineered Cementitious Composites (ECC) Under a Natural Environment. materials, pp. 2831-2845.

Hossain, K.M.A. (2014). Behaviour of ECC link slab for joint-free bridge construction, Proc. Structural Faults + Repair, 8th $-10^{\text {th }}$ July, Imperial College, London, UK. 
Hossain, K.M.A. and Anwar, M.S. (2014). Properties of green engineered cementitious composites incorporating volcanic materials, Proc. Structural Faults + Repair, $8^{\text {th }}-10^{\text {th }}$ July, Imperial College, London, UK.

Hossain, K.M.A. and N. Vinay, N. (2012), Shear bond resistance of composite slabs with high performance concrete, The $6^{\text {th }}$ International Conference on Advanced Composite Materials in Bridges and Structures, ACMBS-VI, 22-25 May, Kingston, Ontario, Canada.

Johnson, R. (1994). composite structures of steel and concrete. volume 1 (beams, slabs, columns, and frames for buildings). Blackwell Scientific Publications, Osney Mead, Oxford:

King MS-S10 SCC (2014)http://industrial.kpmindustries.com/Product_Catalogue/products/Concrete/MSS10_Self-Consolidating Concrete.aspx (Accessed date: 14-05-2014).

Lachemi, M., Hossain, K. M. A., Lambros, V. and Bouzoubaa, N. (2003). Development of cost-effective self-compacting concrete incorporating fly ash, slag cement or viscosity modifying admixtures, ACI Materials Journal, 100 (5) 419-425.

Makelainen, P. and Sun, Y. (1999). The longitudinal shear behavior of a new steel sheeting profile for composite floor slabs, Journal of Constructional Steel Research, 49, 117-128.

Marimuthu, V., Seetharaman, S., Arul Jayachandran, Chellappan, A., Bandyopadhyay, T. K. and Dutta, D. (2007). Experimental studies on composite deck slabs to determine the shear-bond characteristic $m-k$ values of the embossed profiled sheet, Journal of Constructional Steel Research, 63, 791-803.

McGraw-Hill Concise Encyclopedia of Engineering. (2002). McGraw-Hill Companies, Inc. Retrieved Novamber 1, 2014, from http://encyclopedia2.thefreedictionary.com/composite+beam">composite beam</a> Mohammed, B.S. (2010). Structural behavior and $m-k$ value of composite slab utilizing concrete containing crumb rubber, Construction and Building Materials, 24 (7), 1214-1221.

Mohammed, B.S., Al-Ganad M.A. and Abdallah, M. (2011). Analytical \& experimental studies on composite slabs utilizing palm oil clinker, Construction and Building Materials, 25(8) 3550-3560.

Penza, A. (2010). Composite Slabs with Lightweight Concrete. Politecnico Di Milano, Milano.

Rackham, J. W., Couchman, G. H., \& Hicks, S. J. (2009). Composite Slabs and Beams using Steel Decking: Best Practice for Design and Construction. The Metal Cladding \& Roofing Manufacturers Association in partnership with The Steel Construction Institute, Ascot.

Ready Mixed Concrete Association of Ontario. (2009). Best Practices Guidelines for Self-Consolidating Concrete. Ready Mixed Concrete Association of Ontario, Mississauga. 
Sherir, M.A.A., Hossain, K.M.A. and Lachemi, M. (2014). Fracture energy characteristics of engineered cementitious composites incorporating different aggregates, 4th International Structural Specialty Conférence, CSCE, Halifax, NS, and May 28 to 31.

Vainiunas, p., Valivonis, J., Marciukaitis, G., \& Jonaitis, B. (2006). Analysis of longitudinal shear behaviour for composite steel and concrete slabs. Journal of Constructional Steel Research, 62, 1264-1269.

Wright, H. D., Evans, H. R., \& Harding, P. W. (1987). The Use of Profiled Steel Sheeting in Floor Construction. Journal of Constructional Steel Research, 7, 279-295. 